\title{
The next generation of play
}

Citation for published version (APA):

van den Heuvel, R. J. F. (2018). The next generation of play: Robots to support play in rehabilitation and special education for children with physical disabilities. [Doctoral Thesis, Maastricht University]. Datawyse / Universitaire Pers Maastricht. https://doi.org/10.26481/dis.20180704rh

\section{Document status and date:}

Published: 01/01/2018

DOI:

10.26481/dis.20180704rh

Document Version:

Publisher's PDF, also known as Version of record

\section{Please check the document version of this publication:}

- A submitted manuscript is the version of the article upon submission and before peer-review. There can be important differences between the submitted version and the official published version of record.

People interested in the research are advised to contact the author for the final version of the publication, or visit the DOI to the publisher's website.

- The final author version and the galley proof are versions of the publication after peer review.

- The final published version features the final layout of the paper including the volume, issue and page numbers.

Link to publication

\footnotetext{
General rights rights.

- You may freely distribute the URL identifying the publication in the public portal. please follow below link for the End User Agreement:

www.umlib.nl/taverne-license

Take down policy

If you believe that this document breaches copyright please contact us at:

repository@maastrichtuniversity.nl

providing details and we will investigate your claim.
}

Copyright and moral rights for the publications made accessible in the public portal are retained by the authors and/or other copyright owners and it is a condition of accessing publications that users recognise and abide by the legal requirements associated with these

- Users may download and print one copy of any publication from the public portal for the purpose of private study or research.

- You may not further distribute the material or use it for any profit-making activity or commercial gain

If the publication is distributed under the terms of Article $25 \mathrm{fa}$ of the Dutch Copyright Act, indicated by the "Taverne" license above, 
The research presented in this thesis was funded by the Nationaal Regieorgaan Praktijkgericht Onderzoek SIA (RAAK-PRO, grant number PRO 4-10) and by Zuyd University of Applied Sciences.

(C) copyright Renée van den Heuvel, Heerlen 2018

All rights reserved. No parts of this thesis may be reproduced or transmitted in any form or by any means, without permission in writing by the author, or when appropriate, by the publishers of the publications.

Cover design: Shannen Duijzings

Cover photos: Hans Bremmers

Printing: Datawyse | Universitaire Pers Maastricht

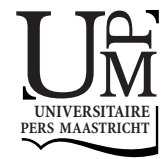

ISBN 9789461598110 


\title{
The Next Generation of Play
}

\section{Robots to support play in rehabilitation and special education for children with physical disabilities}

\author{
Proefschrift \\ ter verkrijging van de graad van doctor aan de Universiteit Maastricht, \\ op gezag van de Rector Magnificus, Prof. dr. Rianne M. Letschert, \\ volgens het besluit van het College van Decanen, \\ in het openbaar te verdedigen \\ op woensdag 4 juli 2018 om 14:00 uur \\ door
}

Renée Johanna Franciscus van den Heuvel 


\section{Promotor}

Prof. Dr. L.P. de Witte

\section{Copromotores}

Dr. M.A.S. Lexis (Zuyd Hogeschool, Heerlen)

Dr. G.J. Gelderblom †

\section{Beoordelingscommissie}

Prof. dr. F.J.M. Feron (voorzitter)

Prof. dr. S. Besio (University of Bergamo, Italië)

Prof. dr. C.M. van Heugten

Prof. dr. S.A.H. van Hooren (Open Universiteit, Heerlen / Zuyd Hogeschool, Heerlen)

Prof. dr. J.A.M.C.F. Verbunt 


\section{Contents}

Chapter 1 General Introduction

Chapter 2 Robots and ICT to support play in children with severe physical disabilities: a systematic review

Chapter 3 Robots supporting play for children with physical disabilities:

exploring the potential of IROMEC.

Chapter 4 Can the IROMEC robot support play in children with severe physical disabilities? A pilot study

Chapter 5 Robot ZORA in rehabilitation and special education for children with severe physical disabilities: a pilot study

Chapter 6 ZORA robot based interventions to achieve therapeutic and educational goals in children with severe physical disabilities

Chapter 7 General discussion

Chapter 8 Valorisation

Summary

Nederlandse samenvatting

Dankwoord

About the author

List of publications 

Chapter 1

General Introduction 



\section{Play}

Article 31 of the Convention on the Rights of the Child (1989) establishes that 'A child has the right to rest and leisure, to engage in play and recreational activities appropriate to the age of the child' [1]. In addition, the Convention of the Rights of Persons with Disabilities stresses the importance of the protection of the rights of children with disabilities in specific (art. 7), indicates that proper educational processes have to be guaranteed to them in an inclusive and life-long educational system (art. 24) and highlights their right to participate in recreational activities, sports and entertainment (art. 30) [2].

Play is widely recognized as the most fundamental activity for the optimal development of all children. It plays an important part in acquiring physical, cognitive, sociopsychological, and relational skills, and contributes to the well-being and participation of a child [3]. Garvey (1990) described play as a range of voluntary, intrinsically motivated activities normally associated with recreational pleasure and enjoyment [4]. This definition was adapted by the COST Action LUDI - Play for children with disabilities in 2014, an international network of researchers, therapists, designers and other experts in the field of play for children with disabilities [3]. The definition encompasses three important dimensions of play: pleasure, self-direction and intrinsic drive. According to LUDI, play is comprised of play for play's sake and play-like activities. Play for play's sake does not have extrinsic preordained goals, which means it lives, arises, develops and stops, only for itself. Although play for play's sake 'produces' a lot of learning in many different areas, it never pursues such a purpose. Play-like activities, on the other hand, include learning objectives or specific means. Play-like activities can have the appearance and structure of play activities and have amusing and fun characteristics, but always have predetermined objectives. Examples of play-like activities are using play in physiotherapeutic sessions to elicit movements in a playful way, and learning new words in a classroom using games [3]. Because play is of crucial importance for the development and well-being of a child, both types of play, play for play's sake and playlike activities, are incorporated in this research.

\section{Children with physical disabilities and play}

Physical disabilities, both congenital and acquired, may, temporarily or permanently, limit the physical abilities or motor skills of a child. Congenital disabilities develop during conception or in utero, as a consequence of for example a gene defect, gene mutation, vitamin deficiency or oxygen deficiency [5]. Acquired disabilities may arise through injuries or disease while the child is developing in a typical way. Impairments in functions, caused by either of these types of disabilities, may result in limited abilities to make movements, coordinate, or perform physical activities. Physical disabilities can for example be caused by a problem of the central nervous system (e.g. cerebral palsy, 
acquired brain injury) and may be accompanied by intellectual and neuropsychological impairments, language and speech disorders, sensory disabilities, as well as emotional and social difficulties [6]. Physical disabilities can also be related to damage of the peripheral nervous system and/or muscles, joints and bones (e.g. muscular diseases). The functional status of children with physical disabilities may vary from mild to very severe which limits the movement possibilities of the children and the level of participation. The impact of the acquired disabilities on the child's physical performance often depends on the age at which the condition develops. Motor impairments or delay in the development of motor skills, may have an impact on the socio-psychological, relational and cognitive development of the child. Physical disabilities may prevent children from behaving in an autonomous way in daily activities, an important one of which is play.

In the Netherlands there are approximately 70.000 children with disabilities. Of these 70.000, 20.000 have a physical disability, and 6.500 have multiple disabilities [7]. Despite the relatively small group of children with physical disabilities, there is still great diversity when it comes to the severity of the disability as well as the type of disability these children have. Children with severe physical disabilities often need assistive technology (AT). AT refers to devices and other resources aimed at supporting people with a disability in performing their daily activities, for example in terms of making movements and communication. Children need to be trained in using the AT and their daily lives require special organization because of their disability. The aforementioned things may create restrictions in social participation as well as difficulties at the psychological level. Assistive technology (AT) solutions may reduce children's limitations in performing activities, improve their participation [8,9], and may have a positive socio-economic effect by improving access to education which can influence and increase achievements [10]. Examples of AT often used in paediatric rehabilitation are wheelchairs, crutches, walkers, adapted shoes and splints, access solutions (e.g. joysticks, eye trackers, mechanical switches), adapted toys, and alternative and augmentative communication devices (AAC).

\section{Mainstream toys and the possibilities of technology}

Children with physical disabilities are at risk of reduced participation [11]. They experience more participation restrictions than their peers without disabilities [12], their activities are more passive, mainly organized at home and lack variety [13]. Heah et al. (2007) describe in their studies that successful participation for children with disabilities means having fun, feeling successful, doing things on their own and doing and being with others [14]. Children with severe physical disabilities often experience problems with commercially available toys. Examples of issues they might encounter range from the toys being equipped with small parts or buttons, which make them difficult to manipulate, toys containing low quality audio, or lights that flash too fast, which scares the 
children [15]. These problems can be frustrating for the child as well as their peers and parents. Mainstream toys are often divided into categories related to the development of the child. For example, toy manufacturers often provide a play guide for their toys related to ages and developmental phases of children. When it comes to children with physical disabilities, taking into account the motor skills of a child is at least equally as important as paying attention to these developmental phases, when selecting a toy.

Because of their physical disabilities these children often need support from other children or adults while playing, or they tend to spend more time watching play rather than playing themselves. As a result, play often becomes very frustrating for the child as well as for their social environment. Many commercially available toys are not suitable for these children at all, which might make them feel more disabled and frustrated. These factors all influence successful participation [14].

New developments in the field of technology and ICT create new opportunities for children with severe physical disabilities. These technologies can improve play possibilities for these children and can create new opportunities for rehabilitation and special education. Technology may offer new possibilities for e.g. monitoring, controlling, creating tailor made interventions, and using specific design requirements. Technology might have potential in for example motivating children, creating more interaction possibilities, stimulating movements, or improving accessibility of existing toys. The use of these technologies may increase the well-being, mood, and enjoyment of children with physical disabilities, and might, in the long run, improve their quality of life and allow for true social inclusion [3].

\section{Rehabilitation and special education for children with severe physical disabilities in the Netherlands}

In the Netherlands, children with severe physical disabilities generally attend special education $(>4 y)$ or go to a day-care centre $(2-4 y)$ where they receive therapeutic and pedagogical support combined with rehabilitation. Some children with physical disabilities (without additional problems) attend mainstream education or day-care centres. In the Netherlands, special education is organized in separate special schools, and divided into clusters. Cluster 1 contains the schools for children with visual impairments, cluster 2 refers to the schools for children with hearing impairments and cluster 4 to schools for children with developmental disorders (such as autism spectrum disorder) and behavioural problems. Cluster 3 contains the schools for special education for children with physical disabilities, cognitive impairments and children with long-term illness [16]. These schools are often integrated with day-care (for children 2-4 y) and rehabilitation, and the rehabilitation centres are generally physically located next to the school or in the same building. In some cases there are also residential facilities for the children. The trained professionals who work in these schools and rehabilitation centres are experts 
in working with this target group. They are, for example, specialized in paediatric rehabilitation, on top of additional courses and training, or they finished a master on special educational needs.

In these specialized rehabilitation and education settings, the Children and Youth version of the International Classification of Functioning, Disability and Health (ICF-CY) is a commonly and widely accepted and used framework and a 'universal language' used by therapists as well as pedagogical caregivers and educators [17]. This classification was developed to be able to describe the characteristics of the developing child and the influence of the environment on the child. Compared to the general International Classification of Functioning, disability and health (ICF), the ICF-CY is extended with learning and playing aspects and the developmental process. The ICF-CY can be used by everyone who is involved in the health, education and well-being of children (age 0-18 years). The ICF-CY offers a conceptual framework and universal language and terminology concerning body functions and structures, disabilities and participation during infancy, childhood and adolescence and the external factors which may influence the development of a child [17].

ICF-CY is used by different disciplines, in different sectors and even in different countries to describe functioning, disability and health, during the development of children and youths. Functioning is the overall term in the ICF-CY for the domains body functions, body structures, and activities and participation. The reporting systems that are used by special educators and therapists to report about the children are based on the different domains and sub-domains of the ICF-CY. Children's RAP (Rehabilitation Activities Profile for children) is an example of a tool that is based on the ICF-CY. It is often used in rehabilitation (centres) in the Netherlands to create one interdisciplinary plan for a child [18]. It aids communication between disciplines as well as with the parent of the child involved, and always gives a central role to the needs of the child (client centeredness). The Rehabilitation Electronic Patient Dossier (REPD), which is currently being used or implemented in many rehabilitation centres in the Netherlands, is also based on the ICF-CY. The set-up of the REPD can be adjusted depending on the preferences of a particular rehabilitation centre.

The concept of play is described in several sections of the ICF-CY: D1313 learning by symbolic play, D9200 play, and E1152 products and technologies for play. The D domain in the ICF is the domain about participation, while all sub-domains starting with $E$ are about the environment; in this case about the products and technologies used for play. In the setting of rehabilitation and special education for children with severe physical disabilities, play is a widely used vehicle to reach rehabilitation and educational goals. Looking at the definitions from LUDI as described in the first paragraph play-like activities are more common in this sector. In this research we incorporate both types of play. 


\section{Current state of robots and technology related to play}

The creation of solutions to support activities and participation for children with severe physical disabilities may be challenging [3]. Technological solutions can be very important for these children, as assistive technologies (ATs) may improve the autonomy of children with severe physical disabilities, may help them to reach goals, or may decrease workload of assistants. Examples of AT improving autonomy of the children are eye tracking systems, speech generating devices, but also single button operation possibilities. AT and mainstream technology are often used together as so called 'assistive solutions' [19]. It is important that AT products should be adapted to the context of use and the specific user's needs; a single piece of technology cannot solve a situation [20].

An important field in which technology is developing very fast is the field of robotics, in which play is a promising testing and application area. Socially assistive robotics (SAR) offer the most new opportunities to bring play possibilities to children. Especially children with disabilities may benefit from these new developments. At the International Conference of Rehabilitation Robotics in 2005 the definition of SAR was established as the intersection of assistive robotics (AR) and socially interactive robotics (SIR). SAR shares with assistive robotics the aim to provide assistance to the user, but this assistance is trough social interaction. Because of the focus on social interaction, SAR has a similar focus as SIR, the key difference lies in the fact that in SIR, the aim is to develop close and effective interactions for the sake of interaction itself while SAR aims to create close and effective interaction with the user for the purpose of giving assistance and achieving measurable progress in, for example, rehabilitation and learning [21]. LUDI states that robots can become powerful facilitators if correctly chosen and situated in a person's daily life [3]. The assumption is that providing tailored means to encourage play through a robotic toy will break down barriers to development through play [22]. A LUDI working group which concentrates on toys and technologies for children with disabilities, has created an online database with examples of toys and technologies for children with disabilities as well as additional information, such as results of studies about these toys (http://ludi.utad.pt/). In addition, this working group is establishing guidelines for usability and accessibility of toys and technologies.

Robotics is a central theme on European research agendas, and a lot of research is being done in this field, mostly in areas such as industry, security, traffic and entertainment, but also in health care. Robotics is, for example, an important part of the current Horizon 2020 (H2020) work programmes. Of this H2020 programme, especially the parts that deal with societal challenges (health, demographic challenge and wellbeing) are relevant for the field of rehabilitation and special education (https://ec.europa.eu/programmes/horizon2020/en/h2020-section/robotics). Technology and robotics create numerous new chances and possibilities, also in the area of healthcare. 
Although there is no state-of-the-art overview available about the use of robots and ICT for children with severe physical disabilities, some small studies indicate positive effects of letting this target group make use of ICT and robots. For example the LEGO Roverbot is a robot which can be controlled with an adapted controller. The children liked this robot and they showed increased attention to task as well as increased vocalisation and verbalisation with other children [23]. Another example of a robotic device being used for children with disabilities is the IROMEC robot, a mobile platform with an interaction module and some control buttons, which was able to improve motor development in a severely motor impaired child [24]. Virtual reality systems and computer systems are other examples of upcoming technologies that may be beneficial for children with severe physical disabilities by supporting play [25].

Because of the new chances technologies offer, in this dissertation we focused on the potential of robots in supporting play for children with severe physical disabilities. The application domain which was chosen is special education and rehabilitation context. At the start of the project the potential of robot IROMEC was explored and tested in daily care practice. Robot IROMEC was developed during a European project from 2006-2009 (www.iromec.org). Figure 1 shows a photo of the IROMEC platform. IROMEC stands for Interactive Robotic Social Mediators as Companions, and is a mobile robotic platform developed for children with motor impairments, children with mental problems and children with autism. It is a mobile platform which can move and has a touch screen on the back and three wireless buttons which can be used to control the robot. Detailed information about the platform and its scenarios are described in chapter 3 of this dissertation.

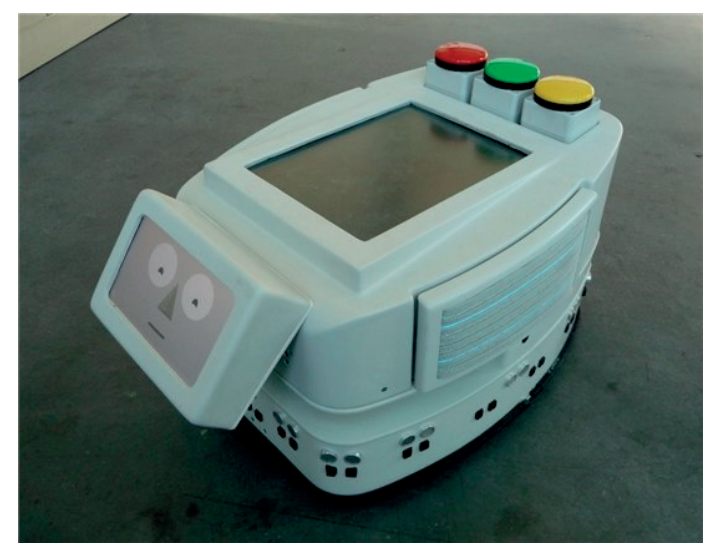

Figure 1 Robot IROMEC

Later the possibilities of robot ZORA were explored together with experts and ZORA was tested in practice with children with severe physical disabilities and their professionals. 
ZORA is a humanoid robot developed by Softbank robotics (hardware) and QBMT (software) (figure 2), able to speak, dance, exercise, play games and more.

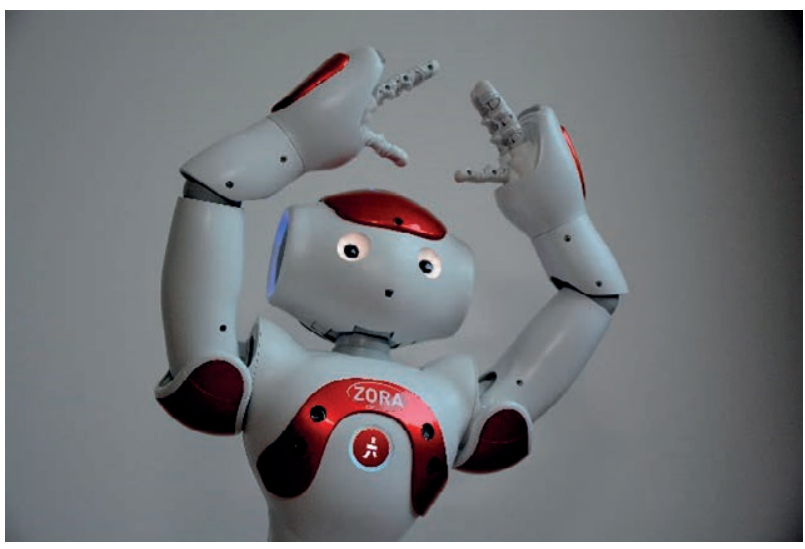

Figure 2 Robot ZORA while dancing

\section{Aims and outline of the dissertation}

This dissertation focuses on the potential of robots in rehabilitation and special education for children (developmental age ranging from 2 to 8 years) with severe physical disabilities. Some examples of robots were tested and evaluated in rehabilitation and special education practice, to gain insight in their contribution in supporting play and therapeutic and educational goals. At the start of this study robot IROMEC was selected to test and evaluate in practice. Later on robot ZORA became commercially available for application in care practice and was selected as second robot which was used in the same context.

The main objectives of this study are:

1. To gain insight into the aims, control options and commercial availability of information and communication technology (ICT) and robots to support play in children with severe physical disabilities.

2. To examine the possibilities of the IROMEC robot in rehabilitation and special education for children with severe physical disabilities.

3. To explore the application of robot IROMEC to support play for children with severe physical disabilities in rehabilitation and special education.

4. To explore the potential of ZORA robot-based interventions in rehabilitation and special education for children with severe physical disabilities.

5. To examine the contribution of robot ZORA to achieve therapeutic and educational goals, and to discover the roles professionals attribute to the robot in ZORA robot- 
based play interventions, within rehabilitation and special education for children with severe physical disabilities.

Chapter 2 shows the results of a systematic literature review of ICT and robots for children with severe physical disabilities, providing a clear overview of recent developments and studies in this field. Three main groups of technology were distinguished: robots $(n=8)$, virtual reality systems $(n=15)$ and computer systems $(n=4)$. The details regarding the aims of the technologies, control options and commercial availability of the different technologies are described in this chapter.

Chapter 3 details the methods used to conduct the study into the potential of robot IROMEC, when combined with professionals and parents of children with severe physical disabilities. These methods were focus groups, semi-structured interviews and a questionnaire. Goals and domains for which application of a robot in treatment and education could be relevant were determined. Next to this, suggestions for (technical/functional) improvement of the IROMEC platform before starting a pilot study in practice were identified. This helped to have a clear insight in application possibilities of robots in this context.

Chapter 4 describes the results of a pilot study with robot IROMEC. Eleven children and six professionals participated in this study to explore the potential of IROMEC to support play for children with severe physical disabilities in rehabilitation and special education. Quantitative and qualitative measures were used to evaluate aspects of feasibility, usability, barriers for the child and therapist, and to gain insight into an indication of the effects on playfulness and achievement of therapeutic and educational goals.

Chapter 5 describes the results of an explorative pilot study among children with severe physical disabilities playing with ZORA during 6 sessions in individual or group settings. Similar to what is done in chapter 4, aspects of feasibility, usability, barriers and facilitators for the child and the professional and an indication of the effects on goal attainment are described. Three domains for promising application of ZORA were identified.

Chapter 6 describes a study using ZORA to examine the ZORA's contribution toward the achievement of therapeutic and educational goals for children with severe physical disabilities, and an exploration of the different roles professionals attribute to ZORA.

The two last chapters of this dissertation are overarching in nature. Chapter 7 provides a summary and discussion of the main findings, and highlights implications for research, practice and policy, while chapter 8 describes the possibilities for valorisation of knowledge gained during this research. 


\section{References}

1. United Nations. Convention on the Rights of the Child. Child Labor. 1989:8.

2. United Nations. Convention on the Rights of Persons with Disabilities. GA Res. 2006;61:106.

3. Besio S, Bulgarelli D, Stancheva-Popkostadinova V. Play development in children with disabilties: Walter de Gruyter GmbH \& Co KG; 2016.

4. Garvey C. Play: Harvard University Press; 1990.

5. World Health Organization. Congenital anomalies 2016 [Available from: http://www.who.int/ mediacentre/factsheets/fs370/en/.

6. Tingle M. The motor impaired child: Psychology Press; 1990.

7. Tierolf B, Oudenampsen D. Kinderen met een handicap in Tel. 2013.

8. Anttila H, Samuelsson K, Salminen A-L, Brandt Å. Quality of evidence of assistive technology interventions for people with disability: An overview of systematic reviews. Technology and Disability. 2012; 24(1):9-48.

9. Henderson S, Skelton H, Rosenbaum P. Assistive devices for children with functional impairments: impact on child and caregiver function. Developmental Medicine \& Child Neurology. 2008;50(2):89-98.

10. Parette HP, Peterson-Karlan GR. Facilitating student achievement with assistive technology. Education and Training in developmental Disabilities. 2007:387-97.

11. Law M, King G, King S, Kertoy $M$, Hurley $P$, Rosenbaum $P$, et al. Patterns of participation in recreational and leisure activities among children with complex physical disabilities. Developmental medicine \& child neurology. 2006;48(5):337-42.

12. Imms C, Reilly S, Carlin J, Dodd K. Diversity of participation in children with cerebral palsy. Developmental Medicine \& Child Neurology. 2008;50(5):363-9.

13. Shikako-Thomas K, Majnemer A, Law M, Lach L. Determinants of participation in leisure activities in children and youth with cerebral palsy: systematic review. Physical \& occupational therapy in pediatrics. 2008;28(2):155-69.

14. Heah T, Case T, McGuire B, Law M. Successful participation: The lived experience among children with disabilities. Canadian Journal of Occupational Therapy. 2007;74(1):38-47.

15. Glowczewski K. Toys in development of children with disabilities. A father's perspective Gdansk: LUDI fifth action conference; September 2017.

16. Rijksoverheid. Organisatie van het speciaal onderwijs 2017 [Available from: https://www.rijksoverheid.nl/ onderwerpen/passend-onderwijs/speciaal-onderwijs.

17. World Health Organization. International Classification of Functioning, Disability, and Health: Children \& Youth Version: ICF-CY: World Health Organization; 2007.

18. Roelofsen EE. The rehabilitation activities profile for children: development, implementation and evaluation 2001.

19. Andrich R, Mathiassen N-E, Hoogerwerf E-J, Gelderblom GJ. Service delivery systems for assistive technology in Europe: An AAATE/EASTIN position paper. Technology and Disability. 2013;25(3):127-46.

20. Besio S. Analysis of critical factors involved in using interactive robots for education and therapy of children with disabilities. Brussels: IROMEC Consortium; 2007.

21. Feil-Seifer D, Mataric MJ, editors. Defining socially assistive robotics. 9th International Conference on Rehabilitation Robotics; 2005.

22. Kronreif G. Robot systems for play in education and therapy of disabled children. Towards intelligent engineering and information technology. 2009:221-34.

23. Cook AM, Adams K, Volden J, Harbottle N, Harbottle C. Using Lego robots to estimate cognitive ability in children who have severe physical disabilities. Disability and Rehabilitation: Assistive Technology. 2011;6(4):338-46.

24. Robins B, Dautenhahn K, Ferrari E, Kronreif G, Prazak-Aram B, Marti P, et al. Scenarios of robot-assisted play for children with cognitive and physical disabilities. Interaction Studies. 2012;13(2):189-234. 
Chapter 1

25. van den Heuvel RJ, Lexis MA, Gelderblom GJ, Jansens RM, de Witte LP. Robots and ICT to support play in children with severe physical disabilities: a systematic review. Disability and Rehabilitation: Assistive Technology. 2016;11(2):103-16. 
Chapter 2

Robots and ICT to support play in children with severe physical disabilities: a systematic review 


\section{Abstract}

Purpose: Play is an essential part of children's lives. Children with physical disabilities experience difficulties in play, especially those with severe physical disabilities. With the progress of innovative technology, the possibilities to support play are increasing. The purpose of this literature study is to gain insight into the aims, control options and commercial availability of information and communication technology (ICT) and robots to support play (especially play for the sake of play) in children with severe physical disabilities.

Methods: A systematic literature search in the databases PubMed, CINAHL, IEEE and ERIC was carried out. Titles and abstracts were assessed independently by three reviewers. In addition, studies were selected using Google Scholar, conference proceedings and reference lists.

Results: Three main groups of technology for play could be distinguished: robots $(n=8)$, virtual reality systems $(n=15)$ and computer systems $(n=4)$. Besides, ICT and robots developed for specific therapy or educational goals using play-like activities, five of the in total 27 technologies in this study described the aim of "play for play's sake".

Conclusions: Many ICT systems and robots to support play in children with physical disabilities were found. Numerous technologies use play-like activities to achieve therapeutic or educational goals. Robots especially are used for "play for play's sake".

\section{Implications for rehabilitation}

- This study gives insight into the aims, control options and commercial availability for application of robots and ICT to support play in children with severe physical disabilities.

- This overview can be used in both the fields of rehabilitation and special education to search for new innovative intervention options and it can stimulate them to use these innovative play materials.

- Especially robots may have great potential in supporting "play for play's sake".

Keywords: ICF-CY, paediatric rehabilitation, special education 


\section{Introduction}

Play is essential in the development of every child and is a fundamental right for every child [1,2]. Play is related to a child's cognitive, social, physical and emotional development $[3,4]$. Free play allows children the possibility to discover their capabilities, try out objects, make decisions, understand cause and effect relationships, learn, persist and understand consequences of actions [5]. In the International Classification of Functioning, Disability and Health for Children and Youth (ICF-CY), the World Health Organization classifies play as one of the most important aspects of the life of children when assessing quality of life [6].

For many reasons, children with disabilities experience difficulties in starting, developing and performing play activities in a natural way [7]. The experience of play may be frustrating or may even be impossible for children with physical disabilities such as cerebral palsy, acquired brain injury or muscular diseases. Most commercially available toys are not designed with the requirements of these children in mind, and are therefore difficult to manipulate. As a result, play activities may be partially or entirely impossible [8]. Consequently, children with physical disabilities are often forced into a passive role and need support to perform activities. Besides, when children with disabilities play with peers without disabilities, for example in a home environment, they tend to spend more time watching rather than participating due to physical and psychosocial barriers [9]. This underlines the importance of accessibility and control options of toys for these children, for example, the use of assistive technology (e.g. adapted switches). According to Goodley and Runswick-Cole [10], play can also be used as a "mechanism for assessment, diagnosis and therapeutic intervention". Therefore, in rehabilitation and educational settings, opportunities for children with disabilities to play are often related to "being assessed" and "being identified as disabled".

The importance of play is becoming more prominent. A currently running European Cost Action TD1309 aims to create a novel, autonomous and multidisciplinary field of research "play for children with disabilities" [11]. Experts in the field of play for children with disabilities are currently establishing definitions to make a clear distinction between play-like activities, to support extrinsic goals using ludic tools and play for play's sake, meaning "just for fun" [12]. We are particularly interested in technology for play for play's sake.

In general, children are open to new technology and often play and learn in interaction with computers [13]. The last few decades have seen huge progress in technological innovations, especially in the field of information and communication technology (ICT) and robots. A robot can be defined as an actuated mechanism programmable in two or more axes with a degree of autonomy, moving within its environment, to perform intended tasks [14]. Artificial intelligence is often an important part of robots. ICT or computer systems can be defined as systems composed of one or more computers (personal computer, tablet, iPad, etc.), and peripheral equipment, such as disks, print- 
ers, keyboards and telecommunication systems [15]. Upcoming technology like video gaming and serious gaming are examples of computer systems.

With the innovation in technology, the possibilities for using technology in play are increasing. This creates new potential for children with severe physical disabilities. Technology can support children with physical disabilities in developing skills to overcome their impairments by giving them access to play activities and enabling them to experience regular cognitive and linguistic development by giving them similar play opportunities to those of their typically developed peers [16].

Insight into the aims, control options and commercial availability of ICT and robots to support play in children with severe physical disabilities is lacking. To date, there has not been another review or scientific article about this topic. Having insight into which ICT based technologies and robots can be applied to stimulate play in children with severe physical disabilities, and how, may be helpful for people working in paediatric rehabilitation and special education (e.g. therapists or special education teachers), enabling them to search for and initiate new innovative opportunities. Furthermore, researchers and product developers can use this information for research, development and implementation of new technologies or for further improvement of existing technologies.

The purpose of this literature review was to gain insight into the aims, control options and commercial availability of ICT and robots to support play in children with severe physical disabilities. Due to the limited evidence and effective evaluations in this research field, we were not interested in the effects and effectiveness of these technologies. Special attention will be on the difference between technologies using play-like activities and technologies supporting play for play's sake.

\section{Methods}

\section{Search strategy}

In January 2014, a systematic literature review was performed in CINAHL, PubMed, ERIC and the IEEE databases. Only scientific literature was used to include the relevant technologies; no grey literature or databases of assistive devices have been included. The search query was composed according to the PICO structure (participants, intervention, comparisons and outcomes) from the Cochrane Handbook [17]. Furthermore, a secondary search was executed using reference lists, Google Scholar (free text word search according to the words used in the search strategy) and conference proceedings from the Association for the Advancement of Assistive Technology in Europe (AAATE) and Rehabilitation Engineering and Assistive Technology Society of North America (RESNA). 


\section{Key terms}

To limit the chance of excluding relevant publications, only the participants (children with physical disabilities) and the intervention (robots and computer systems) were used as selection criteria in the first step of the database search. The search terms for the description of the participants were checked by two paediatric occupational therapists. Appendix Table A1 displays an overview of the complete search strategy: this section only describes the MeSH terms. The MeSH terms (or their database specific equivalent) "Child" or "Preschool child" were combined with the MeSH terms "Motor skills disorders", "Brain injury chronic", "Spinal dysraphism", "Cerebral palsy", "Muscular diseases" and "Arthritis juvenile rheumatoid". Furthermore, the MeSH terms "Disabled children" and "Child, institutionalized" were searched separately. These search terms were combined with the MeSH terms for the interventions: "Robotics", "Artificial intelligence", "Assistive technology", "User computer interface", "Therapy, computer assisted", "Computer", "Computer systems" and "Video games". No limitations were applied for date of publication.

\section{Study selection}

In the second step, three reviewers (R. H., R. J., C. H.) independently assessed the relevance of the titles of the publications for this review on a 3-point scale ( $0=$ not relevant, 1 = doubtful, 2 = relevant). Titles were included if they were about children with physical disabilities or multiple disabilities and robots or computer systems (e.g. video games). Titles were excluded if they were not about children with physical disabilities, if they contained medical surgery robots, measurement, assessment or observation methods, or wheelchairs. To reduce the chance of excluding relevant publications, the abstract of all publications with a total title score of at least two points was assessed.

In the third step, three reviewers (R. H., R. J., L. H.) independently assessed the selected publications on the same 3-point scale based on the abstracts. Next to the inclusion and exclusion criteria from step one, additional criteria were used. Abstracts were included if they contained a play component (play, game etc.). Abstracts were excluded if they comprised technology without a play component (e.g. communication technology or locomotion training), assistive devices (crutches, walkers, etc.), or if they were about parent/sibling experiences. Furthermore, if the abstract was not written in English, it was excluded. In deciding whether or not to select a publication for assessment of the full text, a total score of at least four points on abstract assessment was used. To determine the agreement between the three reviewers in both title assessment and abstract assessment, Cohen's kappa was calculated.

In the fourth step, the full text publications were read in full and judged by one reviewer (author R. H.) and the final set of publications for the review was composed using the same criteria as for the abstract assessment. Only studies in which children participated - for example, intervention studies and pilot studies - were included. In 
addition, publications were selected through an Internet search (Google Scholar) and a manual search in both conference proceedings (AAATE, RESNA) and reference lists of the selected publications. When the first author was doubtful about inclusion of the full text, it was discussed with one of the reviewers (R. J.).

\section{Data extraction}

Of the selected publications, the full text was read to derive the name, description, aim of the technology and the control options. Furthermore, the commercial availability of the technology was determined based on information in the article or information on the website of a distributor or manufacturer. To define the aim of the technology, the researcher determined in collaboration with reviewer R. J. (researcher and occupational therapist) how the aims as mentioned in the article could fit in or be best translated to the domains of the ICF-CY, the aim being to use a universal language for these aims and hence stay as close as possible to the originally defined goals. A formal assessment of the methodological quality of the publications appeared to be of little value, given the often very basic and descriptive character of most studies, and since many publications were conference proceedings.

\section{Results}

In the first step, 2075 publications were found (duplicates were excluded). In the second step, 810 publications were selected as potentially relevant based on their title. Publications without an abstract and full text were excluded. Based on their abstracts, 91 publications were selected in the third step for assessment of the full text. The interrater agreement between the reviewers was calculated using the weighted Cohen's kappa coefficient. In step two, the weighted Cohen's kappa coefficient between R. H. and R. J. was 0.69, between R. H. and C. H. 0.55 and between C. H. and R. J. 0.40. In step three, due to practical reasons, another reviewer from the research team (L. H.) participated instead of C. H. The weighted Cohen's kappa of R. H. and R. J. was 0.67, of R. H. and L. H. was 0.43 and of R. J. and L. H. was 0.49. These weighted Cohen's kappa's indicate a fair to good agreement between the reviewers. In the end, 61 publications were included in the review, of which 45 were from step three and 16 from the additional search (Figure 1).

The 61 included publications reported on 27 different technologies; eight robots, 15 virtual reality systems (six using force/touch feedback, nine screen based) and four computer systems. The virtual reality group was a category which emerged from the results and was not specified in the search strategy beforehand. 
Three main groups of technology supporting play in children with severe physical disabilities

Based on the included publications, three main groups could be identified: robots, virtual reality systems using an artificial environment in the games and computer systems which are systems without the use of virtual reality. Below, these three main groups are described in terms of the aims, characteristics of the technologies and their relation with play. Table 1 gives a description of the technologies, the control options and their commercial availability. Table 2 displays the technologies related to the ICF-CY domains, which were linked to the aims of the technologies [6]. Table 3 describes all the included studies in terms of aims, description of intervention, study population, frequency/duration and outcomes. Appendix Table A2 shows some example pictures of systems from each of the three groups. 


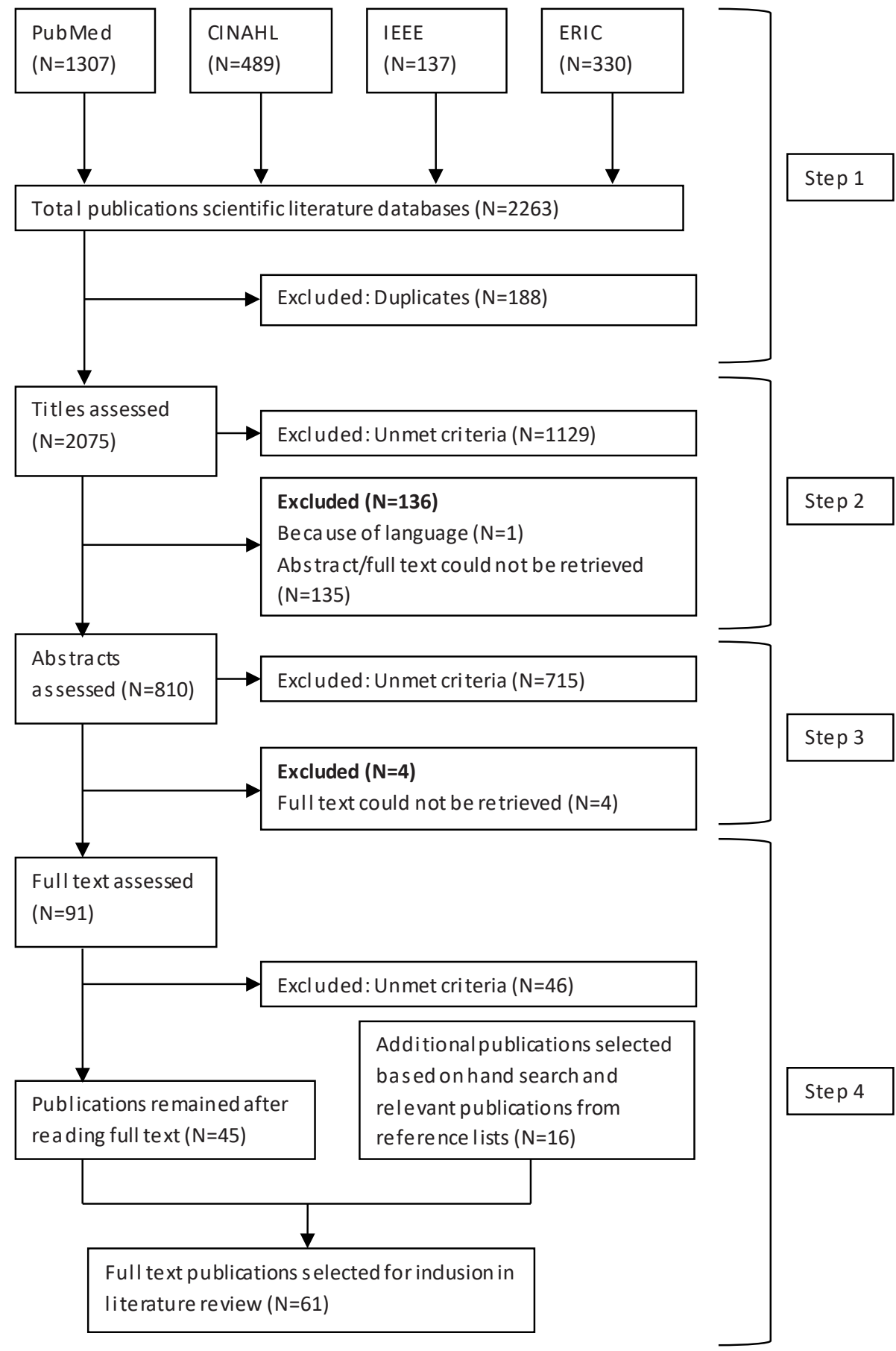

Figure 1 Flow chart article selection 
Robots and ICT to support play in children with severe physical disabilities

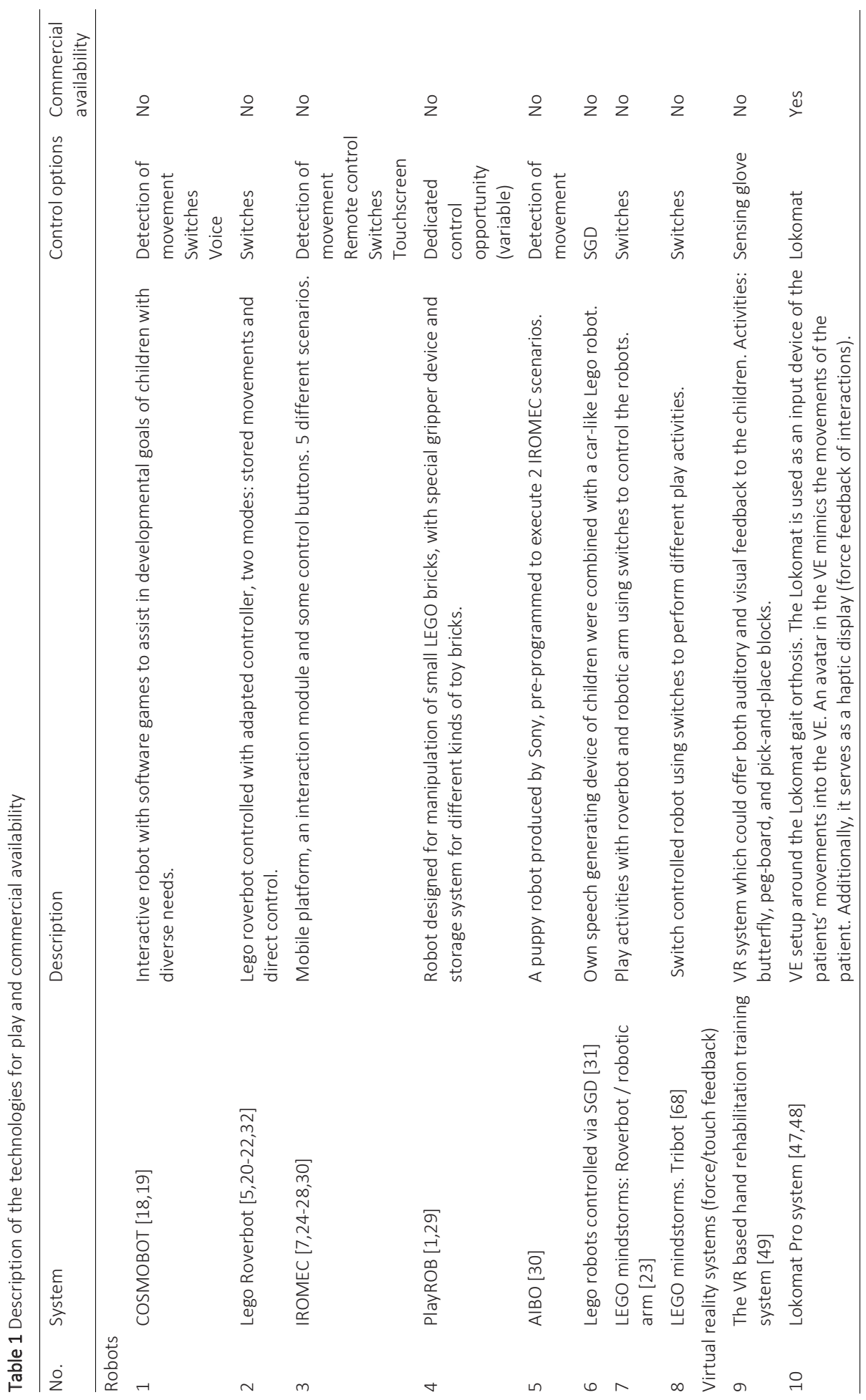




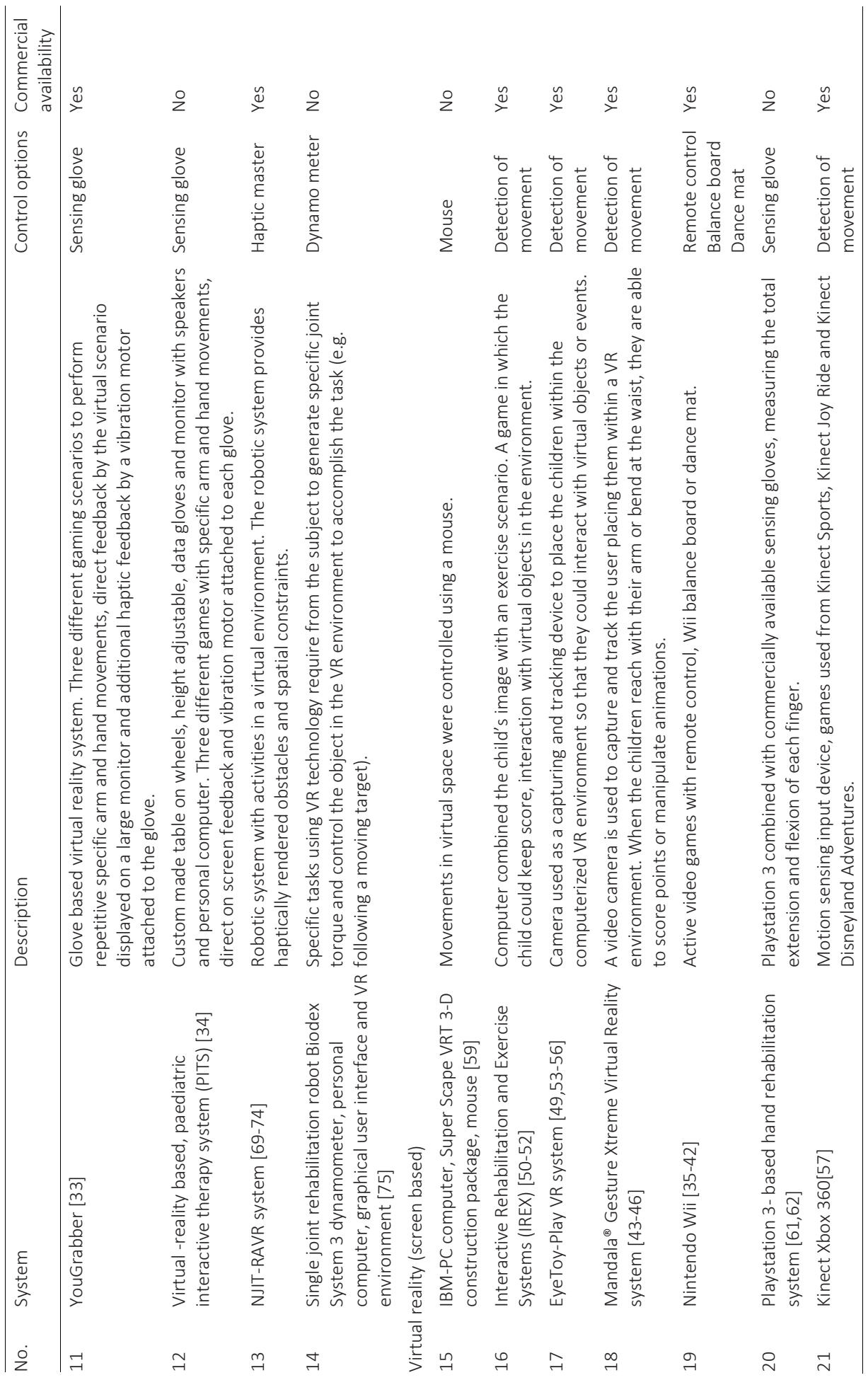


Robots and ICT to support play in children with severe physical disabilities

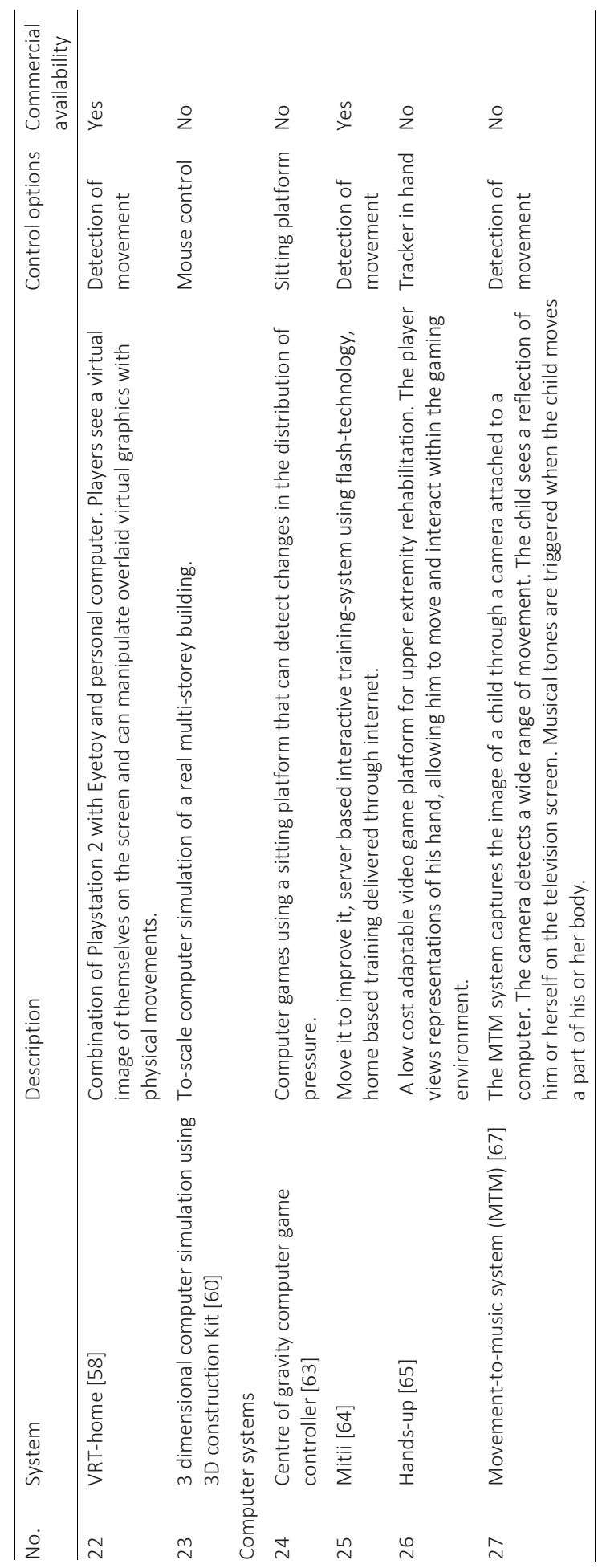


Chapter 2

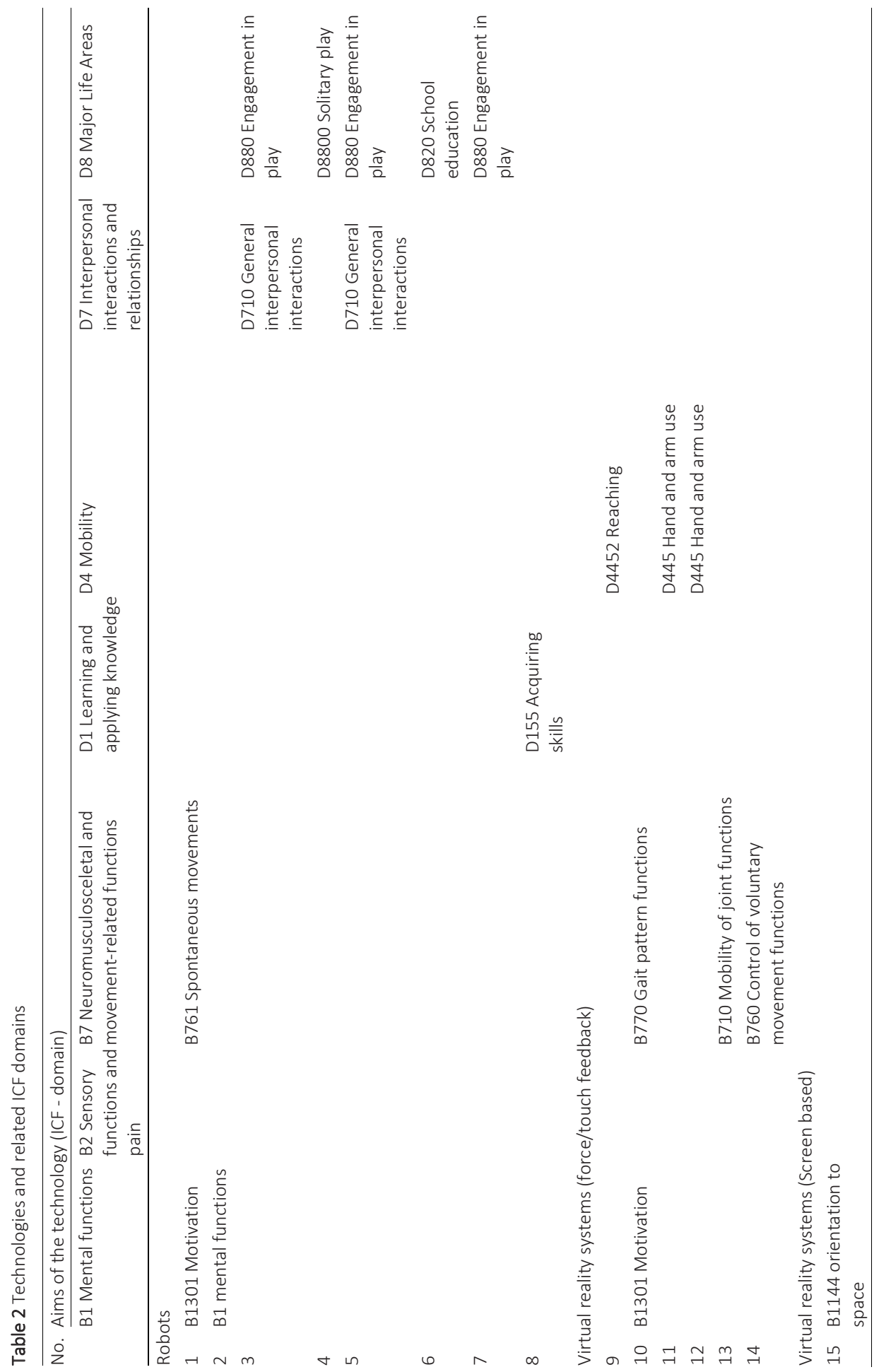


Robots and ICT to support play in children with severe physical disabilities

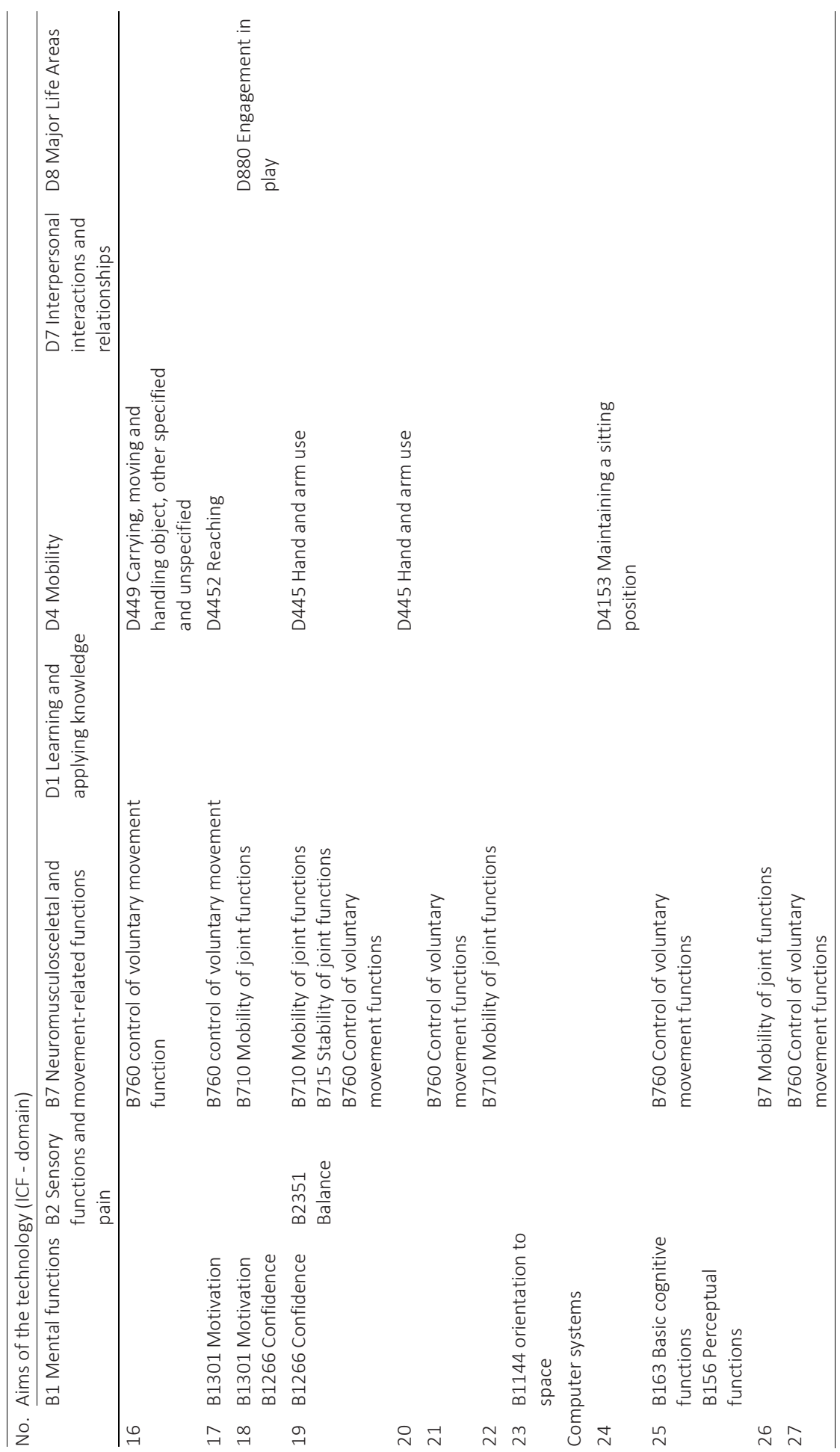




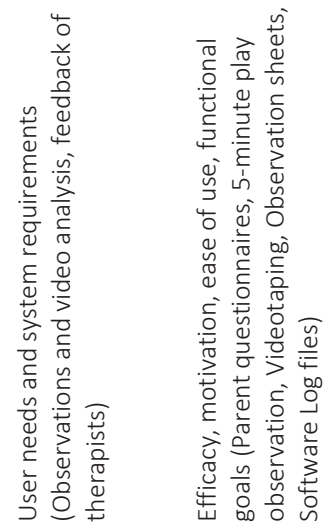

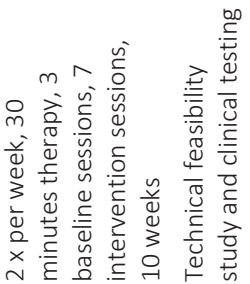

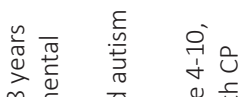

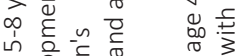

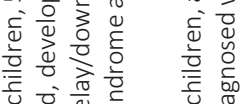

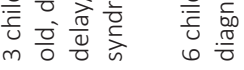

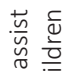

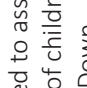

둥

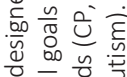

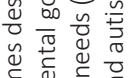

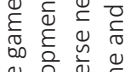

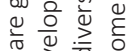

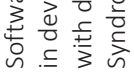

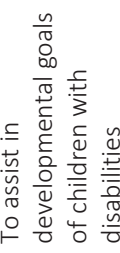

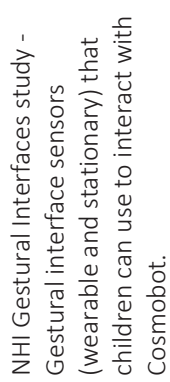

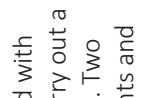

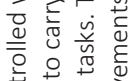

守产

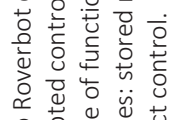

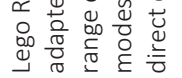

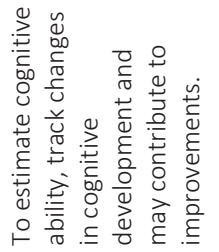

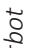

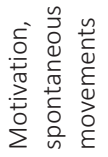

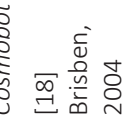

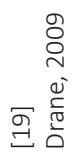

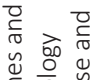

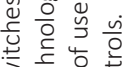

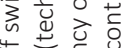

俈产造品

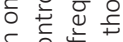

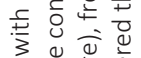

3 䨌

들 है

ह

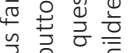

을 旁 बे

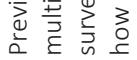

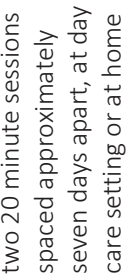

$\stackrel{n}{\frac{\pi}{\pi}}$

응

ये

鬲

을 을

흥ㅎㅁ

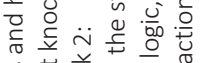

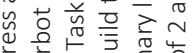

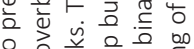
는응 这完

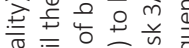

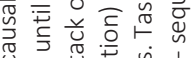

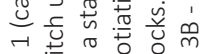

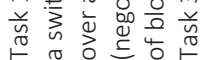

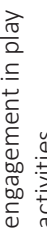

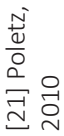




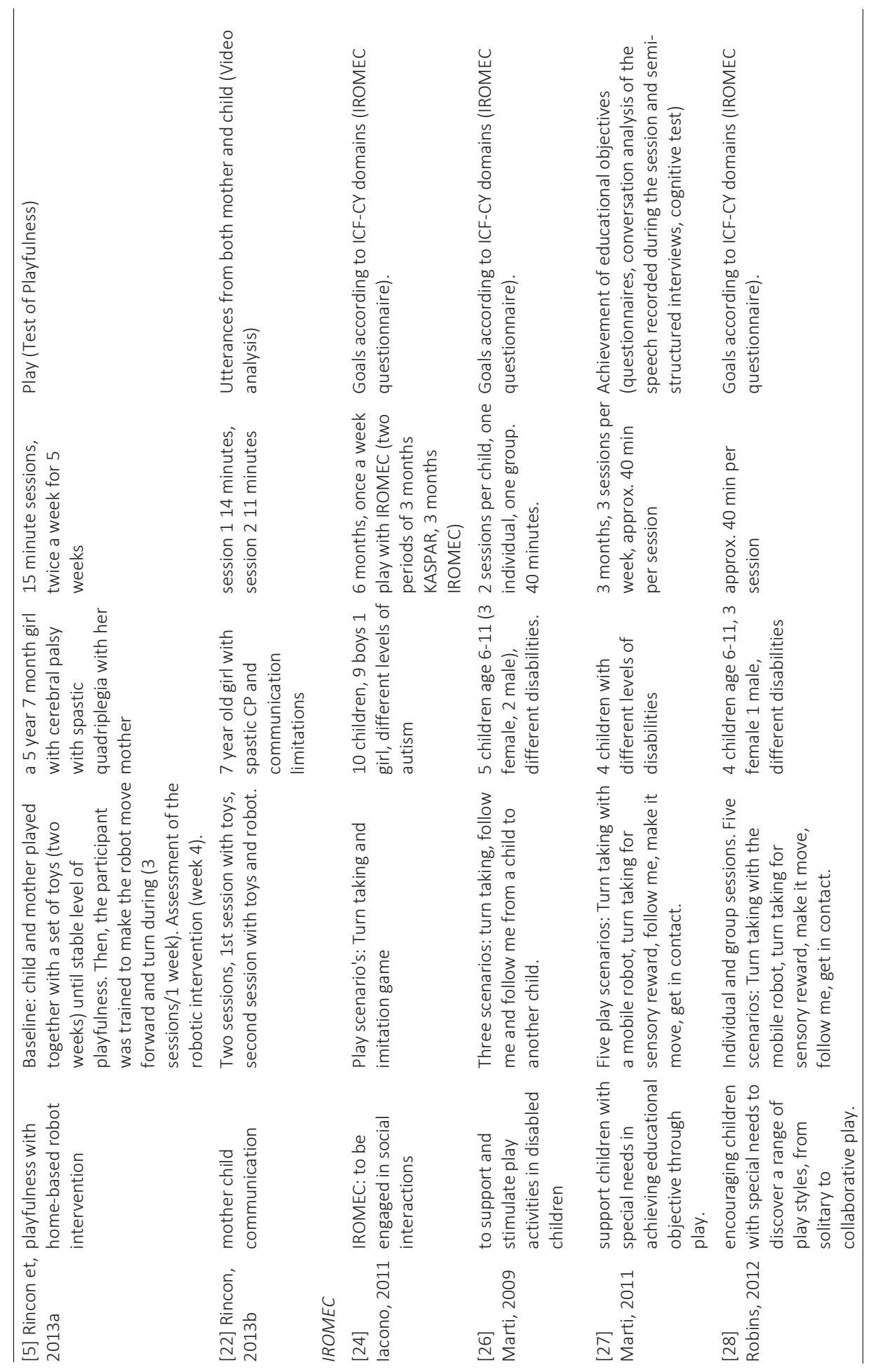




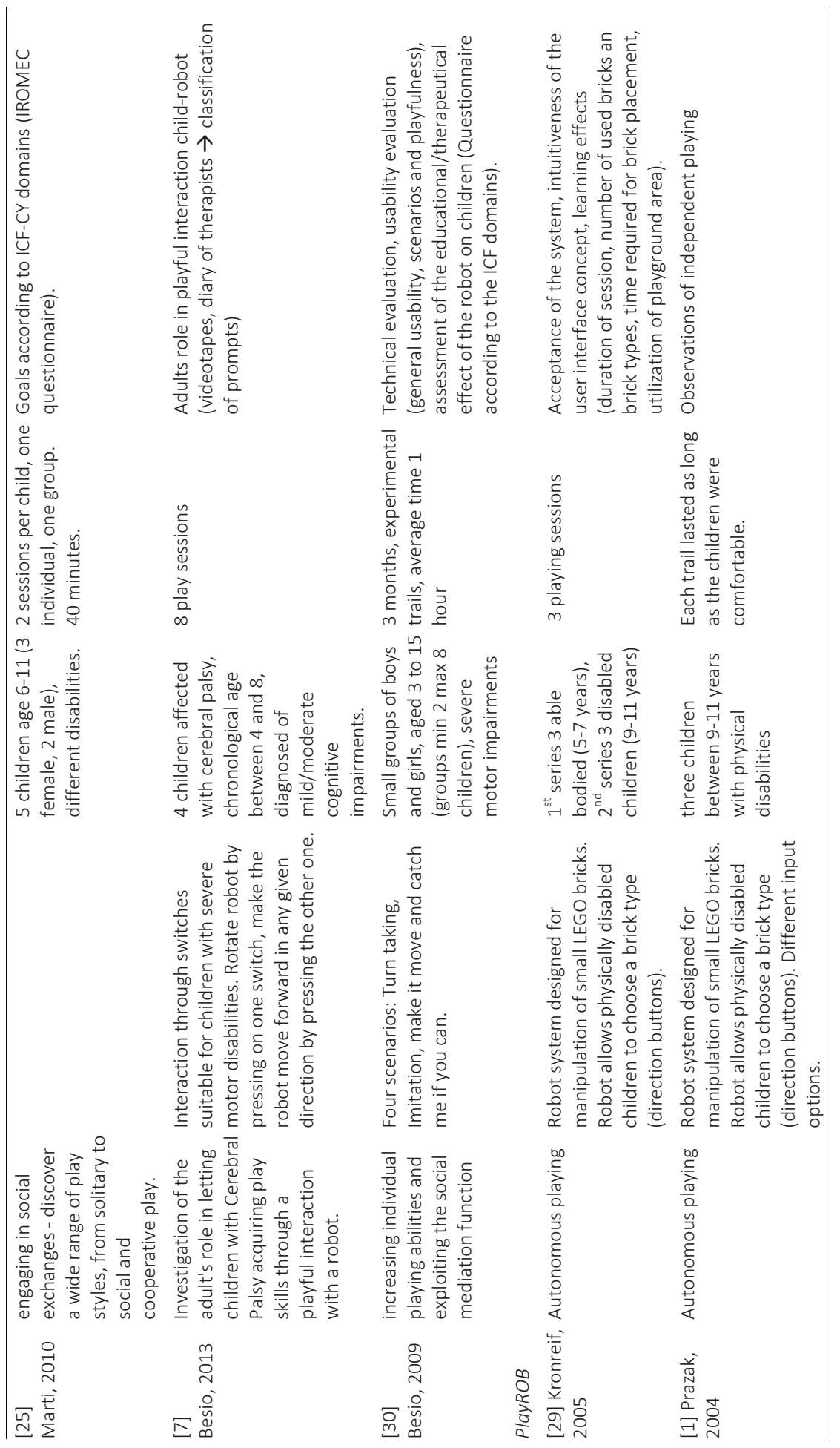



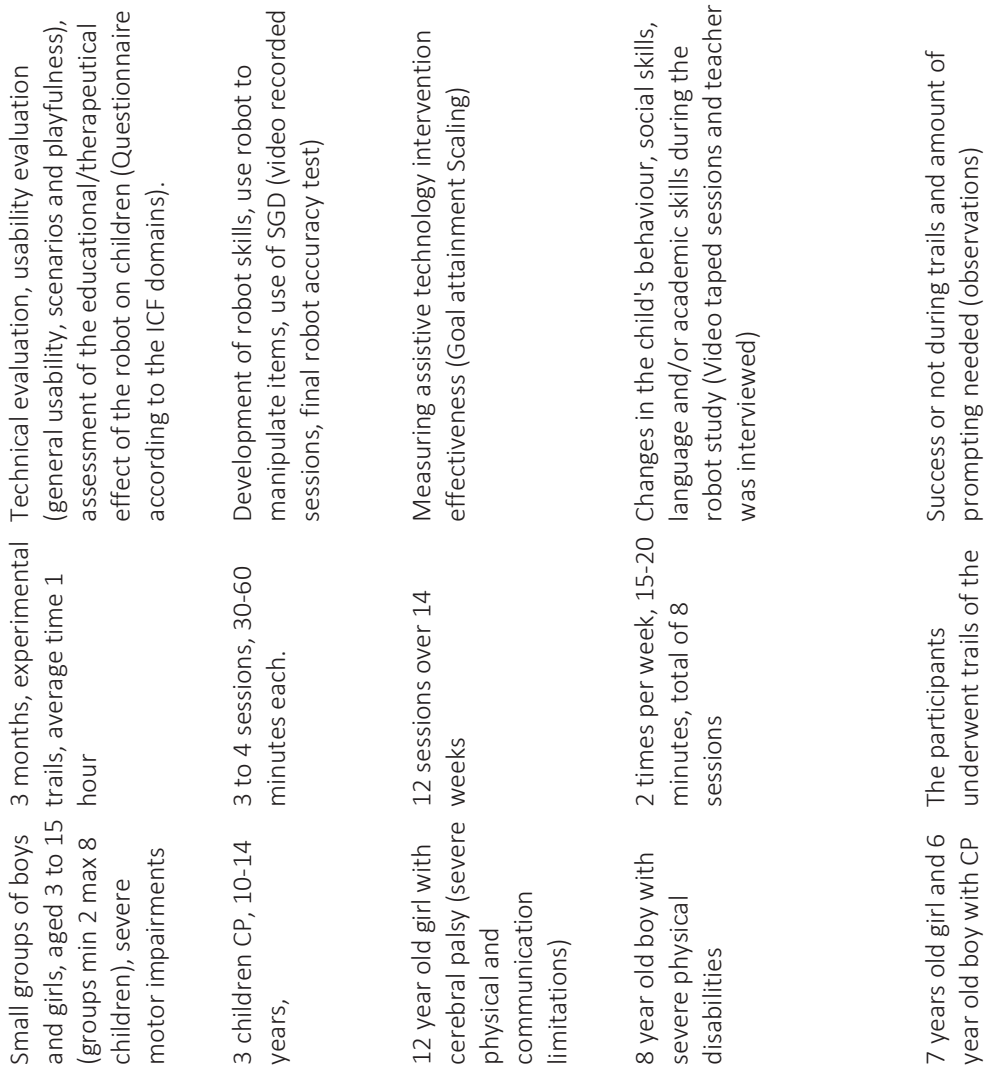

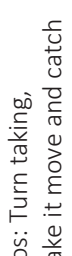

鱼离

离

言莺总

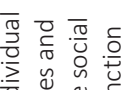

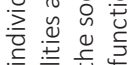

Do

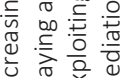
늘

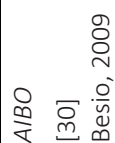

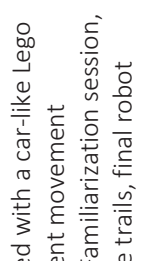

त)

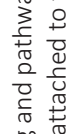

产 步

$\sum_{0}^{0} \frac{0}{0} \frac{0}{0}$

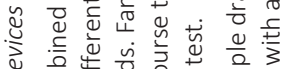

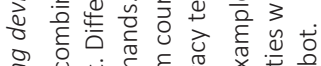

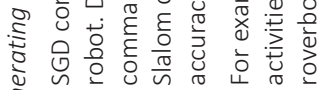
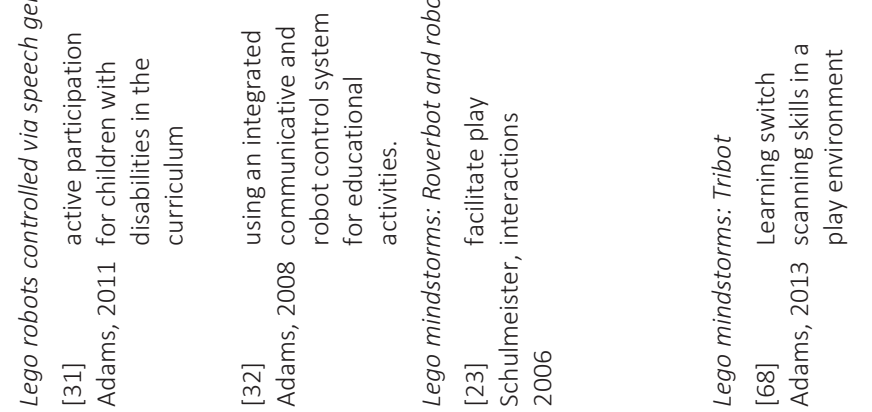

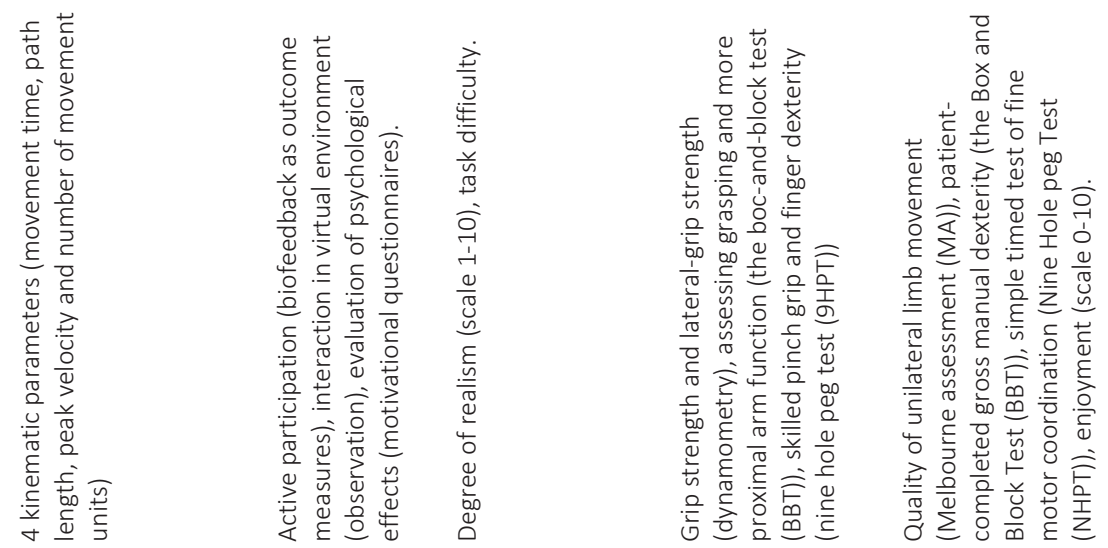

$\frac{1}{0}$
3
3
$\frac{0}{2}$
v
$\frac{0}{0}$
3
4

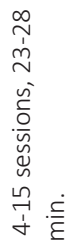
守

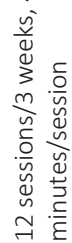

บे

ํํㄹ

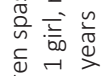

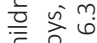

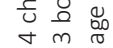

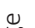

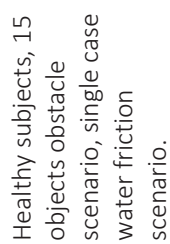

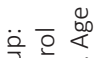

ֻ

㟧

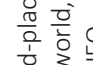

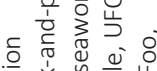

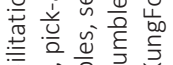

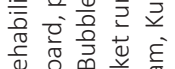

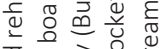

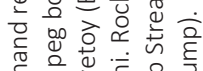

告

ฮั่

毫

음

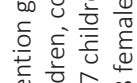

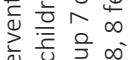

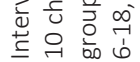

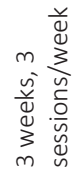

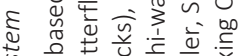

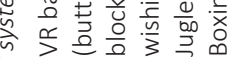

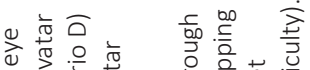

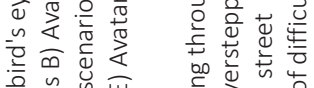

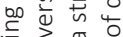

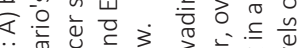

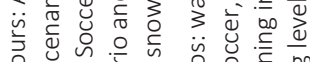

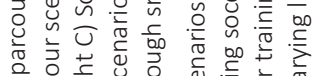

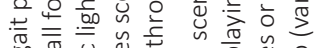

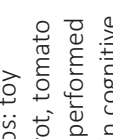

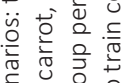

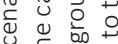

다의

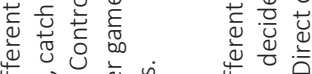

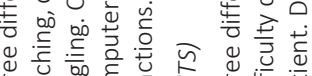

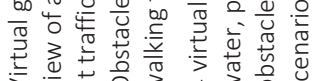

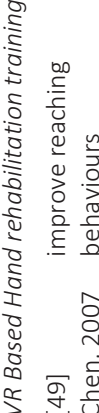

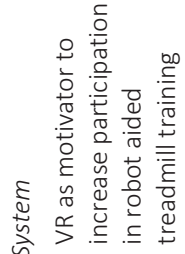

잉

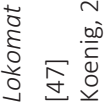

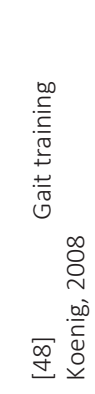

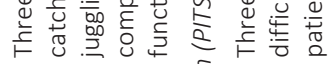

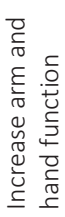

जั

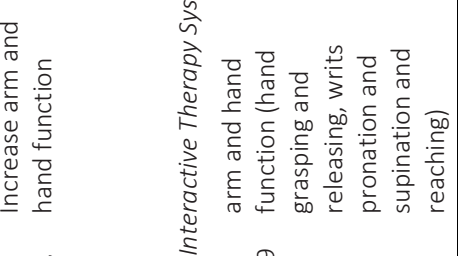

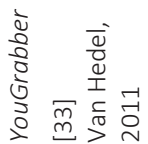

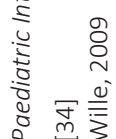

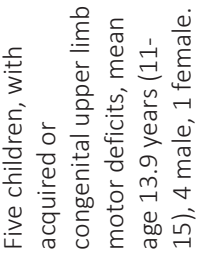

등하

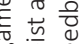

vi

은

ฮิ حิ

心

$+\frac{d}{0}+$ 


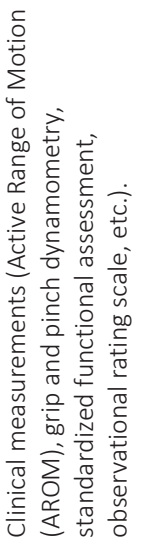

$\frac{m}{\stackrel{N}{0}}$

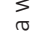

$\overbrace{\substack{0 \\ 0}}^{\infty}$

m

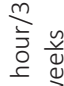

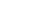

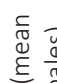

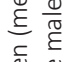

는 ญ

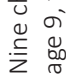

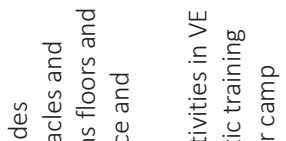

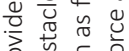

은 合它

ह

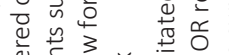

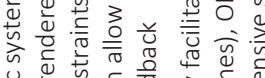

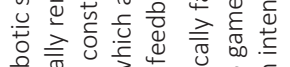

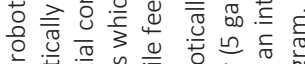

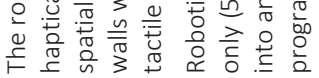

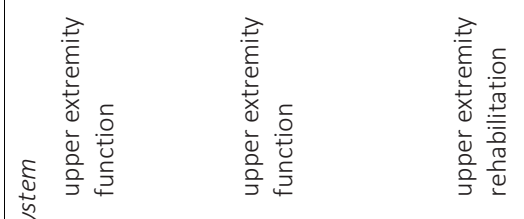

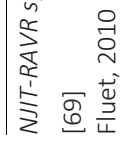

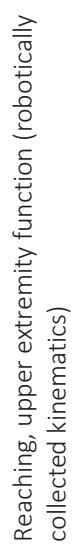

m

$m$
$y$
0
0
0
0
$\frac{1}{0}$
$m$
$m$

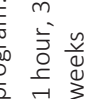

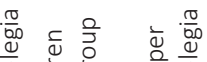

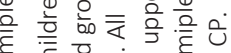

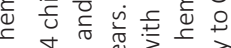

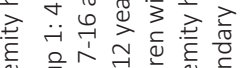

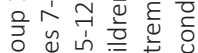

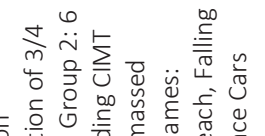

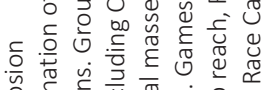

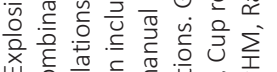

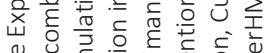

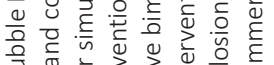

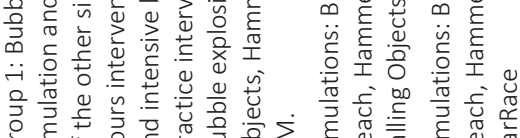

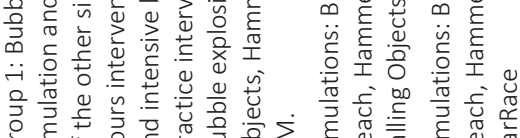

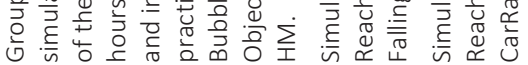

구에

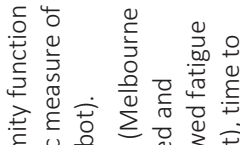

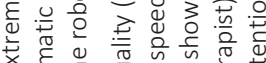

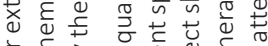

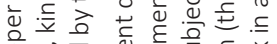

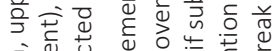

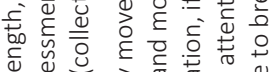

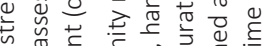

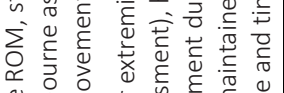

ه ठำ

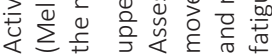

$m \quad m$

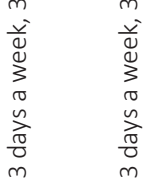

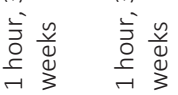

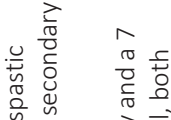

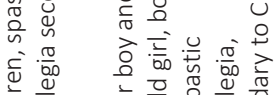

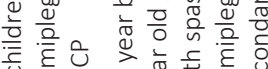

U.

今ं 今

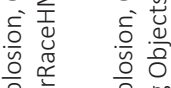

这竞

잉 崩

융 퐁

उ बे ज्ञ

نे है 造 


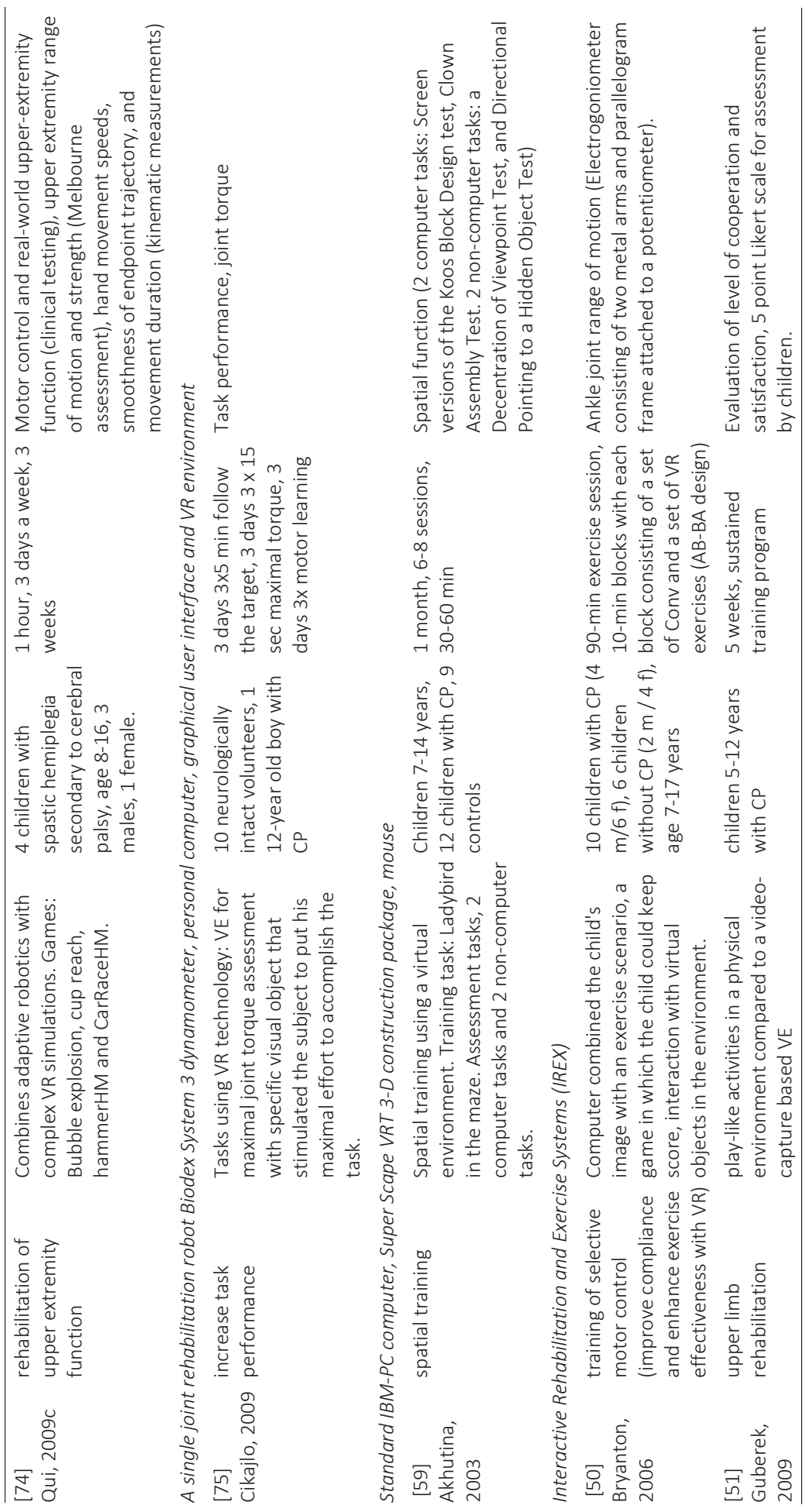




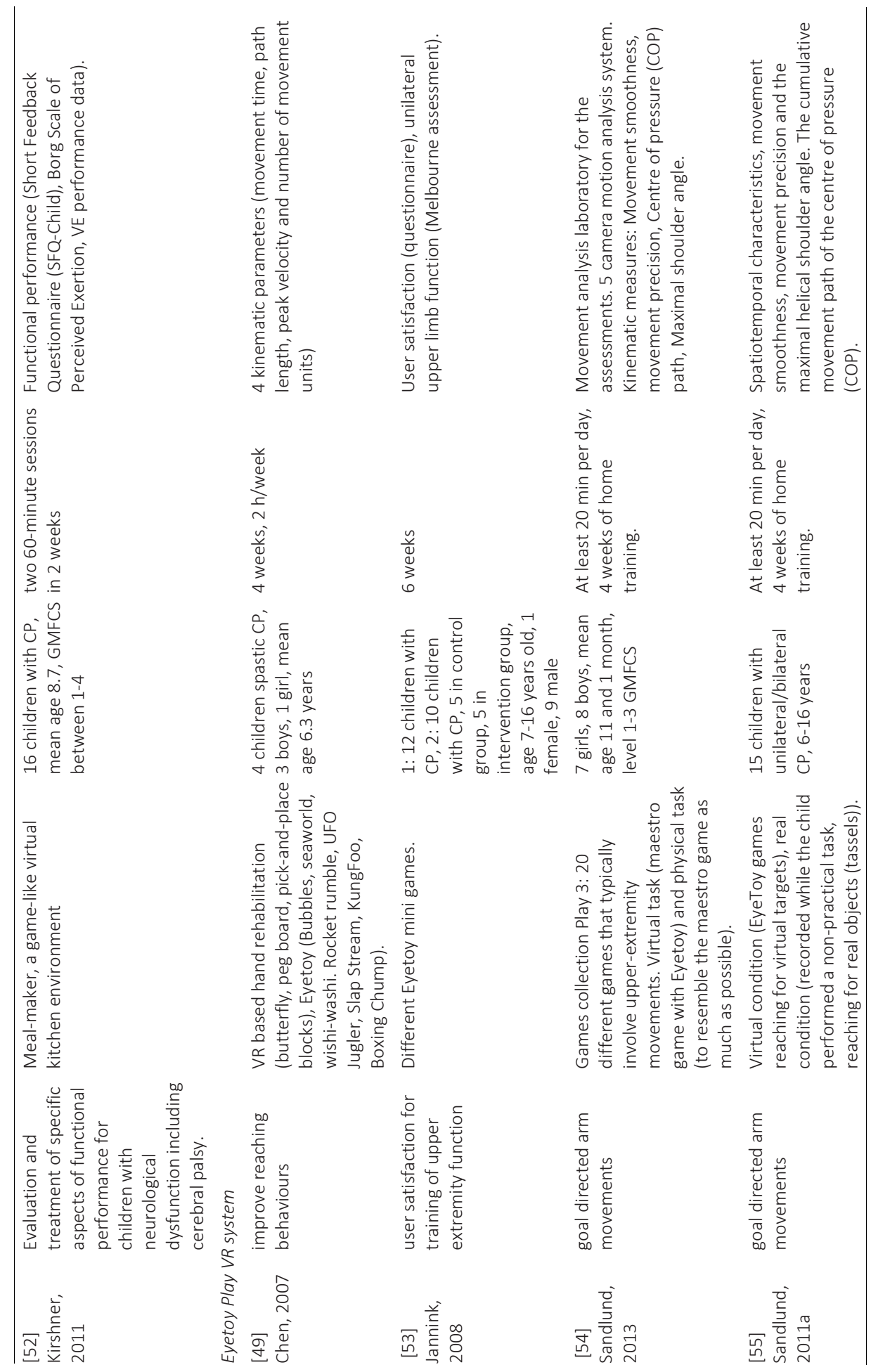




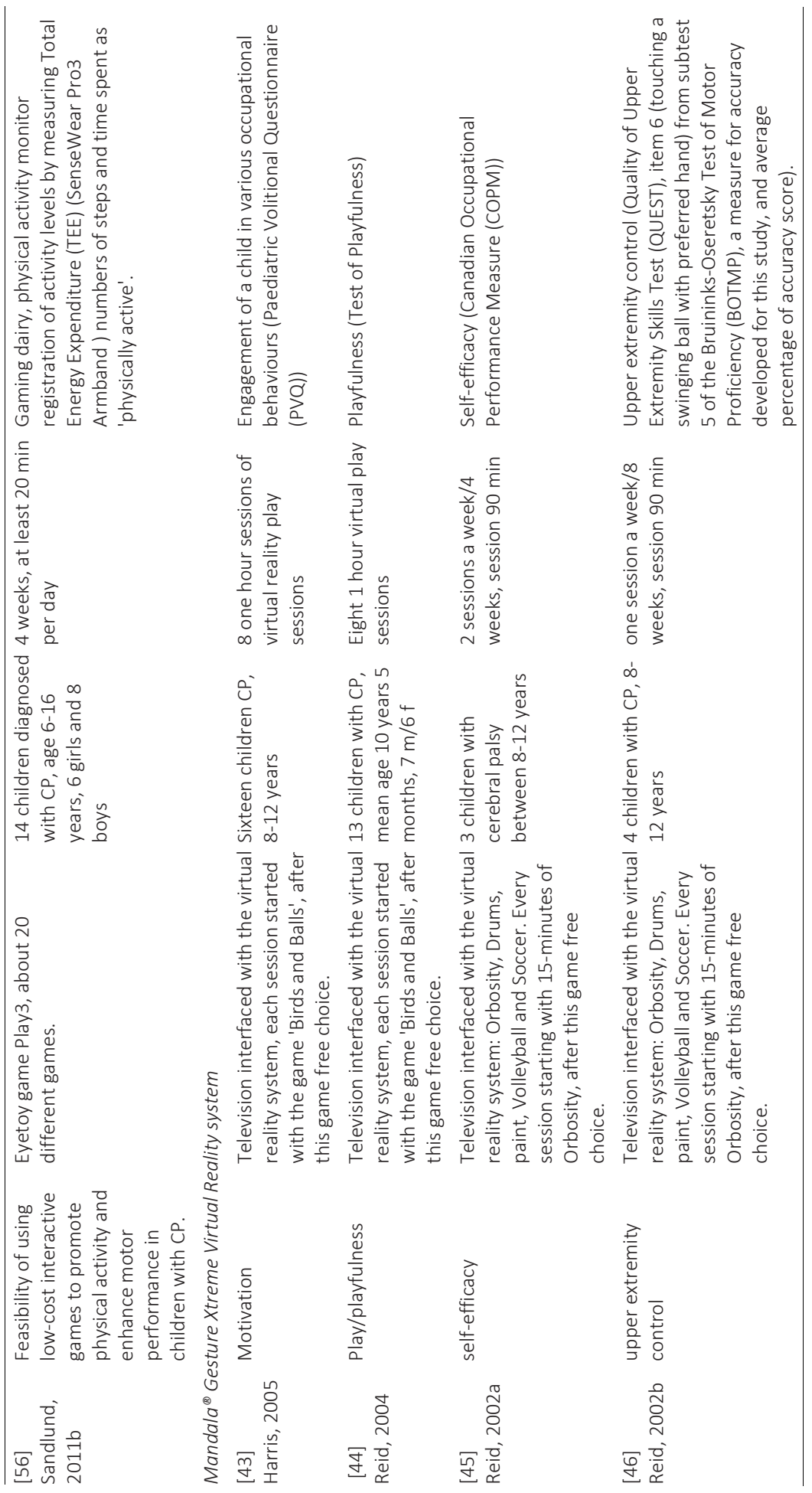



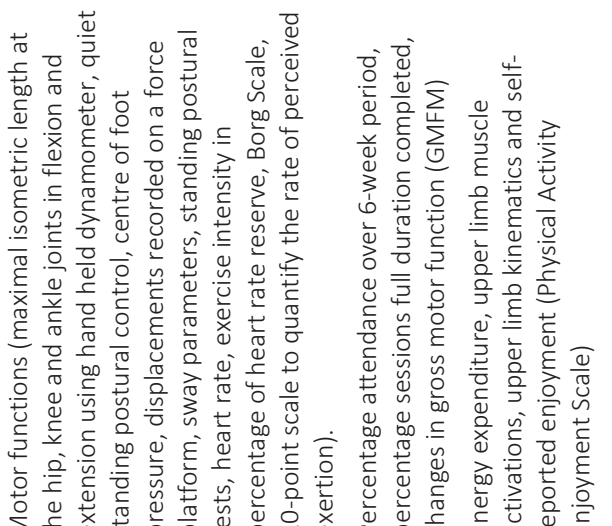

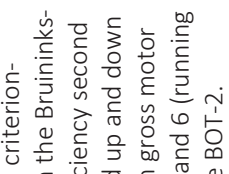

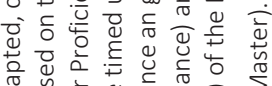

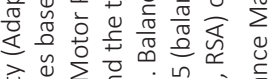

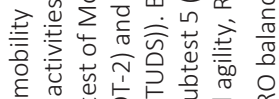

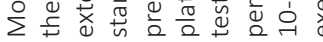

प잉

号

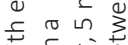

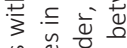

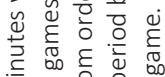

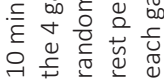

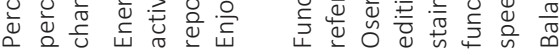

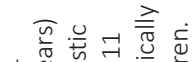

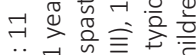

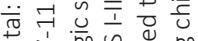

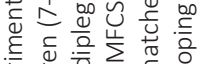

है

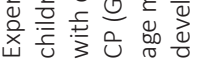

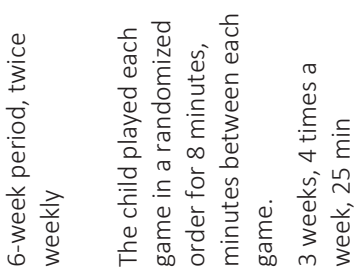

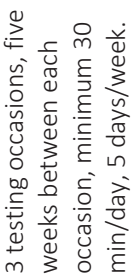

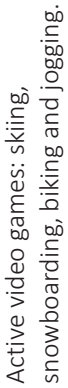

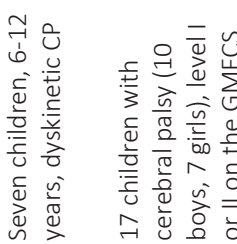

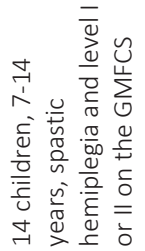

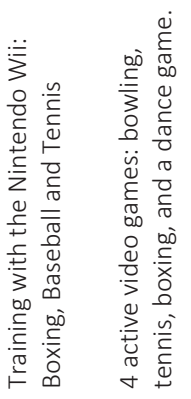

$\frac{\pi}{\frac{5}{2}}$

$\sqrt{5} \frac{\sqrt{2}}{\frac{5}{0}}$

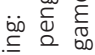

孚

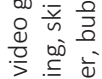

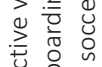

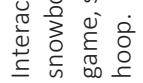

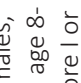

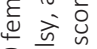

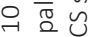

这告

है ปैं

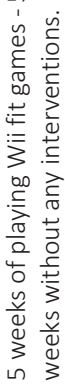

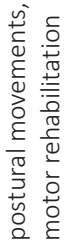

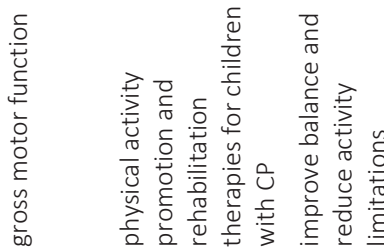

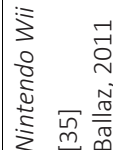

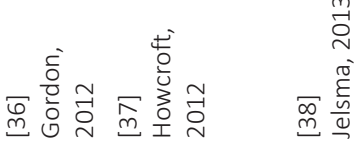

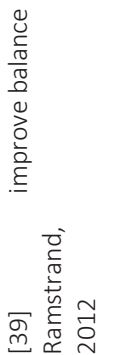




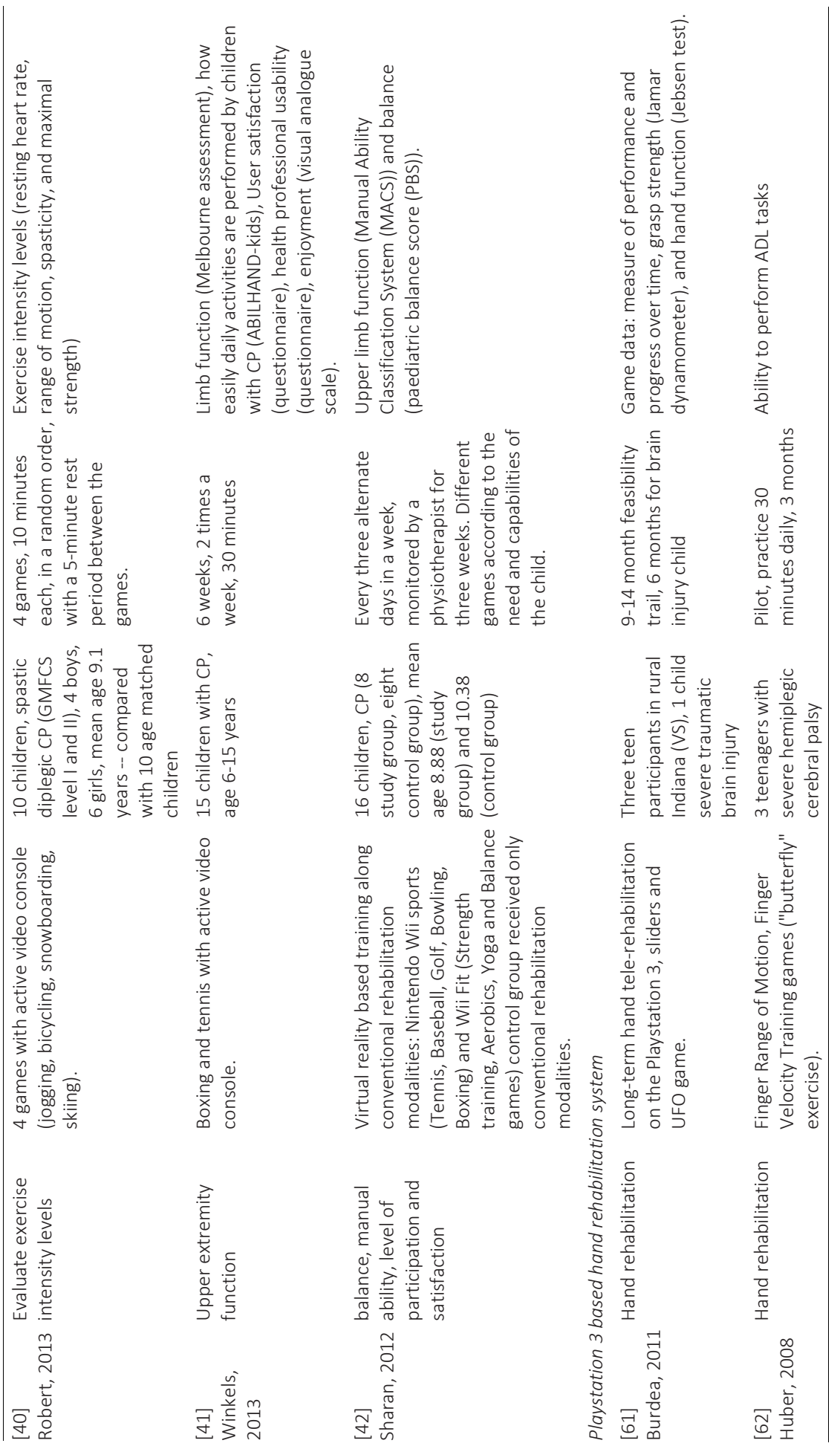




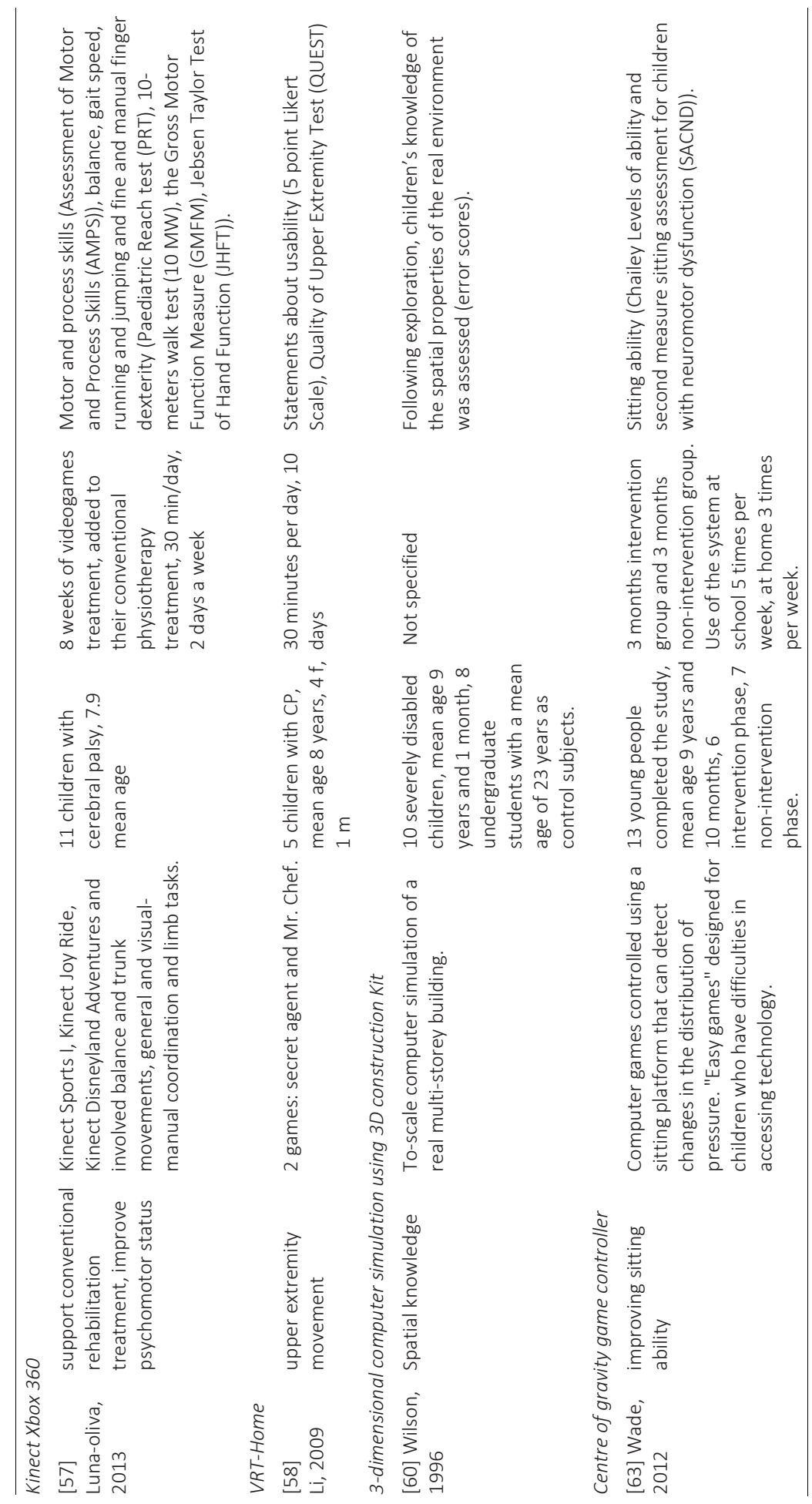




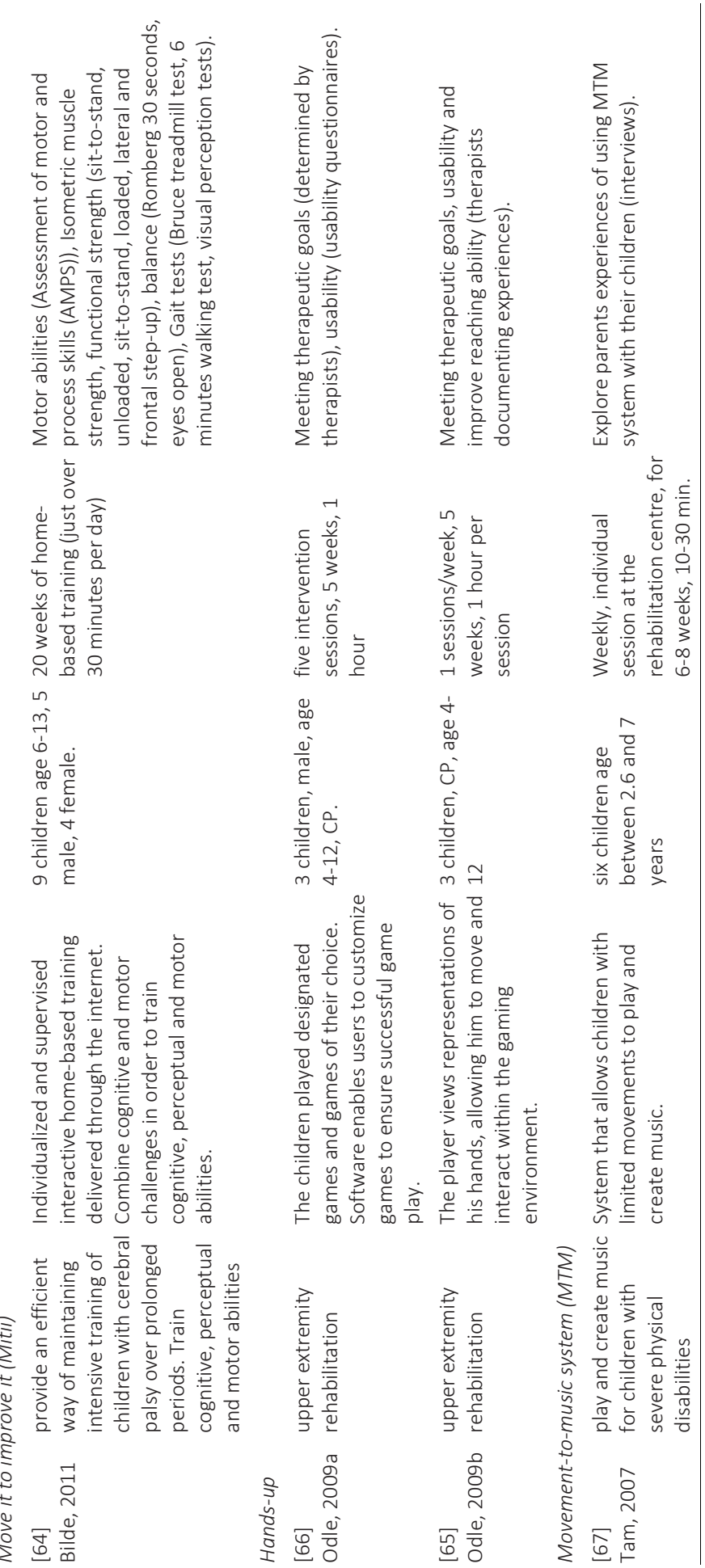




\section{Robots}

In total, 19 out of 61 articles described the use of robots related to play in children with severe physical disabilities. Eight different robots are described in this section and in Tables 1, 2 and Table 3.

\section{Aims of the robots}

Two of the play robots (Cosmobot and Lego Roverbot) in this review aim at supporting the mental functions of children. The Cosmobot $[18,19]$ was developed specifically for the stimulation of motivation, and Lego Roverbot [5,20-22] for the stimulation of mental functions in general. Furthermore, Cosmobot aimed to elicit spontaneous movements, for example by imitation games. Five of the eight robots (IROMEC, PlayROB, AIBO and Lego Mindstorms: Roverbot/Robotic Arm) aimed to stimulate major life areas, which was specified four times as engagement in play or solitary play [1,7,23-30] and one time (Lego robots controlled via speech generating devices) to stimulate school education [31,32]. Next to engagement in play, the aim of the IROMEC robot [7,2428,30] and the AIBO [30] was also to stimulate general interpersonal interactions, a concept considered to be closely related to play. For the four aforementioned robots, the aim of play for play's sake was specifically described in the publications $[1,7,23-30]$.

\section{Characteristics of the robots}

Many different control options were described, e.g. detection of movement and voice input. Some robots have several control options or use a combination of different options. Most robots can be controlled by switches. For the PlayROB robot $[1,29]$, the control options can be adapted to the preferences of the child, for example switches used by hand or as head switches. Three robots, Cosmobot $[18,19]$, IROMEC [7,2428,30] and AIBO [30] are able to detect movement and to react to these movements, for example by changing position or by producing sounds. The Lego robots can be controlled via speech generating devices [31,32] and the Cosmobot $[18,19]$ uses voice as input to perform specific actions. The IROMEC robot $[7,24-28,30]$ also has the possibility of being remotely controlled, e.g. by a therapist. An important characteristic of the robot category is that these technologies are able to move in a room, while the other two groups (virtual reality and computer systems) are stationary systems, without a "movement component" of the technology itself.

\section{Virtual reality systems}

A large degree of variation was found in virtual reality (VR) systems. In this review, 15 different technologies in 37 studies related to play in children with severe physical disabilities were found. A distinction could be made between screen based technologies, which offer only visual feedback, and technologies which offer additional force/touch feedback - for example, a vibrating motor attached to a glove $[33,34]$. 
Aim of the virtual reality systems

Both the screen based virtual reality systems and the virtual reality systems which provide force/touch feedback mostly aim to increase mental functions and to improve movement or mobility related functions. Mental functions include, for example, motivation, orientation to space and self-confidence. Movement related aims are, for example, gait pattern functions, mobility and stability of joint functions, and control of voluntary movement functions. Aims in the domain of mobility comprise, for example, reaching, hand and arm use, and carrying, moving and handling objects. Interventions using the Nintendo Wii [35-42] often mentioned balance as an important aim. In addition, the Mandala ${ }^{\circledR}$ Gesture Xtreme virtual reality system aims to stimulate major life areas, specifically engagement in play [43-46]. For this technology, play for play's sake was mentioned explicitly next to the other play-like activities which aimed at motivation, selfconfidence and mobility of joint functions. This means that only one virtual reality system specified play for play's sake and no virtual reality system seem to exist with the aim of play for play's sake only.

Characteristics of the virtual reality systems

Three of the virtual reality systems (Lokomat Pro system, NJIR-RAVR system, Biodex system $+p c+V R$ ) using force/touch feedback are controlled by a robot as the control opportunity $[47,48]$. These three systems use the rehabilitation robots "haptic master", the "Lokomat gait orthosis" and the "Biodex System 3 dynamometer" as the control opportunity. In addition, they offer force/touch feedback. The other three virtual reality systems (the VR based hand rehabilitation training system, YouGrabber, PITS) use force/touch feedback via sensing gloves, these being the control options of the systems $[33,34,49]$. Most of the screen based virtual reality systems are controlled by the detection of movements (IREX [50-52], EyeToy-Play VR system [49,53-56], Mandala ${ }^{\circledR}$ Gesture Xtreme Virtual Reality system [43-46], Kinect Xbox 360 [57] and VRT-home [58]). Others are controlled using a mouse (IBM-PC computer, Super Scape VRT 3-D construction package [59], 3-dimensional computer simulation using 3D construction kit [60]); a sensing glove (Playstation 3 based hand rehabilitation system [61,62]); a remote control (Nintendo Wii Fit [35-42]), a balance board (Nintendo Wii Fit [35-42]); a dance mat (Nintendo Wii Fit [35-42]); a keyboard (3-dimensional computer simulation using 3D construction kit [60]); or a combination.

\section{Computer systems}

Five out of 61 articles included in this review described computer systems to support play for children with severe physical disabilities. These systems consist of a computer and often additional software. Although this search term was included in the search strategy, no iPad systems were found in this study. 
Aim of the computer systems

One of the computer systems aimed to maintain a sitting position using play-like activities (centre of gravity computer game controller [63]). The other three systems (Mitii [64], Hands-up [65,66], Movement-to-music system [67]) aimed to achieve movement related functions such as arm and hand movements; one of these systems also aimed to support basic cognitive functions and perceptual functions. In this category, there was no computer system which mentioned with the aim of playing for play's sake.

Characteristics of the computer systems

The "centre of gravity computer game" [63] can be controlled by sitting on a platform which reacts to pressure changes due to movement. The "Move it to improve it" (Mitii) [64] and the "Movement-to-music system" [67] both use gesture tracking as the control opportunity for the game, while Mitii uses gesture tracking based on identification of a green band which can be worn on the limbs. The "Hands-up system" $[65,66]$ uses a tracker in the hand as the control opportunity.

\section{Commercial availability of the technologies}

From the group of robots, no robot was found to be commercially available. The group of virtual reality systems consists of nine systems which were found to be commercially available. There is one computer system included in this study which is commercially available. It is important to keep in mind that, for some systems, only parts are commercially available, since in many studies parts were adapted for the target group (e.g. switches) which may not yet be commercially available as an (entire) system.

\section{Discussion}

The purpose of this literature review was to gain insight into the aims, control options and commercial availability of ICT and robots to support play in children with severe physical disabilities. Special attention was given to insight in technologies aiming at play for the sake of play.

The majority of the technologies found in this review have been developed as a means to work on a specific goal or problem. Some technologies were developed for a range of different goals or for play for play's sake. The robots selected in this study are more often related to play for the sake of play, compared with the other technologies, which most of the time use play-like activities aiming at specific goals such as mental aspects, movement related domains or mobility. Making a conscious distinction between using play for the sake of play or play-like activities to support educational or therapeutic goals is an upcoming theme, especially for children with disabilities, since the importance of play is being recognized more and more [12]. This distinction is im- 
portant to keep in mind when developing or improving technologies for this target group.

A wide range of control options for the technologies was identified; however, most of the technologies only seem to have one control opportunity. This may indicate that they are only applicable to a small group of children with physical disabilities. Applicability could be enhanced by combining as many control options as possible to meet the demands of children with different disabilities.

The number of technologies which are commercially available in this study is low, which means that it is not (yet) possible for parents, therapists and special educators to buy these technologies and work with them. In the robot category especially, no systems are commercially available. This might be due to by the early stage of development of these robots and the need for further improvements or further development. Moreover, regarding play, the only commercially available technology explicitly describing play for play's sake is the Mandala ${ }^{\circledR}$ Gesture Xtreme virtual reality system.

When comparing the three groups of technologies, an important difference between robots and the two other categories is that the robots can move in their physical environment, and the others are stationary systems. The mobility of the robots might be an important advantage, because mobility is a common problem for children with severe physical disabilities. Furthermore, many of the identified technologies have comparable characteristics, and further new technologies are constantly being developed. It could be a recommendation for developers to concentrate on the basic functionalities of the technologies which can be used for more goals, with the result that they are more broadly applicable. It would be interesting to use the existing technologies and improve or redesign them to develop new and better technologies which can become commercially available.

The results of this study can be used in paediatric rehabilitation, special education or other settings in which children with physical disabilities are encouraged to play. Awareness on the part of therapists, special educators or parents of the possibilities of these technologies for the children may increase. Technology can provide new ways of offering and monitoring interventions in a controlled manner and can offer children with disabilities new possibilities to play. As therapists especially are used to working with the terminology of ICF-CY, this review can help them easily to relate the technologies to the goals and domains they would like to serve during therapy and to fit them easily to the personalized therapy plans of the children. In addition, this review is meant to increase awareness: without growing awareness of its importance, few studies are conducted in connection with ICT and robots focusing on play for the sake of play. The overview of technologies could also be used for future research and developments in the field of paediatric rehabilitation and special education to support play using innovative technology. When a therapist or teacher wishes to develop a method for therapy and education close to the natural behaviour of the child, play for the sake of play could be a reasonable starting point. 
This review does not give insight into the use of the technologies and their effects. Therefore, it is recommended that more knowledge be gained regarding those factors which may lead to successful use of the technologies. As far as we know, no systematic review on this has been performed.

\section{Study limitations}

Different sources were examined to select the studies presented. It is unlikely that we have missed many relevant studies in this review due to the comprehensive list of key terms in the document search. Furthermore, the scientific database search was complemented by a search with Google Scholar, a hand search of conference proceedings, and reference lists of included articles. In addition, both titles and abstracts are rated by three reviewers. However, relevant articles may have been overlooked due to the inclusion and exclusion criteria, the choice of the key terms or the fair agreement between some of the reviewers. However, the total score of two necessary for inclusion of titles, meaning one reviewer was sure or that two reviewers were in doubt, implies a rather high acceptance rate, which gives more certainty that only a few relevant titles may have been excluded. In the search strategy, the term iPad was included, but no full text article about iPads was included in this review. In practice, it is known that iPads are currently being used in therapy and education, but it might be that there is not yet much research done or published in this field.

Information on commercial availability was extracted from websites of distributors and manufacturers. Information on these websites might not have been up to date, may have been incomplete or could not be found. This may have led to technologies being listed as commercially unavailable when in fact they are available, or vice versa. The translation of the aims of the technologies to the ICF-CY domains has been done by two of the authors, based on the information provided in the articles. Translations have been made as close as possible to the original descriptions. However, for some devices, little detailed information was available in the articles.

\section{Conclusion}

Information and communication technology (ICT) and robots may have great potential in supporting play for children with severe physical disabilities. Due to the lack of commercial availability, it is often not currently possible to use these technologies in daily care and educational practice. A large number of the technologies use play-like activities as a means to achieve other therapeutic or educational goals. Some technologies, especially robots, aim at play for the sake of play. Due to the upcoming importance of play for play's sake, this could be a meaningful focus for the development and improvement of current or new (robot) technologies. Furthermore, developments should aim to combine the different aims and control options found in this review to further improve the accessibility of the technologies for a large group of children with physical 
disabilities, because technology could have an important added value. After studying the effects of the available technologies, it will be worthwhile to invest in making the effective technologies commercially available.

\section{Acknowledgements}

The authors would like to thank our colleague Gert Jan Gelderblom† for his highly appreciated contribution to this work. Furthermore, the authors would like to acknowledge C. Huijnen and L. van der Heide for their contributions to the scoring of the titles and abstracts from scientific databases.

\section{Declaration of interest}

The authors declare no conflicts of interest. 


\section{References}

1. Prazak B, Kronreif G, Hochgatterer A, Fürst M. A toy robot for physically disabled children. Technol Disabil 2004;16:131-6.

2. Convention on the Rights of the Child. United Nation of Human Rights. 1989. Available from: http://www.ohchr.org/en/professionalinterest/pages/crc.aspx [last accessed 12 Jan 2015].

3. Spaargaren MSE. Het meten van spelparticipatie met de Test of Playfulness en Test Of Environmental Supportiveness. Wetenschappelijk Tijdschrift voor Ergotherapie 2011;4:13-21.

4. Besio S. Analysis of critical factors involved in using interactive robots for education and therapy of children with disabilities. Trento: Editrice UNI Service; 2008.

5. Rincon AR, Adams K, Magill-Evans J, Cook A. Changes in playfulness with a robotic intervention in a child with cerebral palsy. In: Encarnação P, ed. Assistive Technology: From Research to Practice, AAATE; 2013 Sept 19-22; Vilamoura. Amsterdam: IOS Press; 2013:161-6.

6. World Health Organization. International Classification of Functioning, Disability, and Health: Children \& Youth Version: ICF-CY. Geneva: WHO; 2007.

7. Besio S, Carnesecchi M, Converti RM. Prompt-fading strategies in robot mediated play sessions. In: Encarnação P, ed. Assistive Technology: From Research to Practice, AAATE; 2013 Sept 19-22; Vilamoura. Amsterdam: IOS Press; 2013:143-8.

8. Besio S. An Italian research project to study the play of children with motor disabilities: the first year of activity. Disabil Rehabil 2002;24:72-9.

9. Poulsen AA, Ziviani JM. Can I play too? Physical activity engagement of children with developmental coordination disorders. Can J Occup Ther 2004;71:100-7.

10. Goodley D, Runswick-Cole K. Emancipating play: dis/abled children, development and deconstruction. Disabil Soci 2010;25:499-512.

11. TD Cost Action TD 1309. European Cooperation in Science and Technology COST; 2015. Available from: http://www.cost.eu/COST_Actions/TDP/Actions/TD1309 [last accessed 22 July 2015].

12. LUDI Network. 2014 Available from: http://ludi-network.eu/ [last accessed 9 Dec 2014].

13. Sandlund M, McDonough S, Hager-Ross C. Interactive computer play in rehabilitation of children with sensorimotor disorders: a systematic review. Dev Med Child Neurol 2009;51:173-9.

14. Definition of Service Robots. International Federation of Robotics; Available from: http://www.ifr.org [last accessed 23 Jun 2015].

15. PubMed MeSH terms. Available from: http://www.ncbi.nlm.nih.gov/mesh/ [last accessed 9 Dec 2014].

16. Besio S. Using assistive technologies to facilitate play by children with motor impairments: a methodological proposal. Technol Disabil 2004;16:119-30.

17. Higgins JP, Green S. Cochrane handbook for systematic reviews of interventions. Wiley Online Library; 2008.

18. Brisben AJ, Lockerd AD, Lathan C. Design evolution of an interactive robot for therapy. Telemed J E Health 2004;10:252-9.

19. Drane J, Safos C, Lathan CE. Therapeutic robotics for children with disabilities: a case study. Stud Health Technol Inform 2009;149:344-56.

20. Cook AM, Adams K, Volden J, et al. Using Lego robots to estimate cognitive ability in children who have severe physical disabilities. Disabil Rehabil Assist Technol 2011;6:338-46.

21. Poletz L, Encarnação P, Adams K, Cook A. Robot skills and cognitive performance of preschool children. Technol Disabil 2010;22:117-26.

22. Rincon AR, Sirard K, Wainer A, Adams K. Lego robots promoting mother-child communication during free play: a pilot study with a child with severe motor impairment. Arlington (VA): RESNA; 2013.

23. Schulmeister J, Wiberg C, Adams K, et al., eds. Robot assisted play for children with disabilities. Arlington (VA): RESNA; 2006. 
24. Iacono I, Lehmann $\mathrm{H}$, Marti $\mathrm{P}$, et al. Robots as social mediators for children with Autism - a preliminary analysis comparing two different robotic platforms. International Conference on Development and Learning (ICDL); 2011 Aug 24-27; Frankfurt am Main. New York: IEEE; 2011:1-6.

25. Marti P, Giusti L. A robot companion for inclusive games: a user-centred design perspective. International Conference on Robotics and Automation (ICRA); 2010 May 3-80; Anchorage. New York: IEEE; 2010:4348-53

26. Marti P, Giusti L, Rullo A. Robots as social mediators: field trials with children with special needs. In: Emiliani PL, ed. Assistive technology for adapted equipment to inclusive environments, AAATE; 2009 Aug 31-Sept 2; Florence. Amsterdam: IOS Press; 2009:165-9.

27. Marti P, lacono I. Learning through play with a robot companion. In: Gelderblom GJ, ed. Everyday Technology for independence and care, AAATE; 2011 Aug 31-Sept 2; Maastricht. Amsterdam: IOS Press; 2011;526-33.

28. Robins B, Dautenhahn K, Ferrari E, et al. Scenarios of robot assisted play for children with cognitive and physical disabilities. Interact Stud 2012;13:189-234.

29. Kronreif G, Prazak B, Mina S, et al. Playrob-robot-assisted playing for children with severe physical disabilities. International Conference on Rehabilitation Robotics (ICORR); 2005 June 28-July 1; Chicago. New York: IEEE; 2005:193-6.

30. Besio S, Potenza MF, Kronreif G. Developing the IROMEC robot for play: results from the first experimental trails. In: Emiliani PL, ed. Assistive technology for adapted equipment to inclusive environments. AAATE; 2009 Aug 31-Sept 2; Florence. Amsterdam: IOS Press; 2009:159-64.

31. Adams K, Encarnação P. A training protocol for controlling Lego robots via speech generating devices. In: Gelderblom GJ, ed. Everyday Technology for independence and care, AAATE; 2011 Aug 31-Sept 2; Maastricht. Amsterdam: IOS Press; 2011:517-25.

32. Adams K, Yantha J, Cook A. Lego robot control via a speech generating communication device for play and educational activities. Arlington (VA): RESNA; 2008.

33. Van Hedel HJA, Wick K, Meyer-Heim A, Eng K. Improving dexterity in children with cerebral palsy. International Conference on Virtual Rehabilitation (ICVR); 2011 June 27-29; Zurich. New York: IEEE; 2011:1-2.

34. Wille D, Eng K, Holper L, et al. Virtual reality-based paediatric interactive therapy system (PITS) for improvement of arm and hand function in children with motor impairment - a pilot study. Dev Neurorehabil 2009;12:44-52.

35. Ballaz L, Robert M, Lemay M, Prince F. Active video games and children with cerebral palsy: the future of rehabilitation? International Conference on Virtual Rehabilitation (ICVR); 2011 June 27-29; Zurich. New York: IEEE; 2011:1-2.

36. Gordon C, Roopchand-Martin S, Gregg A. Potential of the Nintendo Wii as a rehabilitation tool for children with cerebral palsy in a developing country: a pilot study. Physiotherapy 2012;98:238-42.

37. Howcroft J, Klejman S, Fehlings D, et al. Active video game play in children with cerebral palsy: potential for physical activity promotion and rehabilitation therapies. Arch Phys Med Rehabil 2012;93:1448-56.

38. Jelsma J, Pronk M, Ferguson G, Jelsma-Smit D. The effect of the Nintendo Wii Fit on balance control and gross motor function of children with spastic hemiplegic cerebral palsy. Dev Neurorehabil 2013;16:2737.

39. Ramstrand N, Lygnegard F. Can balance in children with cerebral palsy improve through use of an activity promoting computer game? Technol Health Care 2012;20:501-10.

40. Robert M, Ballaz L, Hart R, Lemay M. Exercise intensity levels in children with cerebral palsy while playing with an active video game console. Phys Ther 2013;93:1084-91.

41. Winkels DG, Kottink Al, Temmink RA, et al. Wii-habilitation of upper extremity function in children with cerebral palsy. An explorative study. Dev Neurorehabil 2013;16:44-51.

42. Sharan D, Ajeesh PS, Rameshkumar R, et al. Virtual reality based therapy for post operative rehabilitation of children with cerebral palsy. Work 2012;41 Suppl 1:3612-15.

43. Harris KR, Reid D. The influence of virtual reality play on children's motivation. Can J Occup Ther 2005;72:21-9. 
44. Reid D. The influence of virtual reality on playfulness in children with cerebral palsy: a pilot study. Occup Ther Int 2004;11:131-44.

45. Reid DT. Benefits of a virtual play rehabilitation environment for children with cerebral palsy on perceptions of self-efficacy: a pilot study. Pediatr Rehabil 2002;5:141-8.

46. Reid DT. The use of virtual reality to improve upperextremity efficiency skills in children with cerebral palsy: a pilot study. Technol Disabil 2002;14:53-61.

47. Koenig A, Brutsch K, Zimmerli L, et al. Virtual environments increase participation of children with cerebral palsy in robot-aided treadmill training. International Conference on Virtual Rehabilitation (ICVR); 2009 June 29-July 2; Haifa. New York: IEEE; 2009:121-6.

48. Koenig A, Wellner $M$, Koneke $S$, et al. Virtual gait training for children with cerebral palsy using the Lokomat gait orthosis. Stud Health Technol Inform 2008;132:204-9.

49. Chen YP, Kang $\sqcup$, Chuang TY, et al. Use of virtual reality to improve upper-extremity control in children with cerebral palsy: a single-subject design. Phys Ther 2007;87:1441-57.

50. Bryanton C, Bosse J, Brien M, et al. Feasibility, motivation, and selective motor control: virtual reality compared to conventional home exercise in children with cerebral palsy. Cyberpsychol Behav 2006;9:123-8.

51. Guberek R, Schneiberg S, McKinley $P$, et al. Virtual reality as adjunctive therapy for upper limb rehabilitation in cerebral palsy. International Conference on Virtual Rehabilitation (ICVR); 2009 June 29-July 2; Haifa. New York: IEEE; 2009:219-19.

52. Kirshner S, Weiss PL, Tirosh E. Meal-maker: a virtual meal preparation environment for children with cerebral palsy. Eur J Special Needs Educ 2011;26:323-36.

53. Jannink MJ, Van der Wilde GJ, Navis DW, et al. A low-cost video game applied for training of upper extremity function in children with cerebral palsy: a pilot study. Cyberpsychol Behav 2008;11:27-32.

54. Sandlund M, Domellof E, Grip H, et al. Training of goal directed arm movements with motion interactive video games in children with cerebral palsy - A kinematic evaluation. Dev Neurorehabil 2014;17:318-26.

55. Sandlund M, Grip H, Hager C, et al. Low-cost motion interactive video games in home training for children with cerebral palsy: a kinematic evaluation. International Conference on Virtual Rehabilitation (ICVR); 2011 June 27-29; Zurich. New York: IEEE; 2011:1-2.

56. Sandlund $M$, Lindh Waterworth $E$, Häger C. Using motion interactive games to promote physical activity and enhance motor performance in children with cerebral palsy. Dev Neurorehabil 2011;14:15-21.

57. Luna-Oliva L, Ortiz-Gutiérrez RM, Cano-de la Cuerda R, et al. Kinect Xbox 360 as a therapeutic modality for children with cerebral palsy in a school environment: a preliminary study. NeuroRehabilitation 2013;33:513-21.

58. Li W, Lam-Damji S, Chau T, Fehlings D. The development of a home-based virtual reality therapy system to promote upper extremity movement for children with hemiplegic cerebral palsy. Technol Disabil 2009;21:107-13.

59. Akhutina T, Foreman N, Krichevets A, et al. Improving spatial functioning in children with cerebral palsy using computerized and traditional game tasks. Disabil Rehabil 2003;25:1361-71.

60. Wilson PN, Foreman N, Tlauka M. Transfer of spatial information from a virtual to a real environment in physically disabled children. Disabil Rehabil 1996;18:633-7.

61. Burdea GC, Jain A, Rabin B, et al. Long-term hand tele-rehabilitation on the playstation 3: benefits and challenges. Engineering in Medicine and Biology Society (EMBC); 2011 Aug 30-Sept 3. New York: IEEE; 2011:1835-8.

62. Huber M, Rabin B, Docan C, et al. PlayStation 3-based telerehabilitation for children with hemiplegia. Virtual Rehabilitation; 2008 Aug 25-27; Vancouver. New York: IEEE; 2008:105-12.

63. Wade W, Porter D. Sitting playfully: does the use of a centre of gravity computer game controller influence the sitting ability of young people with cerebral palsy? Disabil Rehabil Assist Technol 2012;7:122-9.

64. Bilde PE, Kliim-Due M, Rasmussen B, et al. Individualized, home-based interactive training of cerebral palsy children delivered through the Internet. BMC Neurol 2011;11:32.

65. Odle BM, Irving A, Foulds R. Usability of an adaptable video game platform for children with cerebral palsy. IEEE 35th Annual North East Conference on Bioengineering, Boston, MA; 2009; 1-2. 
66. Odle BM, Irving A, Foulds R. Evaluating interventions with an adaptive video game platform for children with cerebral palsy. Arlington (VA): RESNA; 2009.

67. Tam C, Schwellnus H, Eaton C, et al. Movement-to-music computer technology: a developmental play experience for children with severe physical disabilities. Occup Ther Int 2007;14:99-112.

68. Adams K, Rincon AMR, Encarnacao P, et al. Learning switch scanning skills by playing with robots. In: Encarnação P, ed. Assistive Technology: From Research to Practice, AAATE; 2013 Sept 19-22; Vilamoura. Amsterdam: IOS Press; AAATE; 2013:360-5.

69. Fluet GG, Qiu Q, Kelly D, et al. Interfacing a haptic robotic system with complex virtual environments to treat impaired upper extremity motor function in children with cerebral palsy. Dev Neurorehabil 2010;13:335-45.

70. Fluet GG, Qinyin Q, Saleh S, et al. Robot-assisted virtual rehabilitation (NJIT-RAVR) system for children with upper extremity hemiplegia. International Conference on Virtual Rehabilitation (ICVR); 2009 June 29-July 2; Haifa. New York: IEEE; 2009:189-92.

71. Qiu Q, Fluet GG, Saleh S, et al., eds. Robot-assisted virtual rehabilitation (NJIT-RAVR) system for children with cerebral palsy. IEEE 36th Annual Northeast Conference on Bioengineering, New York; 2010:1-2.

72. Qiu Q, Ramirez DA, Saleh S, Adamovich S. NJIT-RAVR system for upper extremity rehabilitation in children with hemiplegia. IEEE 35th Annual Northeast Conference on Bioengineering, Boston, MA; 2009:12 .

73. Qiu Q, Ramirez DA, Saleh S, et al. The New Jersey Institute of Technology Robot-Assisted Virtual Rehabilitation (NJITRAVR) system for children with cerebral palsy: a feasibility study. J Neuroeng Rehabil 2009;6:40.

74. Qiu $Q$, Ramirez DA, Saleh $S$, et al. Design of NJIT-robot assisted virtual rehabilitation system to train the hemiplegic upper extremity of children with cerebral palsy. Arlington (VA): RESNA; 2009.

75. Cikajlo I, Matjacic Z. Virtual reality tasks to enhance the therapeutic options of the single-joint rehabilitation robot. IEEE International Conference on Rehabilitation Robotics, Kyoto International Conference Center; 2009: 966-71. 


\section{Appendix}

\section{Appendix A1}

Search strategy PubMed (in the other databases the search strategies were comparable)

\begin{tabular}{|c|c|c|c|c|c|}
\hline Step & Search term & Hits & Step & Search term & Hits \\
\hline \multicolumn{3}{|c|}{ Patient } & \multicolumn{3}{|c|}{ Intervention } \\
\hline 1 & Child.tw. & 1709436 & 29 & Robotics .sh. & 12614 \\
\hline 2 & Children.tw. & 1880513 & 30 & Robot*.tw. & 14988 \\
\hline 3 & Child.sh. & 1501782 & 31 & Artificial intelligence.sh. & 50383 \\
\hline 4 & "Preschool Child".tw. & 729012 & 32 & "artificial intelligence".tw. & 19383 \\
\hline 5 & Preschool Child.sh. & 728884 & 33 & Assistive technology.sh. & 8131 \\
\hline 6 & 1 or 2 or 3 or 4 or 5 & 1880513 & 34 & "assistive technology".tw. & 895 \\
\hline 7 & “Physical disability”.tw. & 2710 & 35 & "robot-assisted therapy".tw. & 56 \\
\hline 8 & "Motor impairment".tw. & 3043 & 36 & User computer interface.sh. & 26492 \\
\hline 9 & "Motor skills disorders".tw. & 1958 & 37 & "user computer interface".tw & 26514 \\
\hline 10 & Motor skills disorders.sh. & 1952 & 38 & Therapy, computer assisted.sh. & 33765 \\
\hline 11 & Brain Injury, Chronic.sh. & 549 & 39 & "computer assisted therapy".tw. & 4875 \\
\hline 12 & "Chronic Brain Injury".tw. & 589 & 40 & Computer.sh. & 68181 \\
\hline 13 & Spinal Dysraphism.sh. & 7120 & 41 & Computer.tw & 550648 \\
\hline 14 & “Spinal Dysraphism”.tw. & 5583 & 42 & Computer systems.sh. & 132968 \\
\hline 15 & Cerebral Palsy.sh. & 15142 & 43 & "computer systems".tw. & 11640 \\
\hline 16 & “Cerebral Palsy".tw. & 19357 & 44 & Video games.sh. & 1915 \\
\hline 17 & Muscular Diseases.sh. & 128671 & 45 & "video games".tw. & 2311 \\
\hline 18 & “Muscular Diseases".tw. & 20125 & 46 & "computer-based devices".tw. & 7 \\
\hline 19 & Arthritis, Juvenile Rheumatoid.sh. & 8132 & 47 & iPad.tw. & 351 \\
\hline 20 & $\begin{array}{l}\text { "Juvenile Rheumatoid } \\
\text { Arthritis".tw. }\end{array}$ & 3004 & 48 & "portable multimedia device".tw. & 2 \\
\hline 21 & $\begin{array}{l}7 \text { or } 8 \text { or } 9 \text { or } 10 \text { or } 11 \text { or } 12 \text { or } 13 \\
\text { or } 14 \text { or } 15 \text { or } 16 \text { or } 17 \text { or } 18 \text { or } 19 \\
\text { or } 20\end{array}$ & 169209 & 49 & "serious gaming".tw & 18 \\
\hline 22 & 6 and 21 & 45463 & 50 & "serious games".tw. & 52 \\
\hline 23 & “Disabled children".tw. & 5467 & 51 & "mobile devices" & 453 \\
\hline 24 & Disabled children.sh. & 3952 & 52 & $\begin{array}{l}29 \text { or } 30 \text { or } 31 \text { or } 32 \text { or } 33 \text { or } 34 \\
\text { or } 35 \text { or } 35 \text { or } 36 \text { or } 37 \text { or } 38 \text { or } \\
39 \text { or } 40 \text { or } 41 \text { or } 42 \text { or } 43 \text { or } 44 \\
\text { or } 45 \text { or } 46 \text { or } 47 \text { or } 48 \text { or } 49 \text { or } \\
50 \text { or } 51\end{array}$ & 614796 \\
\hline 25 & "Institutionalized child".tw. & 1633 & \multicolumn{3}{|c|}{ Patient and intervention } \\
\hline 26 & Child, institutionalized.sh. & 1654 & 53 & 28 and 52 & 1307 \\
\hline 27 & 23 or 24 or 25 or 26 & 7108 & & & \\
\hline 28 & 22 or 27 & 51811 & & & \\
\hline
\end{tabular}




\section{Appendix A2}

Example images of included play technologies

Robots

1

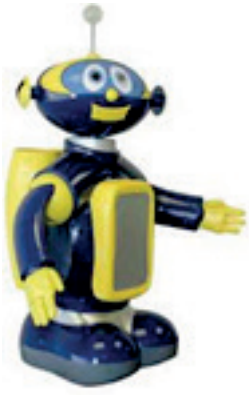

Virtual reality systems (force/touch feedback)

11

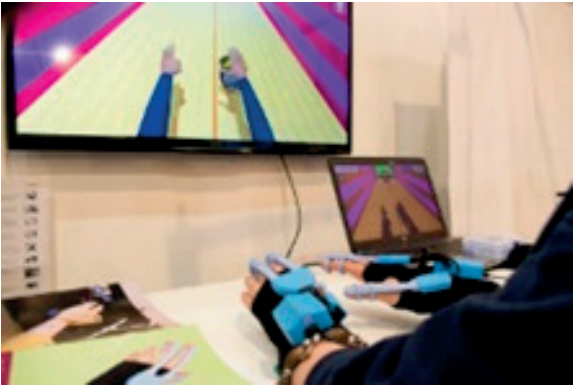

Virtual reality systems (screen based)

19

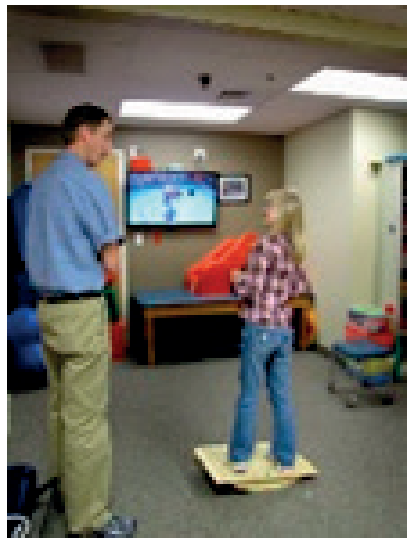

3

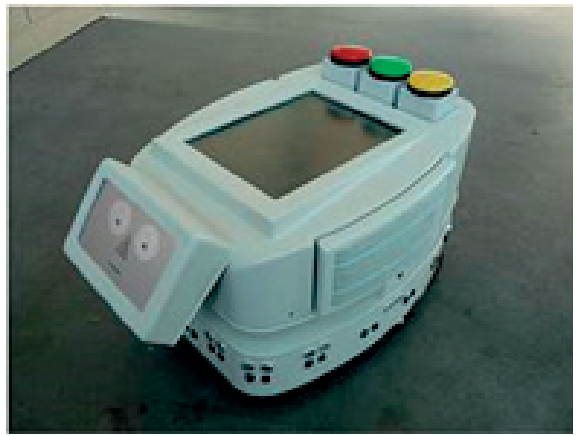

13

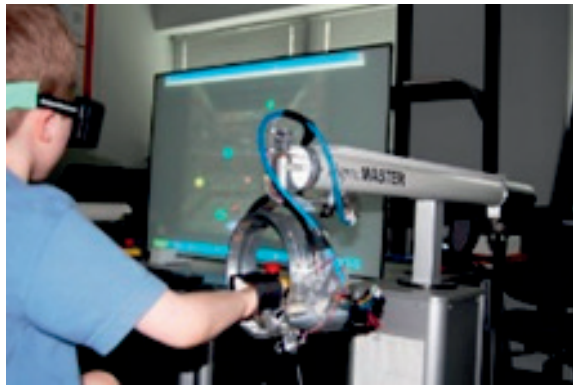

Computer systems

27

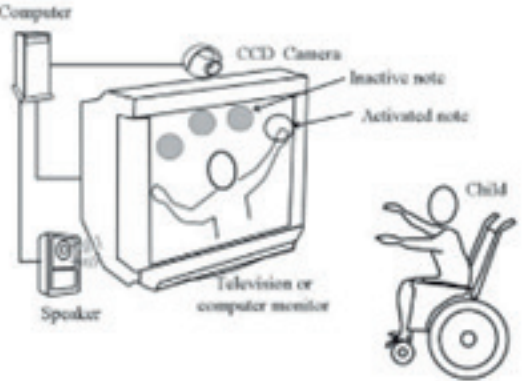




\section{Chapter 3}

\section{Robots supporting play for children with physical disabilities: exploring the potential of IROMEC.}

This chapter was published as: van den Heuvel RJF, Lexis MAS, Jansens RML, Marti P, de Witte LP. (2017) Robots supporting play for children with physical disabilities: exploring the potential of IROMEC. Technology and Disability. 29 (3): 109-120. doi: 10.3233/TAD-160166 


\section{Abstract}

Background: Play is essential for children's development. Children with severe physical disabilities often experience problems engaging in play. In rehabilitation and special education for children with physical disabilities play-like activities and play for play's sake are important.

Objective: The current study aimed at examining the possibilities of using the IROMEC robot in rehabilitation and special education for children with severe physical disabilities.

Methods: A mixed methods approach, using individual interviews, two rounds of focus group interviews, a questionnaire and a final session to reach consensus, was used to examine the match between the goals in therapy and special education and the IROMEC robot.

Results: The existing play scenarios of IROMEC have the potential to support play for children with severe physical disabilities, especially in the domains of movement functions, learning and applying knowledge, communication/interpersonal interactions and relationships, and play.

Conclusions: The current study helped to build a body of evidence to the possibilities of the IROMEC robot. The results of this study can be used to further develop meaningful robotic play interventions for children with severe physical disabilities.

Keywords: Robot, play, children, physical disabilities, special education, rehabilitation 


\section{Introduction}

Play is very important for children's development. Play can be defined as a structured or unstructured activity described in terms of how children use objects, pretend, socialize and interact with other people [1]. Children can develop sensory, motor, social, communicative and cognitive skills through play. Through play they explore their social environment and build up relationships [2].

Currently, more attention has been directed at the importance of play, especially for children with disabilities. A multidisciplinary network with 32 countries and almost 100 participants called 'LUDI - Play for children with disabilities' aims to study the topic of play for children with disabilities and to spread awareness about the importance of providing children with disabilities opportunities to play (Action financed by COST European Cooperation in Science and Technology Action number TD1309) [3]. LUDI adopted the definition of play as proposed by Garvey (1990): Play is a range of voluntary, intrinsically motivated activities normally associated with recreational pleasure and enjoyment $[4,5]$.

Children with severe physical disabilities, as a consequence of, for example, cerebral palsy or acquired brain injury, commonly experience problems when engaging in play due to their physical limitations which are often accompanied by cognitive disabilities. These children experience significantly reduced participation in leisure activities and in physical play activities specifically. They are at life-long risk of health and social difficulties [6]. Most commercially available toys are not designed keeping in mind the requirements of these children, and therefore are difficult for them to manipulate. As a result, play activities may be partially or entirely impossible [7]. Play can be used to achieve therapeutical or educational goals, e.g. in rehabilitation and special education, but play can also be play for play's sake. There are already a number of examples of play devices, such as robots and ICT systems supporting play in children with severe physical disabilities. Some systems use play-like activities as a means to achieve external therapy and educational goals; others aim at play for play's sake. Examples of such systems include the Lokomat Pro System which aims to support motivation and gait pattern function, and the Interactive Rehabilitation and Exercise Systems (IREX) to support control of voluntary movement functions and carrying, moving and handling objects. The IROMEC robot has been developed to support play and attainment of goals related to general personal interactions which are closely related to play [8-11]. Since this robot has been showing to be a promising tool in supporting play, we decided to explore its possibilities for children with severe physical disability more thoroughly. Within the LUDI network, a database was created in which several potential robots and other tools and technologies to support play in children with disabilities are described [12]. When exploring the database, it is evident that there are not many toys on the market tailored to disabled children. Considering the characteristics of the described tools and technol- 
ogies, IROMEC seems a promising robot to support play, and therapy and educational goals among children with severe disabilities.

IROMEC is a robot developed during the IROMEC (Interactive Social RObotic Mediators as Companions) FP6 European project between 2006-2009 (Figure 1). This European project investigated how a robotic toy can become a social mediator for children who are prevented from playing, due to cognitive, developmental or physical impairments [13]. Compared to other robots in this field, IROMEC has a unique combination of interaction possibilities using actuators, sensors, a touch screen and buttons to control the robot, which makes it suitable to the specific needs of this target group. One important outcome of this project was a set of ten play scenarios developed for children with severe motor impairments, children with mild mental problems and children with autism spectrum disorder. The play scenarios describe the use of the robot in a particular context. Five of these scenarios were actually implemented in the robot: turn taking, sensory reward, make it move, follow-me and get in contact [13]. In the next section of this paper and in figures $2-4$ these scenarios are described in more detail.

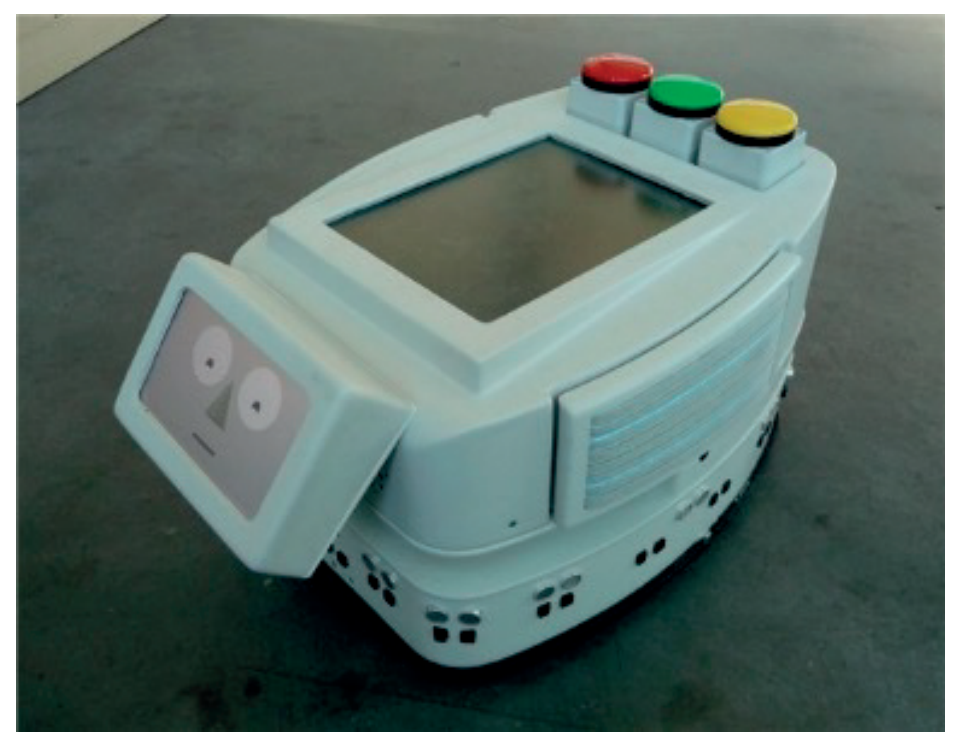

Figure 1 The IROMEC Robot

In the current study, the possibilities for application of IROMEC were studied for children with severe physical disabilities, since previous pilot studies have indicated that the robot may be a promising tool especially for this target group [14-16]. Interventions with the robot showed, for example, a positive impact on the level of playfulness [14]. A study with children with different levels of impairments showed encouraging results in terms of learning and enjoyment for children. Most of the improvements in this study have been observed in the motor development area [16]. The number of participants in 
these studies was relatively low, therefore it is worthwhile to further specify the application possibilities of the robot and to study the effects of the robot in larger groups of participants. However, besides positive results, several studies also reported shortcomings, mainly including the design of the robot. Besio et al. [15] demonstrated little added value for children with cerebral palsy, given the limited match between the children's needs in play and the robot itself as a toy. The main aim of the study presented in this paper was to study more thoroughly IROMEC's possibilities for children with severe physical disabilities. The research question was:

Is the IROMEC robot suitable for application in rehabilitation and special education for children with severe physical disabilities? The results of this study are being used for a future pilot study with the robot.

\section{IROMEC robot}

Before the demonstration the different technical components of the robot were introduced:

- Sensors

- Camera

- Touchscreen

- Screen (face)

- Wheels

- Moving lights

- Wireless buttons

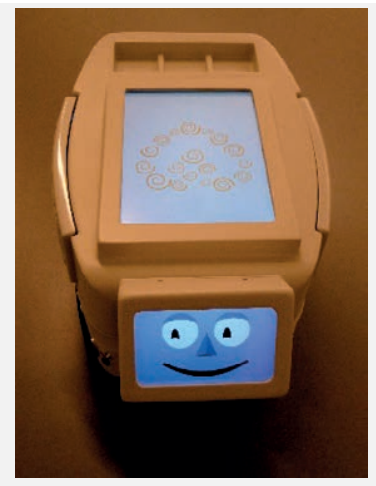

\section{Scenarios:}

- Turn taking: Collaborative turn taking activity. Robot has start/stop activation mechanism that can be controlled by the user. First player turns the robot to face the second player and presses on the touch screen causing the robot to move to the second player. Robot stops at a predefined distance from the second player. The second players turns the robot around, presses on the touchscreen and sends it back.

- Turn taking for sensory reward: Two buttons (one for each player) to activate a corresponding sensory output display.

- Make it move: Pressing a green button to move the robot forward, a red button to turn right and an yellow button to turn left.

- Follow me: Robot starts to move searching for a child, when it finds a child it follows him/her within a predefined distance. If the child stops, the robot stops too. When the child and the following robot reach the second player, and the robot is closer to the second player, it starts to follow the second player.

- Get in contact: Therapist can select the robot's behaviour: Tactile mode (robot does not move, child may touch and explore the robots surface), fear (robot moves back with a scared face), communicative mode (robot tries to approach the child with a happy face).

Figure 2 Description of IROMEC and scenarios 

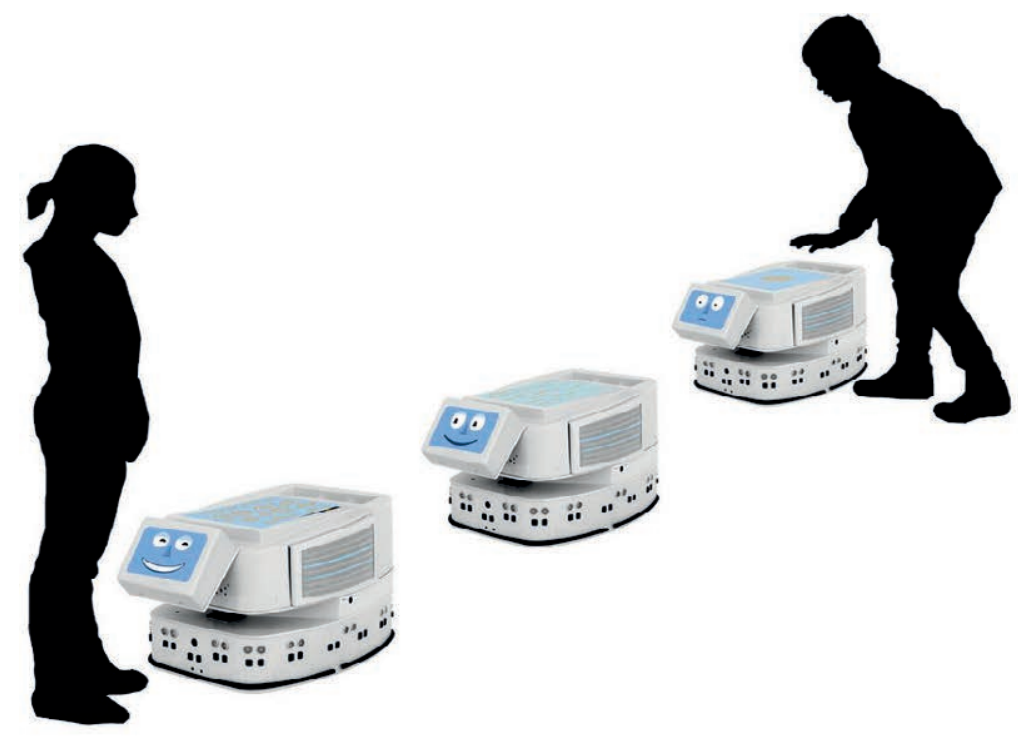

Figure 3 Turn taking
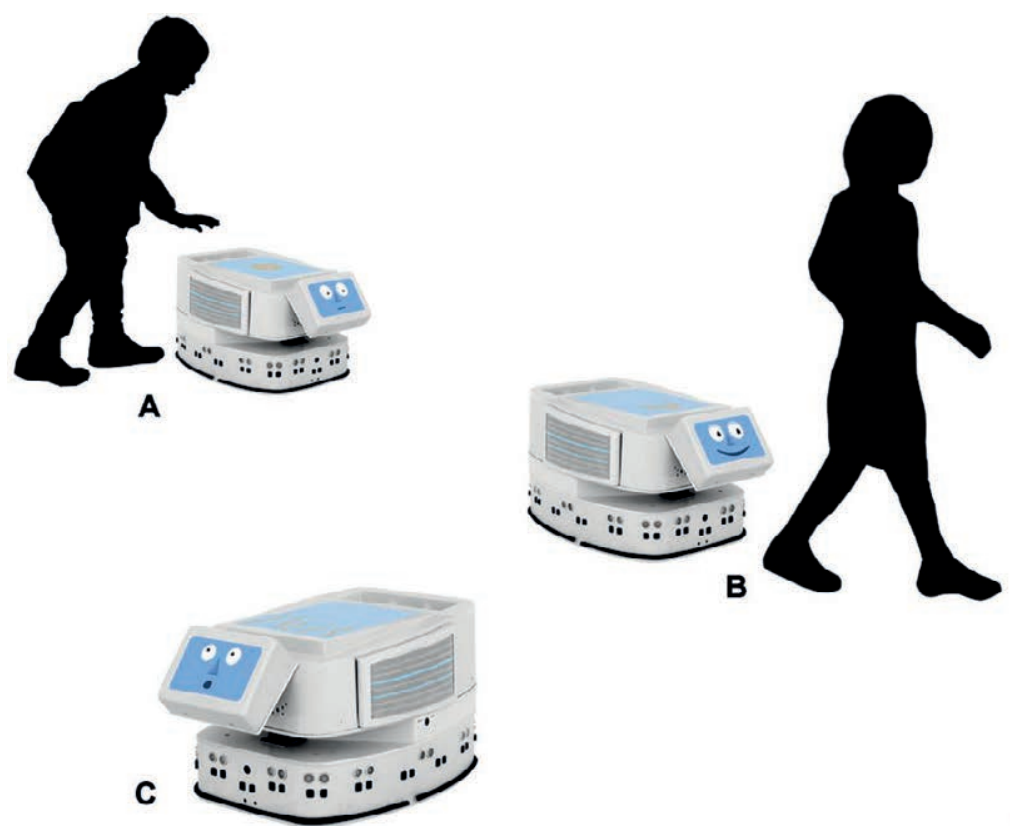

Figure 4 Follow me 


\section{The robotic platform}

IROMEC is a mobile robotic platform developed to become a social mediator encouraging children with distinct levels of disabilities to discover a different range of play styles. It is addressed to children with autism spectrum disorder, children with severe motor impairments and children with cognitive disabilities. IROMEC was developed by Robosoft (www.robosoft.fr) to have controls related to movement, localization and navigation and is equipped with 13 ultrasound and 18 infrared sensors and a laser scanner to allow obstacle detection, navigation in space and reaction to external stimuli. Movement and speed are controlled through a motor/gearbox/encoder ensemble that makes movement safe and suitable for the interaction with children. The platform, which weights around $10 \mathrm{kgs}$, contains a video camera for colour tracking. The application module, developed by Profactor (www.profactor.at), manages the user interaction through a set of digital components and interfaces. It can be plugged on or unplugged from the mobile platform through hooks that safely and invisibly fasten the two modules. The interaction module measures $35 \times 55 \times 17 \mathrm{~cm}$ and weights around $8 \mathrm{kgs}$. The module is composed of two parts: the body and the head. The body displays graphical interface elements related to different play scenarios on a 13 inch digital touch screen. The body screen, for example, can represent the features of an imaginary cartoon-like character displaying a digital fur which moves according to the direction of the platform's movement. When the robot stops, fur clumps appear that extend when it moves again. The head is constituted of an 8 inch digital screen that displays the robot's facial expressions. Three wireless buttons connected via Bluetooth can be used by the children to control the robot and to play different games. The robotic platform can be configured to engage in a number of play scenarios as described in figure 2. Marti (2010) described the scenarios in more detail, with supplementary images, which give a good insight into the course of the scenarios [17]. Figures 3 and 4 give a visual representation of two scenarios.

\section{Methods}

\section{Design}

A mixed method design using mainly qualitative assessments and an additional quantitative assessment was conducted. Individual interviews, focus group interviews (two rounds), a digital questionnaire and a final session to reach consensus were conducted, involving experts in the field of rehabilitation and education for children with physical disabilities. Together with the experts, relevant goals in the therapy and education for children with severe physical disabilities were explored and the possibilities for IROMEC interventions to support these goals were identified. The research activities and the accompanying aims of each of the activities are displayed in figure 5. 


\section{Step 1: Interviews + Focus group interviews 1 (27 professionals involved)}

Aim:

To create an overview of goals in therapy and education important for children with severe physical disabilities.

\section{Step 2: Questionnaire (10 professionals involved)}

Aim:

Member check to check the goals

To match goals with possibilities of overview. the IROMEC robot.

\section{Step 3: Focus group interviews 2 ( 25 professionals involved)}
Aim:
To discuss how the possibilities of To discuss the possibilities of the the IROMEC robot could match IROMEC robot and new ideas for with the goals (demonstration). improvements/interventions.

\section{Step 4: Final session (5 professionals involved)}

Aim:

To discuss the results and determination of the most important requirements before first application of the IROMEC robot in practice.

Figure 5 Research activities and aims

\section{Study context, participants and selection procedures}

The study was conducted in two Dutch rehabilitation centres and one primary school for special education. In the Netherlands, children with severe physical disabilities mostly attend these two kinds of institutions for therapy and education. Professionals participating in this research had no or very little experience with technology or robots in their work. One of the professionals worked with the IROMEC robot once before and some of them use technology like computers or Ipads in their therapy or education.

In step 1, which included individual interviews and the first round of focus groups, the participants for the individual interviews were approached via a Dutch network for therapists and special educators who are 'pioneers' in the field of rehabilitation for 
children with Cerebral Palsy. The invitation for participation was disseminated via their online portal and e-mail. The first round of focus group interviews was organised with therapists and special educators from the participating organisations.

In step 2, the participants of step 1 were invited to complete the digital questionnaire which included a member check for the goals overview and was used to match the goals with the possibilities of the IROMEC robot.

In step 3, the second round of focus group interviews with experts was organised to match the goals with the possibilities of IROMEC with a larger audience.

In step 4, a final session to reach consensus was organised. The participating centres were represented by two people who already participated in the focus group sessions.

\section{Data collection}

\section{Interviews}

The professionals who agreed to participate were scheduled for an approximately onehour interview with a trained interviewer (author RH). The interviews included questions on what the most important goals for children with severe physical disabilities are and if and how the participants use the International Classification of Functioning, Disability and Health for Children and Youth (ICF-CY) [18] to determine goals and activities during therapy. Furthermore, questions were asked about the usage and importance of play to achieve these goals, and if they think the IROMEC robot could be suitable to contribute to these goals.

\section{First round of focus group interviews}

The focus group interviews were carried out by author $\mathrm{RH}$, assisted by a colleague with background in occupational therapy to take notes and to ask additional questions when needed. The goals and activities in therapy and education, the importance of play and opportunities for application of robots in their professional work setting were discussed. To create an overview of goals in therapy and education, the metaplan methodology was used [19]. All participants were asked to write down all important goals for children with severe physical disabilities on separate memos without discussing with the others. Afterwards, these memos were categorised and discussed with the participants.

\section{Questionnaire}

A digital questionnaire was distributed among the participants who took part in the interviews and first focus group by e-mail. To increase participation, two reminders were sent. The questionnaire was used as a member check for the overview of goals created with the data from the individual interviews and from the first focus group [20]. Professionals were asked if the ICF-CY categorisation was correct and if the overview was complete according to them. Furthermore, after watching an IROMEC demo video, 
participants were asked to identify which goals IROMEC could address. In the demo video, the different scenarios and functionalities of the robot were displayed.

\section{Second round of focus group interviews}

The second round of focus group interviews was organised to discuss how the robot and its current scenarios could be matched with the overview of goals identified in the first round of focus groups. During these sessions first the researcher gave a demonstration of the IROMEC robot (see Figure 2). Participants were asked about spontaneous reactions regarding the application of the robot in their daily work. In addition to professionals, parents were invited via a Dutch client organisation for people with physical disabilities. These focus groups discussed the suitability of IROMEC for different kinds of disabilities, ages of the children and settings. Thereafter, a discussion was initiated regarding the possibilities for application of the robot to meet the goals used in therapy and education.

\section{Final session to reach consensus}

After the interviews, the first focus group interviews, the digital questionnaire and the second focus group interviews, a final session was organised together with five therapists and special educators who had also participated in the sessions described before. The aim of this final session was to reach consensus on initial practical application of the IROMEC robot: for which children and in which sessions they would apply IROMEC in the first instance and what requirements must be met before the robot can actually be applied in daily care practice.

\section{Data analysis}

The individual interviews and focus groups were audio recorded and transcribed verbatim. For the interview data and first focus group interviews a summary was written, and an overview of goals was created based on the transcripts and memos from the metaplan methodology. This summary and goals overview were created by two researchers together to increase the credibility of the results. The questionnaire was used as a member check, in which the participants of the interviews and first round of focus groups got the opportunity to react on the goal overview and to make additions if needed [20].

For the second focus group interviews the researchers used the qualitative research software Nvivo 10 [21] to identify and code relevant fragments after carefully reading the transcripts. Based on the principles of conventional content analysis and directed content analysis a coding tree was created. The overview from the first focus group interviews (ICF-CY based) was used (directed content analysis) and additional codes derived from the data (conventional content analysis) [22]. Firstly, relevant fragments 
were labelled and open coding took place. Secondly, axial coding took place and the fragments with the same codes were compared.

Different methods of data triangulation were used. Data were collected from different levels of participants (person triangulation). Furthermore, two researchers analysed and interpreted the data set to reduce the possibility of biased interpretation of the data (investigator triangulation) and multiple methods of data collection were used to gather similar and additional information (method triangulation) [20].

The answers on the digital questionnaire were exported to Microsoft Excel and descriptive statistics were used to describe these outcomes. The number of respondents choosing the relevant goals for application of the IROMEC robot comprised the quantitative data for this study.

From the final session, a summary of the results was written and checked by two researchers who were also present during this session, to make sure this was the complete overview of the session.

\section{Results}

\section{Data characteristics}

In step 1, a total of 9 persons were interviewed, 2 males and 7 females. A combination of therapists and special educators working with children with physical disabilities participated, for example occupational therapists, a rehabilitation doctor, a child psychologist and a speech therapist. The working experience varied from 2 to 25 years. The first focus group interviews consisted of three sessions with a total of 17 individual participants. In all groups, therapists as well as special educators with a wide working experience (ranging from 2 to 37 years) with children with severe physical disabilities and different levels of cognitive abilities participated.

In step 2, the digital questionnaire was distributed to this entire group of 26 participants from the interviews and first round of focus group interviews. In total 10 participants completed the questionnaire anonymously.

In step 3 (second focus group interviews), six sessions included 25 participants in total, with a mix of special educators, therapists and one parent. Working experience ranged from 3 months to 32 years.

In the final session (step 4), five people participated, including the therapists and special educators who participated in the earlier sessions. Table 1 displays an overview of the participants of steps 1 to 4 with their working experience and gender. 
Table 1 Overview of participants

\begin{tabular}{|c|c|c|c|c|}
\hline & Number & Mal & $\begin{array}{l}\text { e Average working } \\
\text { experience [years] }\end{array}$ & $\begin{array}{l}\text { Standard deviation } \\
\text { [years] }\end{array}$ \\
\hline \multicolumn{5}{|l|}{ Therapists } \\
\hline Occupational therpists & 8 & $1 / 7$ & 12.88 & 5.84 \\
\hline Physiotherapists & 3 & $1 / 2$ & 25.67 & 6.03 \\
\hline Speech therapists & 3 & $0 / 3$ & 20.00 & 8.66 \\
\hline Group leaders early treatment & 3 & $0 / 3$ & 24.00 & 12.12 \\
\hline Other & 5 & $1 / 4$ & 8.45 & 7.83 \\
\hline \multicolumn{5}{|l|}{ Educational participants } \\
\hline Teacher special education & 8 & $1 / 7$ & 16.75 & 10.93 \\
\hline Teacher assistant & 4 & $0 / 4$ & 23.75 & 11.76 \\
\hline Other & 2 & $2 / 0$ & 9.00 & 12.73 \\
\hline
\end{tabular}

Table 2 Overview of goals and possibilities for application of IROMEC

\begin{tabular}{|c|c|c|c|}
\hline ICF-CY Domains & $\begin{array}{l}\text { Goals and IROMEC } \\
\text { possibilities in bold }\end{array}$ & $n$ & Examples \\
\hline \multirow{6}{*}{$\begin{array}{l}\text { Mental functions } \\
\text { (B1) }\end{array}$} & Build up trust & 4 & \\
\hline & Experiencing own body & & \\
\hline & To build a relationship and to & 5 & The robot can be used as a kind of friend. \\
\hline & feel safe & & $\begin{array}{l}\text { Some children have problems with direct contact, the robot } \\
\text { may be a mediator in making contact with the child. }\end{array}$ \\
\hline & Imagination in someone else & 0 & \\
\hline & Social intercourse & 2 & \\
\hline \multirow{4}{*}{$\begin{array}{l}\text { Sensory functions } \\
\text { and pain (B2) }\end{array}$} & Sensory processing & 3 & \\
\hline & To watch & 9 & $\begin{array}{l}\text { To find the robot in the classroom/therapy room. } \\
\text { To watch the games when other children are playing with } \\
\text { the robot. }\end{array}$ \\
\hline & Balance & 0 & \\
\hline & Senso-motor skills & 4 & \\
\hline \multirow{4}{*}{$\begin{array}{l}\text { Movement } \\
\text { functions (B750- } \\
\text { b749) }\end{array}$} & Fine motor skills & 6 & To stimulate the use of buttons. \\
\hline & Gross motor skills & 7 & To walk behind the robot. \\
\hline & Eye-hand coordination & 8 & To stimulate the use of buttons. \\
\hline & Motor skills & 6 & $\begin{array}{l}\text { To stimulate the use of buttons and walking against the } \\
\text { robot. }\end{array}$ \\
\hline $\begin{array}{l}\text { Leaning and } \\
\text { applying }\end{array}$ & Spatial awareness & 8 & $\begin{array}{l}\text { The child may explore the space around him/her by using the } \\
\text { robot. }\end{array}$ \\
\hline \multirow[t]{8}{*}{ knowledge (D1) } & Learning & 5 & $\begin{array}{l}\text { To learn to understand the size of the room and to estimate } \\
\text { distances. } \\
\text { To learn how to manipulate the robot. } \\
\text { To send the robot to the right place. }\end{array}$ \\
\hline & Imitation & 7 & To imitate robot's movements. \\
\hline & $\begin{array}{l}\text { Planned and structured } \\
\text { working }\end{array}$ & 3 & \\
\hline & Concentration & 9 & To concentrate on finishing a game. \\
\hline & Problem solved learning & 3 & \\
\hline & Work attitude & 3 & \\
\hline & Making jokes and pretending & 3 & \\
\hline & Listening & 5 & To let the robot hide and to let it make sounds. \\
\hline
\end{tabular}




\begin{tabular}{|c|c|c|c|}
\hline ICF-CY Domains & $\begin{array}{l}\text { Goals and IROMEC } \\
\text { possibilities in bold }\end{array}$ & $\mathrm{n}$ & Examples \\
\hline \multirow{10}{*}{$\begin{array}{l}\text { Communication } \\
\text { (D3) / } \\
\text { Interpersonal } \\
\text { interactions and } \\
\text { relationships (D7) }\end{array}$} & \multicolumn{2}{|l|}{$\begin{array}{l}\text { Language comprehension and } 4 \\
\text { expression }\end{array}$} & \\
\hline & Reading & 2 & \\
\hline & Numeracy skills & 2 & \\
\hline & Turn taking & 5 & To stimulate turn taking and to teach turn taking behaviour. \\
\hline & Cooperation & 5 & To play games together. \\
\hline & Interaction & 8 & $\begin{array}{l}\text { To get in contact with the 'follow me' game. } \\
\text { To get in contact with each other via the robot, getting } \\
\text { attention via the robot. }\end{array}$ \\
\hline & Using voice & 3 & \\
\hline & Taking initiative & 6 & $\begin{array}{l}\text { To stimulate the child to take initiative otherwise nothing } \\
\text { happens (e.g., follow me, pressing buttons). } \\
\text { The robot can e.g. challenge the child to follow, to take } \\
\text { initiative. }\end{array}$ \\
\hline & Get in contact & 6 & $\begin{array}{l}\text { To get in contact with the 'follow me' game. } \\
\text { To get in contact with each other via the robot, getting } \\
\text { attention via the robot. }\end{array}$ \\
\hline & Language & 3 & \\
\hline \multirow[t]{5}{*}{ Mobility (D4) } & Being able to move & 5 & To stimulate/motivate a child to move. \\
\hline & Climbing stairs & 0 & \\
\hline & Maintaining posture & 1 & \\
\hline & $\begin{array}{l}\text { Independent wheelchair } \\
\text { driving }\end{array}$ & 4 & \\
\hline & Being able to make transfers & 0 & \\
\hline \multirow[t]{5}{*}{ Self-care (D5) } & Dressing and undressing & 0 & \\
\hline & Eating and drinking & 0 & \\
\hline & Self help & 2 & \\
\hline & Independence & 3 & \\
\hline & Control skills & 6 & To use the buttons to control the robot. \\
\hline \multirow{7}{*}{$\begin{array}{l}\text { Engagement in } \\
\text { play (D880) }\end{array}$} & Playing independently & 5 & To stimulate play by using the robot. \\
\hline & Playing together & 5 & $\begin{array}{l}\text { To stimulate playing together, which may be more } \\
\text { interesting with use of the robot. }\end{array}$ \\
\hline & Fantasy play & 2 & \\
\hline & Understanding of simple rules & 56 & $\begin{array}{l}\text { Play should be the basis for application of the robot; if } \\
\text { children } \\
\text { like it, other goals may be achieved as well. }\end{array}$ \\
\hline & Having play fun & 8 & $\begin{array}{l}\text { To motivate play. Play can be fun and predefined goals are } \\
\text { not always necessary. } \\
\text { In therapy, play is an important motivator. }\end{array}$ \\
\hline & Role play & 2 & \\
\hline & Competition & 3 & \\
\hline \multirow{3}{*}{$\begin{array}{l}\text { Education (d810- } \\
\text { d839) }\end{array}$} & Toddler skills & 3 & \\
\hline & Pre-school skills & 4 & \\
\hline & School skills & 2 & \\
\hline
\end{tabular}




\section{Goals and application possibilities}

The most important goals in therapy and special education identified in the interviews and first round of focus group interviews are displayed in the first two columns of table 2. Domains of the International Classification of Functioning for Children and Youth (ICF$\mathrm{CY}$ ) were used to categorise the goals [18]. The participating professionals suggested to use the ICF-CY as a categorization tool because they are used to work with this framework when establishing goals. Categorisation was done by 2 researchers and all the participants of the questionnaire agreed with this categorisation.

Since some subdomains of the ICF-CY came up as very relevant for this target group during the sessions, these domains were used as the main domains in this overview (Movement functions, engagement in play and education). The subcategories in the goal overview were not translated literally to ICF terminology; since the professionals should be able to recognise their own answers, their goal formulations were used. Professionals in the interviews and first round of focus groups indicated that using play with this target group is very important, for achieving all goals it is essential to use play activities because it makes it attractive to the children. All professionals are using playlike activities, but some of the professionals were also convinced of the importance of play for play's sake. In column two of Table 2, the goals presented in bold were identified in the questionnaire as the most promising goals (at least $50 \%$ of the participants thought this was a promising goal) for application of IROMEC. These goals were discussed in the second round of focus group interviews as well. Column 3 describes the number ( $n$ ) of participants who chose these goals as being 'promising'. Examples of how IROMEC could contribute to these most promising goals are displayed in the last column of Table 2. According to the professionals, e.g. eye-hand coordination could be stimulated by application of IROMEC with the alternative use of the three buttons which are part of the platform to perform tasks. This is part of the so-called 'make it move' scenario. Skills with regard to spatial awareness could be supported when the child controls the robot in order to explore the space around, also belonging to the 'make it move' scenario. Playing games together could be performed using for example the 'turn taking' game or the 'follow me' game.

\section{Improvement of IROMEC scenarios}

Besides the overview of goals and the possibilities for application of IROMEC, many suggestions for improvement of the robot and for new applications of the robot were reported. These suggestions were mainly general suggestions to improve the robot and the scenarios, and were not specifically linked to one of the existing scenarios. The most important suggestions can roughly be divided into three categories: suggestions concerning aspects related to the robot, concerning the context of the intervention and concerning the role of the professional. They are displayed in table 3. 
Table 3 Suggestions for improvement of IROMEC scenarios

\begin{tabular}{|c|c|c|}
\hline Aspects related to the robot & Aspects related to the context & $\begin{array}{l}\text { Aspects related to the behaviour of } \\
\text { the professional }\end{array}$ \\
\hline $\begin{array}{l}\text { - Appearance } \\
\text { - Control of the robot } \\
\text { - New game ideas }\end{array}$ & $\begin{array}{l}\text { - Inside/outside use } \\
\text { - Group/individual sessions } \\
\text { - Therapy/educational setting }\end{array}$ & $\begin{array}{l}\text { - Concrete instructions to the child } \\
\text { - Introduction and preparation of } \\
\text { the child } \\
\text { - First session to let the child dis- } \\
\text { cover the robot }\end{array}$ \\
\hline
\end{tabular}

Q1 You should definitely use the four basic colours in your design, those are the first colours to be recognised by our children'.

Q2 'The robot can behave the same, but if you change the coat of the robot it can be the witch today, tomorrow the dog and the day after the car'.

Q3 'I can imagine that you can train motor skills with for example button control, perhaps something with a joystick'.

Q4 'When you have to bend to turn the robot that is of course not very easy and comfortable. If there was a sort of handle it would be easier to turn'.

Q5'I can imagine that something with reading will also be interesting. Using play to do something with letters. If you are not able to move yourself, but you can control the robot for example to combine letters into words or to combine digits, like a trail'.

Q6 'It is interesting for a child to follow the robot instead of one of us. Can the robot also go outside? Because I think that is important'.

Q7'I was just thinking, when you have a group of children in a circle and you put the robot in the middle, the children can press the button and the robot moves towards the child. Then the child can send the robot to another child. I can imagine group games like that'.

Q8 'For every child there is another goal, so then you would use the robot individually'.

Q9'I definitely think that we should prepare the children. That is very important. A new friend will come, let's sing a song for him. His name is... etc. Maybe showing a picture before'.

Figure 6 Illustrating quotes from the second round of focus groups

Suggestions regarding aspects related to the robot can be subdivided into appearance of the robot, control of the robot and new game ideas for the robot. Illustrating quotes related to these suggestions are displayed in figure 6 and referred to in the text as e.g. Q1. The robot could be more attractive by using more colours (Q1), a more natural appearance and a 'dressing box' with several coats for the robot (e.g., a dog, a car) (Q2). Control of the robot could be elaborated with, for example, a joystick or speech recog- 
nition (Q3) and turning the robot should be easier (e.g. a grip attached to the robot) (Q4). Furthermore, the participants suggested numerous ideas for new games with the robot, e.g.; games with letters and numbers, robot being a memory aid and the robot providing instructions about daily life routines (dressing, eating etc.) (Q5).

A suggestion related to the context of the robot included that the robot should be able to be used inside as well as outside (Q6). Additionally, they mentioned that the robot should be suitable to be used in individual sessions as well as in group sessions $(Q 7, Q 8)$. Furthermore, the robot should be able to support educational sessions in the classroom with groups of children as well as group or individual therapy sessions.

The professionals indicated that they should be able to instruct the child with concrete tasks. Introduction and preparation of the child to the robot seemed important to them before starting to work with the robot (e.g., a picture of the robot in the classroom and explanation of its functioning) (Q9). Finally, the first session with the robot is important to get acquainted with the robot and to make the child feel comfortable (e.g., in this session goal setting should be of minor importance and it is important to let the child discover the robot).

In the final group session, the most important outcomes of the previous activities were discussed and a list comprising topics which are most relevant and urgent to change before starting to use the robot within a pilot study was created. The main conclusions of this session were that the existing play scenarios of the robot seem suitable for children with severe physical disabilities and worthwhile. The current scenarios of the robot were indicated to be most interesting for children between 2 and approximately 5 years old or older children with cognitive impairments. The 'turn taking for sensory reward' scenario was indicated as the least interesting, since the robot is not moving in this scenario and the robot does not seem to have an added value, compared to other possibilities in rehabilitation, e.g. using a computer. One of the most desired changes was related to the appearance of the robot. The initial design was kept very simple and neutral basically to address also the needs of children with autism spectrum disorder who were one of the three target groups of the European project IROMEC, as specified in section 2 above. The study presented in this paper shows the importance of adapting the robot features to the specific needs of the target audience. A robot design for children with autism spectrum disorder is unlikely to be accepted by children with physical disabilities who prefer a more attractive appearance and expression capabilities to get engaged in playing with the robot. Other relevant required changes were related to extending the opportunities to control the robot. For example the platform was required to be more flexible and adaptable to the preferences of the child in terms of speed change, and sound volume control. Furthermore, the emotions the robot displays should preferably be changed into the four basic emotions (happiness, sadness, fear and anger) which are the first emotions learned by children. An important remark mentioned by all the participants was that the best ideas for application will probably arise when testing the robot in 
real-life sessions with children. Currently, they can only speculate about possible applications; children's responses to the robot may be unpredictable.

\section{Discussion and conclusion}

This study contributes to more insight into application possibilities for robots, especially IROMEC, for children with physical disabilities in rehabilitation and special education. The professionals participating in our study were very familiar with children with severe physical disabilities. Professionals indicated that the most promising meaningful applications of IROMEC were related to the following ICF-CY domains: movement functions, learning and applying knowledge, communication/interpersonal interactions and relationships, and engagement in play. Thus, the professionals did see possibilities for meaningful application of IROMEC. Based on the demonstration, the functionalities and the scenarios of the robot were indicated to be the most promising for these goals. In the future, based on practical experiences of using the robot, other goals may appear interesting as well. The current functionalities and characteristics of the robot were evaluated as useful in supporting play for play's sake and play like activities in therapy as well as in a special education setting. Professionals came up with several ideas as described in the results section.

The goals overview corresponded with the domains of the ICF-CY [18] which is the common framework and language used in the field of therapy and special education. When having a closer look at the goals for application of IROMEC and the goals of other robots for children with severe physical disabilities, as reported in the literature, there are some more robots which concentrate on play or play related goals. The COSMOBOT for example is one of the few robots described in the literature as supporting movement functions, or the LEGO Mindstorms Tribot which aims at learning and applying knowledge [11]. This indicates that IROMEC may offer a meaningful addition to this field in terms of useful tools to support reaching therapy or educational goals for this target population. There are more platforms available on the market, however in the literature review described before, only robot platforms and ICT systems that have been evaluated scientifically were included [11]. As described in the results the professionals also came up with ideas how to improve the platform or the scenarios to make application of the robot as meaningful as possible. Aspects related to the robot, related to the professional and related to the environment were described. Cook et al. [23] describe similar aspects in their paper in which they highlight design considerations for robots for children with disabilities. Appearance of the robot came up as very important as well, because it should be attractive for the children and personalized based on the preferences of a child. Furthermore, easy access to the interface was highlighted by Cook et al., which is comparable with the several control options which were suggested by our participants. 
This study leads to requirements for designers which will help them to create toys and robots for this target group. Furthermore, the study may create general awareness in professionals working with children with severe physical disabilities, and makes them aware of the kind of expectations they may have.

A strength of this study is the broad spectrum of professionals in therapy and education involved in the different steps, which contributes to the generalisability for a population of professionals working with children with severe physical disabilities. Furthermore, the actual experience with the robot during the demonstration session enabled them to have a good idea about the possibilities of using the robot. In this study only professionals and a parent were involved, since in this phase of the study these individuals are the most important to decide what the children need. In a next phase, children were involved to actually test the robot. This explorative pilot study with IROMEC was positively evaluated by professionals as well as the children and meaningful application possibilities were observed. Lacking adaptability, extensibility and technical stability of the IROMEC robot unfortunately make daily application and a large effect study with this specific robot impossible [24]. While application of robots is promising a meaningful for this target group future research should provide more insight into the actual application and feasibility of robots in rehabilitation and special education for children with severe physical disabilities.

\section{Acknowledgments}

This work was supported by a grant of the RAAK PRO programme of SIA ("Stichting Innovatie Alliantie") for the project "Social robots in care" (project number PRO-4-10). This is a program from the Dutch ministry of education, culture and science to stimulate collaboration between public and private organisations. The authors would like to thank our colleague Gert Jan Gelderblom † for his highly appreciated contribution to this work. Furthermore, our acknowledgements go to the professionals who participated in this research and came up with numerous meaningful feedback and ideas.

\section{Conflict of interest}

None to report. 


\section{References}

1. Spitzer S. Play in children with autism: Structure and experience. Play in Occupational Therapy for Children (2nd ed) St Louis, MO: Mosby Elsevier. 2008: 351-74.

2. Besio S. Analysis of critical factors involved in using interactive robots for education and therapy of children with disabilities: Editrice UNI Service. 2008.

3. Besio S, Bulgarelli D, Stancheva-Popkostadinova V. Play Development in children with disabilities. LUDI publication in press. 2016.

4. Bulgarelli D, Bianquin N. Conceptual review of play. In: Besio S, Stancheva-Popkostadinova V. Play Development in Children with Disabilities. LUDI publication in press. 2016.

5. Garvey C. Play. Cambridge: MA: Harvard University Press. 1990.

6. Kolehmainen N, Francis JJ, Ramsay CR, Owen C, McKee L, Ketelaar M, et al. Participation in physical play and leisure: developing a theory-and evidence-based intervention for children with motor impairments. BMC pediatrics. 2011; 11(1): 100.

7. Besio S. An Italian research project to study the play of children with motor disabilities: the first year of activity. Disability \& Rehabilitation. 2002; 24(1-3): 72-9.

8. Bryanton C, Bosse J, Brien M, Mclean J, McCormick A, Sveistrup H. Feasibility, motivation, and selective motor control: virtual reality compared to conventional home exercise in children with cerebral palsy. Cyberpsychology \& behavior. 2006; 9(2): 123-8.

9. Klein T, Gelderblom GJ, De Witte L, Vanstipelen S, et al. Evaluation of short term effects of the IROMEC robotic toy for children with developmental disabilities. International Conference on Rehabilitation Robotics (ICORR). 2011: IEEE.

10. Koenig A, Wellner M, Köneke S, Meyer-Heim A, Lünenburger L, Riener R. Virtual gait training for children with cerebral palsy using the Lokomat gait orthosis. Studies in health technology and informatics. 2007; 132: 204-9.

11. van den Heuvel RJ, Lexis MA, Gelderblom GJ, Jansens RM, de Witte LP. Robots and ICT to support play in children with severe physical disabilities: a systematic review. Disability and Rehabilitation: Assistive Technology. 2015; 1-14.

12. LUDI. Database of assistive technologies to support play for children with disabilities. 2016 [cited 2016 29 September]. from http//ludi.utad.pt/.

13. Robins B, Dautenhahn K, Ferrari E, Kronreif G, Prazak-Aram B, Marti P, et al. Scenarios of robot-assisted play for children with cognitive and physical disabilities. Interaction Studies. 2012; 13(2): 189-234.

14. Bernd T, Gelderblom GJ, Vanstipelen S, De Witte L. Short term effect evaluation of IROMEC involved therapy for children with intellectual disabilities. Social Robotics: Springer. 2010; 259-64.

15. Besio S, Carnesecchi M, Converti RM. Prompt-fading Strategies in Robot Mediated Play Sessions. Proceedings of Assistive Technology: From Research to Practice, AAATE 2013: IOS Press Amsterdam. 2013; 143-8.

16. Marti P. Bringing playfulness to disabilities. Proceedings of the 6th Nordic Conference on HumanComputer Interaction: Extending Boundaries; 2010: ACM.

17. Marti P, lacono I. Learning through play with a robot companion. Proc 11th European Conference for the Advancement of Assistive Technology, AAATE. 2011.

18. World Health Organization. International Classification of Functioning, Disability, and Health: Children \& Youth Version: ICF-CY: World Health Organization. 2007.

19. Schnelle E. The Metaplan-Method: Communication Tools for Planning and Learning Groups. Hamburg: Quickborn. 1979.

20. Polit D, Beck C. Nursing research: Generating and assessing evidence for nursing practice Ninth. Philadelphia, Pennsylvania Wolters Kluwer Health, Lippincott Williams \& Wilkins. 2012.

21. Richards T, Richards L. NVIVO 10 [software]. Australia, QSR International Pty. 2008.

22. Hsieh H-F, Shannon SE. Three approaches to qualitative content analysis. Qualitative Health Research. 2005; 15(9): 1277-88. 
Chapter 3

23. Cook A, Encarnação P, Adams K. Robots: Assistive technologies for play, learning and cognitive development. Technology and Disability. 2010; 22(3): 127-45.

24. van den Heuvel RJ, Lexis MA, de Witte LP. Can the IROMEC robot support play in children with severe physical disabilities? A pilot study. International Journal of Rehabilitation Research. 2017. 


\section{Chapter 4 \\ Can the IROMEC robot support play in children with severe physical disabilities? \\ A pilot study}

This chapter was published as:

van den Heuvel RJF, Lexis MAS, de Witte LP. (2017) Can the IROMEC robot support play in children with severe physical disabilities? A pilot study. International Journal of

Rehabilitation Research. 40(1): 53-9. doi: 10.1097/MRR.0000000000000200 


\section{Abstract}

The aim of this study was to explore the application of the IROMEC (Interactive social RObotic Mediators as Companions) robot to support play for children with severe physical disabilities in rehabilitation and special education. Within a 2-month pilot study, physically disabled children with a developmental age between 2 and 8 years participated in sessions with the robot. A combination of qualitative and quantitative outcome measures was used to collect data on aspects of feasibility, usability, barriers for the child as well as the therapist and an indication of the effects on playfulness and the achievement of therapeutic and educational goals. A total of 11 children participated in this study (four boys, seven girls). Individually Prioritized Problem Assessment scores indicated a positive effect of the IROMEC robot on the achievement of goals for the children. Professionals did observe meaningful application possibilities, but the lacking adaptability, expandability and technical stability of the robot platform make application in daily care practice impossible. The application of a robot like IROMEC for children with severe physical disabilities seems to be positive and worthwhile, but usability and feasibility aspects are crucial for success.

Keywords: disabled children, play and playthings, rehabilitation, robotics, special education 


\section{Introduction}

Play is essential in the development of every child and related to children's cognitive, social, physical and emotional development [1,2]. The abilities to play for children with severe physical disabilities are limited. For many reasons, children with physical disabilities experience difficulties in starting, developing and performing play activities in a natural way [3]. Accessibility and control opportunities of toys for these children are important.

There are already a number of examples of assistive technology including robots and ICT supporting play in children with severe physical disabilities. The IROMEC robot for example, supports play and therapy and educational goals related to general personal interactions that are closely related to play [4]. To date, several studies with the IROMEC robot have been carried out, with promising effects on for example, playfulness and play skills [3, 5-7]. Further research is needed to investigate the effects of the robot in various settings and to test the robot among larger samples.

As this robot has potential in supporting play, it was decided to investigate its possibilities more in depth. A qualitative study combining focus group interviews, individual interviews and a questionnaire with professionals and parents familiar with children with physical disabilities determined for which goals IROMEC could be applied and what adaptations are necessary before starting a pilot study. The results of the former study clearly indicated that the IROMEC robot and the currently available IROMEC scenarios have potential in supporting play for children with severe physical disabilities in relation to therapy and educational goals, especially for the domains play, movement functions, learning and applying knowledge, communication/interpersonal interactions and relationships. Changing the appearance of the robot was the most important recommendation before starting a pilot study.

Despite more than 20 years of development in the field of rehabilitation robotics, these robots have still not found widespread use in daily life and remain a topic of academic research. More studies are necessary to be able to show effects and possibilities of robots in this field [8]. This pilot study aimed to explore the application of the IROMEC robot-based play intervention within rehabilitation and special education for children with severe physical disabilities with a developmental age between 2 and 8 years. Aspects of feasibility, usability, barriers and facilitators for the child as well as the therapist/special educator and an indication of the effects on playfulness and the achievement of therapeutic and educational goals were determined. 


\section{Methods}

\section{Study design}

A multicentre explorative pilot study was carried out over a 2-month period (October 2015-November 2015) involving children with severe physical disabilities with a developmental age from \pm 2 to 8 years.

\section{Study participants}

The study was carried out in a school for special education (institution 1) and a paediatric rehabilitation centre (institution 2) in the Netherlands. Therapists and special educators working at these centres invited parents for participation of their child. The parents were free to refuse participation. Participation was also discussed with the children themselves if possible. Children were included in the study if they had severe physical disabilities, e.g. as a consequence of cerebral palsy or acquired brain injury. Children were selected if they had a developmental age between \pm 2 and 8 years and a chronological age between 2 and 20 years. Furthermore, the cardio-pulmonary status of the children had to be stable. Children were excluded if they had epilepsy, deafness, blindness or when they showed severe aggressive behaviour. We planned a total sample size of 10-12 children.

\section{Intervention}

The intervention with the IROMEC robot started with a session to introduce the robot to the child or children and to become familiar with the robot. After this first session, five intervention sessions followed. The available scenarios are described in Figure 1. In a session, the professionals could decide to use one or more scenarios. A session lasted $\pm 30 \mathrm{~min}$. Goals besides the main aim of play for play's sake established before the session were for example: the child should be able to control the robot independently within the turn taking game, the child should be able to visually follow the robot within six sessions (concentration) and the child should be able to link the robot with language within six sessions. Four different appearances for the robot were available: a pig, a car, a lion and a chameleon. The professional decided together with the child(ren) the preference for the appearance that had to be used during the session. Group sessions as well as individual sessions were organized. A child participated in six individual sessions or in six group sessions. The professionals were able to decide on the use of the robot in the session on the basis of their own experience and the preferences of the child. The robot could be controlled by the professional with a tablet interface. 


\section{IROMEC Scenarios:}

- Turn taking: Collaborative turn taking activity. Robot has start/stop activation mechanism that can be controlled by the user. First player turns the robot to face the second player and presses on the touch screen causing the robot to move to the second player. Robot stops at a predefined distance from the second player. The second players turns the robot around, presses on the touchscreen and sends it back.

- Turn taking for sensory reward: Two buttons (one for each player) to activate a corresponding sensory output display.

- Make it move: Pressing a green button to move the robot forward, a red button to turn right and an yellow button to turn left.

- Follow me: Robot starts to move searching for a child, when it finds a child it follows him/her within a predefined distance. If the child stops, the robot stops too. When the child and the following robot reach the second player, and the robot is closer to the second player, it starts to follow the second player.

- Get in contact: Therapist can select the robot's behaviour: Tactile mode (robot does not move, child may touch and explore the robots surface), fear (robot moves back with a scared face), communicative mode (robot tries to approach the child with a happy face).

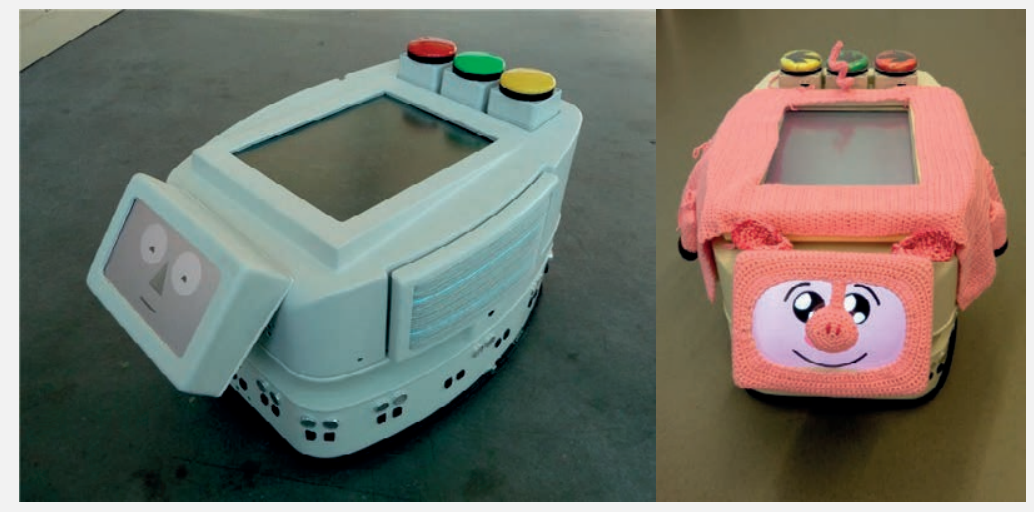

Figure 1 Description of IROMEC scenarios

\section{Study procedure}

After selection of the children, parents of the children received full information and they were allowed at least $48 \mathrm{~h}$ to decide whether they agreed their child to participate in the study and whether they agreed with the sessions to be videotaped. Signed informed consent led to the inclusion of children in the study. The week before the study started, a training session for the professionals was organized in which the different scenarios were demonstrated and a role play between the professionals was done. Two sessions per child per week were organized in a period of 3 weeks. The study was approved by an accredited medical ethics committee (Medisch Ethische Toetsingscommissie Zuyderland NL54310.096.15). 


\section{Measurements and data collection}

A combination of qualitative and quantitative outcome measures was used to collect data on aspects of feasibility, usability, barriers for the child as well as the therapist and an indication of the effects on playfulness and the achievement of goals.

\section{Quantitative outcome measures}

From our focus group and interview study, it appeared that play is an important aim related to interventions with the IROMEC robot. For this reason, the outcome measure of playfulness was chosen.

A 10-point visual analogue scale to assess playfulness from a professional's view was used. They were asked: 'How high was the level of playfulness for the child during the play session in your eyes?'. A score of zero means no playfulness and a score of 10 means as high as possible playfulness [9].

The Individually Prioritized Problem Assessment (IPPA) assesses the effectiveness of assistive technology [10]. Because problems that the children are experiencing are also the goals in therapy and education, IPPA was used to assess to what extent the goals established before the series of IROMEC sessions by the professional were reached. During a baseline interview, the professional was asked to determine goals for each child and to rate the difficulty of each goal on a baseline form. A checklist was used to help the professional to think about possible goals. Related to each goal, the importance for the child was established. After the sixth session, a follow-up interview was conducted in which the follow-up form was filled in.

Children's viewpoint on the play sessions was taken into account. After every session, the children were asked to provide a description of their feelings (like, neutral, dislike) using smileys. The playfulness scale and smileys were used before in a former study with the IROMEC robot [6].

\section{Qualitative outcomes}

Qualitative interviews were performed with the professionals on aspects of feasibility, usability, barriers and facilitators. Example items that were included in the interviews were What do you think about the usability of the robot? What makes it easy or hard to use? Which factors influenced the use of the robot in a positive or negative way? How could the robot be applied best in the future? Furthermore, the professionals were able to reflect on their own impression of the possible effects on play and achieving therapeutic and educational goals of the robot during this interview.

\section{Procedure}

Quantitative data were collected by the first author during and after the IROMEC sessions. All sessions were video recorded with video cameras from two perspectives to be able to review the sessions afterwards. The IPPA forms and playfulness scale were filled 
in by the professionals and the smileys were filled in by the researcher after the children indicated their opinion. The qualitative interviews lasted 30-45 min and were conducted individually.

\section{Data analysis}

Descriptive statistics were used to establish the mean, range and SD of the data of the playfulness scale. The total IPPA score was calculated by using the rated importance of the first interview as a weighting factor and multiplying the importance with the difficulty before, respectively, after the intervention [10]. The difference between before and after the intervention represents the effectiveness or the degree to which the difficulty has decreased. A nonparametric statistical test (Wilcoxon signed-rank test) was used to compare the means at both moments $(\alpha=0.05)$. Descriptive statistics were used to display children's viewpoint on the IROMEC intervention by the number of happy, neutral or sad smileys. Interviews were transcribed verbatim. Relevant information from the interviews was divided into fragments and labelled afterwards according to themes and subthemes from the interview guide (Figure 2).
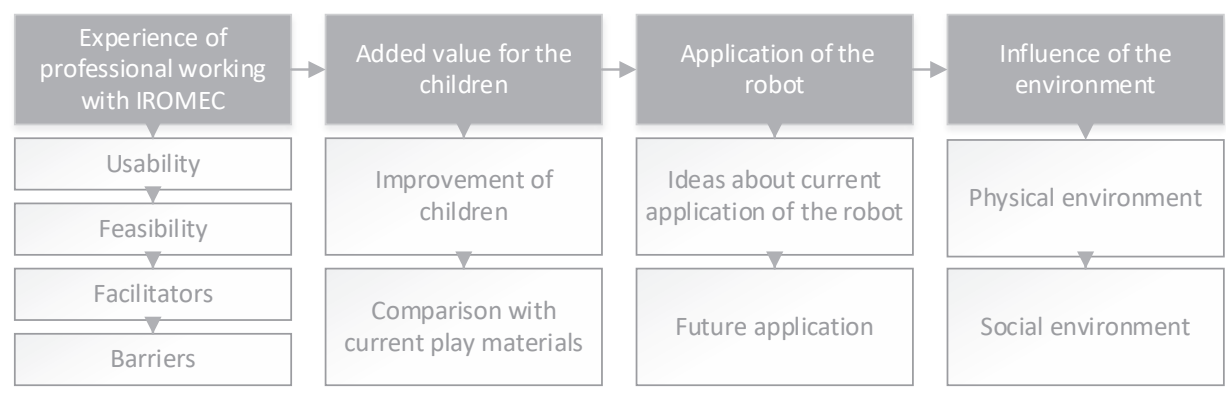

Figure 2 Coding scheme

\section{Results}

A total of 11 children participated in this study (four males, seven females). Because of illness or absence, some participants missed one or more sessions. Table 1 shows the characteristics of the participants. All children were physically disabled as a result of for example spastic diplegia, with a Gross motor function ranging from Gross Motor Function Classification System level II to V (mild to severe physical disabilities) [11]. Most of the children had an encompassing cognitive disability; 18 months to 19 years and the cognitive age of the participating children was between 18 months and 8 years. Children $A, B, K$ and $L$ participated in individual sessions and the other children participated in group sessions. Six professionals participated in the implementation of the IROMEC sessions; of these, four participated in the qualitative interviews: an occupational ther- 
apist, a physical education teacher, a physiotherapist and a group teacher. Their age ranged between 29 and 63 years, with working experience with children with physical disabilities ranging from 2 to 32 years.

Table 1 Description of the participants

\begin{tabular}{|c|c|c|c|c|c|}
\hline Child & Chronological age & Gender & Ability to walk & Assistive device & GMFCS level \\
\hline Child A & 10 year, 6 months & Female & Yes & - & II \\
\hline Child B & 15 year, 10 months & Male & Yes & - & II \\
\hline Child C & 16 year, 2 months & Female & Yes & - & II \\
\hline Child D & 11 year, 5 months & Male & Yes & - & ॥ \\
\hline Child E & 9 year, 11 months & Male & No & Electric wheelchair & V \\
\hline Child F & 19 year & Female & No & Wheelchair & IV \\
\hline Child G & 18 months & Female & No & - & IV \\
\hline Child I & 46 months & Female & No & - & IV \\
\hline Child J & 29 months & Female & No & - & IV \\
\hline Child K & 29 months & Male & Yes & Walker & III \\
\hline Child L & 24 months & Female & No & - & IV \\
\hline
\end{tabular}

\section{Quantitative outcomes}

Examples of goals determined in the IPPA interviews were as follows: the child should be able to control the robot independently within the turn taking game, the child should be able to visually follow the robot within six sessions (concentration) and the child should be able to link the robot with language within six sessions. Figure 3 shows the IPPA scores. The mean score for IPPA before was 12.7, with a minimum of 7 and a maximum of 16.4 (SD 2.7). The mean score for IPPA after was 10.3, with a minimum of 4.3 and a maximum of 16.6 (SD 3.9). A related-samples Wilcoxon signed-rank test in SPSS 22 [12] showed a significant difference $(P=0.028)$ between IPPA before and IPPA after scores $(\alpha=0.05)$.

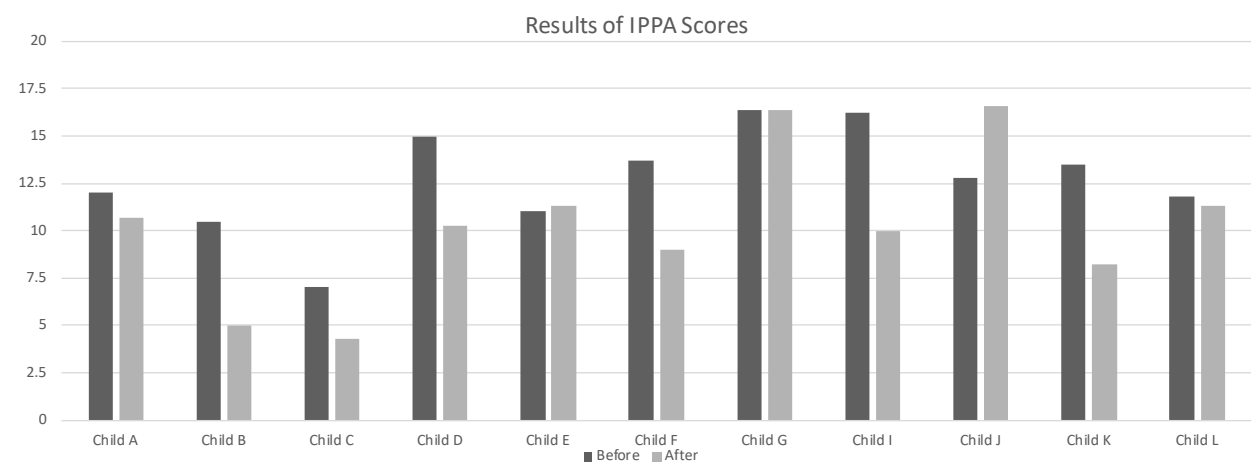

Figure 3 IPPA scores before and after the IROMEC intervention. IPPA, Individually Prioritized Problem Assessment. 
Table 2 shows the results of the playfulness scores. The maximum score of all sessions was 9 and the minimum score was 5 . A slight increase in means from the first session till the last session was observed, indicating a small influence of IROMEC sessions on the level of playfulness observed by the professionals. Children were asked to express their feelings about the sessions by choosing the smiley best representing their emotions. Because of their age, for the children $\mathrm{G}, \mathrm{I}, \mathrm{J}, \mathrm{K}$ and $\mathrm{L}$, it was impossible to assign smileys. In total, 30 sessions were evaluated; six values were missing because the children were not present. Twenty-nine sessions were liked and one session was disliked.

Table 2 Results on the 10-point playfulness scale

\begin{tabular}{lllcll}
\hline & Mean & Std. Deviation & N & Minimum & Maximum \\
\hline Session 1 & 6.9 & 1.46 & 7 & 5 & 9 \\
Session 2 & 6.7 & 0.97 & 10 & 5 & 8 \\
Session 3 & 7.4 & 1.24 & 9 & 5 & 9 \\
Session 4 & 7.2 & 0.89 & 10 & 6 & 8 \\
Session 5 & 7.1 & 0.94 & 10 & 5 & 8 \\
Session 6 & 7.4 & 0.92 & 8 & 6 & 8 \\
\hline
\end{tabular}

\section{Experience of professionals working with IROMEC}

The tablet interface for the professionals was evaluated as easy to use by the professionals who were able to try this during the sessions. Two professionals indicated that it was too complicated to use the tablet combined with focusing on the robot and child. The control of the robot with buttons was of additional value, the touchscreen was easy to use and the robot was considered safe.

The positive aspects mentioned were that IROMEC supported cooperation, control and transportation and that the different appearances were experienced as positive, interesting and funny. Children were unaware of for example, training motor skills because they were distracted from their original exercise. Besides the positive aspects, barriers were mentioned: the size of the robot, which is large and unpractical for small children and children in a wheelchair, and the motor skills that are necessary to turn the robot or to control the buttons. An important improvement to be made was technical stability of the robot. Because of the instability and lack of adaptability (e.g. scenarios and speed) of the robot, interest of the children decreased.

According to the professionals, six sessions were too limited to be able to let the children play independently. The professionals indicated that if they had had more time to try out IROMEC before the actual start of the pilot study they could have prepared and executed the sessions better. Preparation was experienced as stressful. One professional indicated that the trust relationship between the professional and the child diminished because of the interference of the robot. Furthermore, the number of sessions with the IROMEC was too low for some children because they needed more time to become familiar with the robot. 
Some professionals found that it was hard to establish goals because they did not have experience with the robot and they did not know how the children were going to react. Because of the different levels of the children, specific goals worked out better than general goals for the entire group. The course of the IROMEC sessions was e.g. dependent on the mood of the children at that specific moment.

\section{Added value for the children}

According to the professionals, the added value of the robot was most visible for the severely motor impaired children. Besides motor functions, the target group experienced problems with decision making. Deciding on the appearance of the robot and the direction in which the robot is going to move did have an added value for them. Furthermore, the robot facilitated gross motor skills, walking, turning and balance. Besides, the robot stimulated enthusiasm, social interaction, communication and action. As structure in daily activities is very important for the target group, the malfunctioning of the robot was disappointing. It is important for both the child and the professional that the robot functions as expected. Working with IROMEC was a learning experience, especially for severely physically disabled children when using buttons and obstacles. It influenced spatial awareness and children improved action-reaction skills. The professionals do see potential in using robots on a regular basis, but only when it is possible to apply the robots on moments when they think application is beneficial. Goals for which professionals believe that IROMEC is most relevant are communication, spatial awareness, social interaction, movements, gross motor skills, speech and language skills.

To be able to control the robot, children should have certain basic cognitive and motor functions. For some children, the robot did not match their level of functioning. Certain motor abilities are required to control for example, a button or to sit independently. The professionals expect that the robot may no longer be interesting for children with a developmental age above 6 years. When comparing IROMEC with other play materials, professionals indicate that for children with more severe physical disabilities (not able to walk), it was sometimes hard to reach the robot and other play materials are easier to reach or to place on the table or wheelchair.

\section{Application of the robot}

For the professionals, it was difficult to prepare and execute IROMEC play sessions. It was difficult to reach task-oriented goals with the platform. One professional was confident with the course and progress of the sessions and believed that adding more options to the platform would be too much for the children. Application of the robot for play for play's sake appeared to be tough. One of the professionals indicated that it was hard to aim at play without aiming at other goals. Another professional pointed out that he aimed to achieve play for play's sake. Some professionals believed that some children were too young to be able to experience play for play's sake. Some professionals 
stated that play for play's sake is not possible for most of these children because of their cognitive level. Children need considerable assistance and hardly show own initiative. The occupational therapist indicated that it was hard to choose goals related to her discipline; IROMEC would be more suitable for speech therapy or physical therapy.

It would be useful to use IROMEC before children start to control an electric wheelchair. By playing with the robot, they can improve their spatial awareness and the children can learn to use different control options. It was suggested to use the robot at the start and end of the therapy session; therefore, professionals saw IROMEC more as an additional tool in therapy.

\section{Influence of environment}

The physical environment as well as the social environment influenced the IROMEC sessions. The room in which the sessions took place contained minimal sensory stimuli, which supported the attention of the child. Furthermore, all rooms were familiar for the children, which created a safe environment. A negative point was that some sessions took place in a therapy room that was too small; for this reason, the robot sometimes did not work as expected. For children able to walk, it was suggested to have a larger area.

The social environment was pointed out as a crucial factor. The children have to feel safe, with familiar individuals around. According to the professionals, the presence of technical support and the researcher might have influenced the attention of the child. Furthermore, the professionals pointed out that in group sessions, it was difficult to challenge every child and to adapt to the different levels of the children. In individual sessions, it is easier to challenge a child and to adapt to the preferences of the child.

\section{Discussion}

The aim of this study was to explore the application of the IROMEC robot-based play intervention within rehabilitation and special education for children with severe physical disabilities with a developmental age between 2 and 8 years. On the basis of qualitative as well as quantitative results, IROMEC clearly has potential in supporting play in rehabilitation and special education. Several evaluation methods were used. A significant result was found on the IPPA, which indicates a positive effect of the IROMEC robot on the achievement of predetermined goals. The children evaluated the sessions as nice and funny. The professionals did observe meaningful application possibilities, but the lacking adaptability, expandability and technical stability of the platform make its use in daily care practice impossible so far. Comparable issues were also highlighted in the review of Yakub et al. (2014), who recommended improvement in sensors, robustness and flexibility for ease of use. The professionals preferred individual sessions above 
group sessions [13]. Looking at the results, the children scoring lower on playfulness and IPPA all participated in group sessions. It might be that individual sessions would have worked out better for them because they could spend all the time with the robot and the sessions might be more effective. Because the field of social robots in paediatric rehabilitation and special education is relatively new, there is a paucity of scientific research, but there surely is a large potential.

The number of participants of this study is low, but to get an idea of usability and feasibility aspects, this number of participants provides worthwhile insights. Intervention sessions with the robot were highly dependent on the professional's creativity, which led to a large variety of sessions. The professionals had a professional relationship for some years with the main researcher, which might have led to socially desirable answers in the interviews, 10-point playfulness scale and IPPA measurement. In terms of feasibility, the measurements are recommended for use in a future study as well.

During this study, it seemed that play for play's sake was not easy for professionals. On the basis of their current work, they are used to working with therapeutic and educational goals, and are more familiar with using play as a means to achieve other goals.

The largest problem occurring in this study was the technical instability of the robot platform. It is recommended within a new study to have a technically stable platform. Furthermore, to be able to draw conclusions on the effects of the robot, it is suggested to use an $A B A B$ design in which therapy with and without the robot can be compared for each child individually. This has been done in earlier robot intervention evaluation studies as well [14]. More participants, more measurements and a longer intervention period should be part of this study. In practice, it also appeared that the professionals should have had more training and experience with the robot before starting the intervention period.

\section{Conclusion}

The application of a robot such as IROMEC for children with severe physical activities seems to be positive and worthwhile, but the current IROMEC platform is not satisfactory enough. Technical stability, adaptability and expandability are important factors influencing the effects of the robot and commitment of professionals. Next to these usability aspects feasibility is a crucial factor for successful application in care practice.

\section{Acknowledgements}

The authors sincerely thank their colleague the late Gert Jan Gelderblom t for his dedication to this study. This work would not have been possible without the children, their parents and the professionals participating in this study. They also acknowledge their occupational therapy students for their enthusiasm and support during the study. This 
work has been carried out in the context of the project 'Social robots in care' (project number PRO-4-10) funded by the RAAK-PRO programme of Stichting Innovatie Alliantie.

\section{Conflicts of interest}

There are no conflicts of interest. 


\section{References}

1. Besio S. Analysis of critical factors involved in using interactive robots for education and therapy of children with disabilities. Trento, Italy: UNI Service; 2008.

2. Spaargaren E. Het meten van spelparticipatie met de test of playfulness en test of environmental supportiveness. Scientific Journal for Occupational Therapy 2011;4:13-21.

3. Besio S, Carnesecchi M, Converti RM. Prompt-fading strategies in robot mediated play sessions. In: Encarnação P, Azevedo R, Gelderblom GJ, Newell A, Mathiassen NE, editors. Assistive Technology: From Research to Practice: AAATE 2013. Amsterdam: IOS Press. 2013; pp. 143-148.

4. Van den Heuvel R, Lexis M, Gelderblom G, Jansens R, de Witte L. Robots and ICT to support play in children with severe physical disabilities: a systematic review. Disabil Rehabil Assist Technol 2015; 11:103-116.

5. Besio S, Potenza MF, Kronreif G. Developing the IROMEC robot for play: results from the first experimental trails. In: Emiliani PL, Burzagli L, Como A, Gabbanini F, Salminen A-L, editors. Assitive Technology from adapted equipment to inclusive environments: AAATE 2009. Amsterdam, the Netherlands: IOS Press. 2009; pp. 159-164.

6. Bernd T, Gelderblom GJ, Vanstipelen S, De Witte L. Short term effect evaluation of IROMEC involved therapy for children with intellectual disabilities. In: Ge SS, Li H, Cabibihan J-J, Tan YK, editors. Social robotics. Berlin, Heidelberg: Springer Verlag. 2010; pp. 259-264.

7. Iacono I, Lehmann H, Marti P, Robins B, Dautenhahn K. Robots as social mediators for children with Autism - a preliminary analysis comparing two different robotic platforms. Int Conf Devel Learn. 2011.

8. Fazekas G. Robotics in rehabilitation. Int J Rehab Res 2013; 36:95-96.

9. Freyd M. The graphic rating scale. J Educ Psychol 1923; 14:83.

10. Wessels R, Persson J, Lorentsen $\varnothing$, Andrich R, Ferrario M, Oortwijn W, et al. IPPA: individually prioritised problem assessment. Technol Disabil 2002; 14:141-145.

11. Palisano R, Rosenbaum P, Bartlett D, Livingston M, Walter S, Russell D, et al. GMFCS-E\&R. CanChild Centre for Childhood Disability Research, McMaster University. 2007. Available at: https://canchild.ca/ system/tenon/assets/attachments/000/000/058/original/GMFCS-ER_English.pdf [Accessed 12 September 2016].

12. SPSS. SPSS 22.0 for Windows. New York, NY: IBM Corp Armonk. 2016

13. Yakub F, Md. Khudzari A, Mori Y. Recent trends for practical rehabilitation robotics, current challenges and the future. Int J Rehab Res 2014; 37:9-21.

14. Bemelmans R, Gelderblom GJ, Jonker P, De Witte L. Effectiveness of Robot Paro in intramural psychogeriatric care: A multicenter quasi experimental study. J Am Med Dir Assoc 2015; 16:946-950. 


\section{Chapter 5}

\section{Robot ZORA in rehabilitation and special education for children with severe physical disabilities: a pilot study}




\section{Abstract}

The aim of this study was to explore the potential of ZORA robot-based interventions in rehabilitation and special education for children with severe physical disabilities. A twocentre explorative pilot study was carried out over a 2.5-month period involving children with severe physical disabilities with a developmental age ranging from 2 to 8 years. Children participated in six sessions with the ZORA robot in individual or in group sessions. Qualitative and quantitative methods were used to collect data on aspects of feasibility, usability, barriers and facilitators for the child as well as for the therapist and to obtain an indication of the effects on playfulness and the achievement of goals. In total, 17 children and seven professionals participated in the study. The results of this study show a positive contribution of ZORA in achieving therapy and educational goals. Moreover, sessions with ZORA were indicated as playful. Three main domains were indicated to be the most promising for the application of ZORA: movement skills, communication skills and cognitive skills. Furthermore, ZORA can contribute towards eliciting motivation, concentration, taking initiative and improving attention span of the children. On the basis of the results of the study, it can be concluded that ZORA has potential in therapy and education for children with severe physical disabilities. More research is needed to gain insight into how ZORA can be applied best in rehabilitation and special education.

Keywords: disabled children, play and playthings, rehabilitation, robotics, special education 


\section{Introduction}

Play is essential in children's development and contributes towards cognitive, physical, social and emotional development [1,2]. A large variety of tools and technologies to support play in children with disabilities are being developed. Developments in the field of robotics create new opportunities for this target group. Besides supporting play for play's sake, new technologies may also contribute towards the achievement of therapeutic and educational goals, making use of play-like activities.

During the past decade, the field of robotics has been an upcoming field of research and development, characterized by a rapid increase in the application of robottechnology among a large variety of populations. Several studies have been carried out using robots for children with disabilities. Especially for children with physical disabilities in rehabilitation and special education, meaningful application possibilities for robots have been reported. The LEGO Mindstorms and the PlayROB system, for example, are both robots that can stimulate engagement in play [3-5]. The LEGO Mindstorms has been found an excellent tool to facilitate play and learning activities for children with physical disabilities and the PlayROB system successfully improved the opportunity to play with LEGO for physically disabled children $[3,4]$. However, the results of these studies were all based on relatively small studies with low numbers of participants (one to six children). Within a European research project (https://www.iromec.org), the IROMEC robot was developed. An explorative pilot study with the IROMEC robot among children with severe physical disabilities showed a promising positive effect on achievement of individual therapy or educational goals. In addition to achievement of therapeutic or educational goals, playing and having play fun were indicated by the professionals involved (therapists and teachers) to be of equal importance. The children enjoyed playing with IROMEC and the professionals indicated that robots may be attractive for this target group. Professionals reported meaningful application possibilities for IROMEC for this target group; however, the robot appeared to have limited adaptability, expandability and technical stability [6]. The IROMEC robot was developed for research purposes and is not a commercially available product. This also accounts for the LEGO robots and PlayROB, which are not commercially available as used in these studies. Accessibility of these robots for daily care practice is therefore still very limited. Other commercially available robots, such as the social robotic toy animals PARO and Pleo, are often used in care [7]; however, they have different aims and technical possibilities. In contrast, ZORA is a commercially available care robot encompassing several characteristics suitable to support play and rehabilitation or special education goals. When comparing ZORA with the aforementioned robots/robotic systems, ZORA seems to have some major benefits, such as an attractive appearance, better technical stability and ease of control and transport.

ZORA is a humanoid robot actually produced as the NAO robot by Softbank Robotics (https://www.ald.softbankrobotics.com). The Belgium company Zora Robotics 
(https://www.zorarobotics.be) developed together with the producer accessible and unique software for the robot to enable application in the field of care and they called this combination of robot and software ZORA. ZORA is a $58 \mathrm{~cm}$ high humanoid robot with seven senses for natural interaction: moving, feeling, hearing and speaking, seeing, connecting and thinking. ZORA is one of the first humanoid robots that is commercially available and sold as a care robot. Pre-programmed scenarios can be used to let the robot dance or interact with the user. Sensors can be programmed to react on the user's touch and some scenarios can be executed with the tablet control using the Wizard of Oz technique because with the current software, it is not possible to create all the behaviours of ZORA as autonomous scenarios. With its attractive appearance and variation of interaction and communication possibilities, this robot is promising. Figure 1 shows a picture of ZORA.

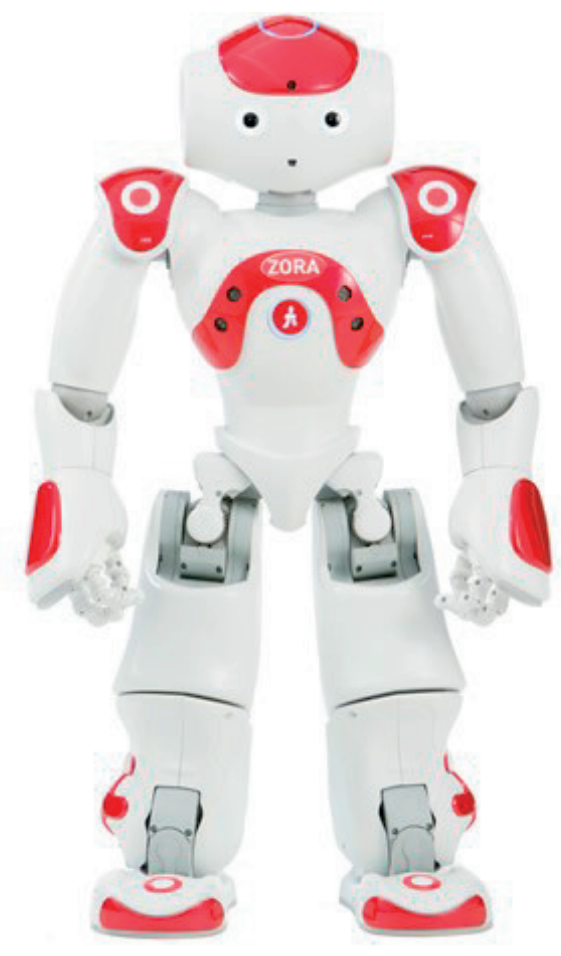

Figure 1 The ZORA robot

ZORA is a commercially available robot that is increasingly being used in the care sector. As described before, NAO is the same robot; the difference is the simplified software developed for ZORA, focused on application in the rehabilitation and care sector. Studies carried out with NAO in elderly care aimed to support and motivate elderly individuals to perform movement exercises [8]. In an intervention programme for children with autism spectrum disorder, NAO was used to stimulate communication [9], and in chil- 
dren with cerebral palsy, NAO was used to improve treatment efficiency [10]. Stimulated by the positive results of scientific studies with ZORA or NAO in different healthcare sectors, attention towards ZORA in healthcare is increasing rapidly and questions have been raised on what its possibilities could be for children with severe physical disabilities in supporting play activities in therapy and special education. The current possibilities of the robot seem to be meaningful to explore its potential further in this area.

This study aimed to explore the potential of ZORA robot-based interventions in rehabilitation and special education for children with severe physical disabilities. Aspects of usability, feasibility, barriers and facilitators for the child as well as the therapist/special educator and an indication of the effects on playfulness were studied. Furthermore, the choice for the types of therapeutic and educational goals by the educators and therapists of different professions (e.g. physical therapists, occupational therapists, speech therapists) and the achievement of these goals were determined.

\section{Participants and methods}

\section{Study design}

A two-centre explorative pilot study was carried out from October 2016 to December 2016 involving children with severe physical disabilities with a developmental age between \pm 2 and 8 years.

\section{Study participants}

The study was carried out in two institutions in the Netherlands: a school for special education (institution 1) and a paediatric rehabilitation centre (institution 2). Parents were invited for participation of their child through the therapist or special educator and they were free to refuse participation. Children were included in the study if they had severe physical disabilities, for example as a consequence of cerebral palsy or acquired brain injury, if they had a developmental age between \pm 2 and 8 years and a chronological age between 2 and 20 years. Furthermore, the cardiopulmonary status of the children had to be stable. Children were excluded when they suffered from epilepsy, deafness, blindness or when they showed severe aggressive behaviour. It was intended to include $\pm 12-16$ children. Professionals, including teachers, group leaders or therapists, were invited through the coordinator of each centre.

\section{Intervention}

The intervention with ZORA started with a first session to introduce the robot to the child or children and to become familiar with the robot. After this session, five intervention sessions with ZORA were scheduled. The available scenarios can be divided into 
four different categories: movement exercises, dance exercises, robot control and cognitive exercises. When scenarios were executed according to the Wizard of Oz technique, they still fitted into these four categories. Table Table11 describes the ZORA scenarios and examples of games. During the sessions, the professionals were in charge of deciding which scenarios they were going to use depending on the preferences of the child at that specific moment and on the basis of their own experience. A session lasted $\pm 30 \mathrm{~min}$, with at least $20 \mathrm{~min}$ effective therapy time. Goals established before the sessions were for example: 'The child is able to imitate all the movements of the robot within 6 sessions', 'The child has a longer attention span using ZORA' and 'The child is able to use the grammatical construction He+verb'. Each child participated in six individual sessions or in six group sessions. The robot was controlled by the researcher with a tablet interface.

Table 1 Description of ZORA scenarios

\begin{tabular}{|c|c|c|}
\hline Category & Example scenarios & Description of scenarios \\
\hline Movement exercises & $\begin{array}{l}\text { Leg exercises (on a chair) } \\
\text { Movement exercises }\end{array}$ & $\begin{array}{l}\text { Movement exercises, robot explains and } \\
\text { carries out exercises }\end{array}$ \\
\hline Dance exercises & $\begin{array}{l}\text { Head, shoulders, knees and toes } \\
\text { Hansje, pansje, kevertje (Dutch song) } \\
\text { Smakelijk eten (Dutch song) }\end{array}$ & $\begin{array}{l}\text { Movement exercises carried out by the } \\
\text { robot and supported by songs }\end{array}$ \\
\hline Robot Control & $\begin{array}{l}\text { Press my sensors } \\
\text { Stop, stand, step }\end{array}$ & $\begin{array}{l}\text { Child can control the behaviour of the } \\
\text { robot via vocal commands or pressing } \\
\text { sensors }\end{array}$ \\
\hline Cognitive exercises & $\begin{array}{l}\text { QR Quiz * } \\
\text { QA Quiz }\end{array}$ & $\begin{array}{l}\text { Card games: robot asks to show a specific } \\
\text { card (e.g. animal), child has to show the } \\
\text { right card and show it to ZORA. ZORA gives } \\
\text { positive feedback or asks to try it again in } \\
\text { case of wrong answer. Question and } \\
\text { answer games with cognitive tasks the } \\
\text { child has to complete }\end{array}$ \\
\hline
\end{tabular}

* $Q R$ refers to quick response code ( $Q R$ code) on the cards

\section{Study procedure}

After selection of the children, their parents received full information and they were given at least 7 days to decide whether they agreed to their child's participation in the study and whether they agreed to the videotaping of the sessions. After a signed informed consent was obtained, children were included in the study. The week before the study started, a training session for the professionals was organized in which the different scenarios were demonstrated and a role play between the professionals was done to become familiar with the robot. Two sessions per child per week were organized over a period of 3 weeks. Because of the regular planning of group therapy, the group sessions were scheduled once a week over a period of 6 weeks. The study was approved by an accredited medical ethics committee (Medisch Ethische Toetsingscommissie Zuyderland NL58646.096.16). 


\section{Measurements and data collection}

A mixed-methods approach was used, combining qualitative and quantitative methods to collect data on aspects of feasibility, usability, barriers and facilitators for the child as well as the therapist and an indication of the effects on playfulness and the achievement of goals.

\section{Quantitative outcome measures}

In addition to 'play' being an important aim in therapy and education, the professionals indicated that play is often being used as a means to achieve other goals. To assess the effect of the robot in achieving these goals, an instrument to assess the effectiveness of assistive technology was used: the Individually Prioritized Problem Assessment (IPPA) [11]. With IPPA, it is possible to assess to what extent the goals established by the professional before the series of ZORA sessions were reached. During a baseline interview, each professional was asked to determine goals for each of the children and to rate the importance and level of difficulty associated with each goal on a baseline form (scales 1-5). A checklist with the goal overview from our former study was used to help the professional to think about possible goals [12]. After the sixth session, a follow-up interview was conducted in which the participants were asked to complete the follow-up form (scales 1-5) to evaluate the level of difficulty associated with each goal.

A previous study on robots for children with severe physical disabilities showed that play is an important aim related to interventions with robots [12]. Play as goal in itself came up as one of the main domains in the goal overview [12]. For this reason, the outcome measure playfulness was chosen. A 10-point visual analogue scale was used to assess playfulness from the professional's point of view. They were asked: 'How high was the level of playfulness for the child during the play session in your eyes?'. A score of zero means no playfulness and a score of 10 means as high as possible playfulness [13]. The aim of this score was to be able to evaluate playfulness over time for the group of participants.

The success of the ZORA-based interventions mainly depends on the children's viewpoint about the ZORA sessions. However, for children with severe physical disabilities, this was challenging. The children were asked to indicate their feelings (like, neutral, dislike) by pointing out smileys after every session. The playfulness scale and indication of smileys have been used successfully before in former studies with the IROMEC robot $[6,14]$.

\section{Qualitative outcomes}

Qualitative interviews were performed with the professionals on aspects of usability, feasibility, barriers and facilitators in the use of ZORA. Usability can be defined as 'The extent to which a product can be used by specified users to achieve specified goals with effectiveness, efficiency and satisfaction in a specified context of use' [15]. Feasibility 
refers to the state of being possible, in the case of this study being able to work with ZORA in the future. Items included in the interviews are as follows: what was your experience working with ZORA? What do you think about the usability of the robot? What makes it easy or hard to use? Which factors influenced the use of the robot in a positive or a negative way (e.g. physical and social environment)? How could the robot be applied best in the future? Furthermore, the professionals were able to reflect their own impression of the possible effects of the robot during this interview. A more detailed description of the main topics of the interview guide is presented in Table 2.

Table 2 Overview of the topics and subtopics

\begin{tabular}{ll}
\hline Main topics & Subtopics \\
\hline Usability and feasibility aspects & General experience of working with ZORA \\
& Time investment working with ZORA \\
& Satisfaction with usability of ZORA (easy to use, errors) \\
& Safety of the robot for the children \\
& Ability to use robot independently \\
& Influence of the social and physical environment \\
& Domains where the robot is most valuable \\
Effects of ZORA & Comparison with regular therapy \\
& Improvement of the children using ZORA \\
\hline
\end{tabular}

\section{Procedure}

Quantitative data were collected at the start, during and after the ZORA sessions. All sessions were video recorded using two cameras at two positions to enable review the sessions afterwards. The IPPA forms and the playfulness scale were completed by the professionals after each session. The researcher registered the smileys that the children indicated by pointing their finger representing their feeling of playing with ZORA. The qualitative interviews lasted \pm 30 min and were conducted individually 1 week after the last session with ZORA with all professionals involved.

\section{Data analysis}

To establish the mean, range and SD for the playfulness scale, descriptive statistics were used. The total IPPA score was calculated by using the rated importance of the first interview as the weighting factor and multiplying the importance with the level of difficulty before and after the intervention [11]. The difference between the score before and after the intervention represents the degree to which the difficulty has diminished. A nonparametric statistical test (Wilcoxon signed-rank test) was used to compare the two means $(\alpha=0.05)$. Descriptive statistics were used to show children's viewpoint on the ZORA intervention by counting the number of happy, neutral or sad smileys.

Interviews were transcribed verbatim. Relevant information from the interviews was divided into fragments and labelled afterwards, according to themes and subthemes from the interview guide, on the basis of the principles of content analysis (Table 2) [16]. 


\section{Results}

A total of 17 children participated in this study (10 boys and seven girls). Some children missed one or more sessions because of illness or absence. The characteristics of the participants are described in Table 3.3. All children were physically disabled and the severity ranged from Gross Motor Function Classification level II (mild) to IV (severe) [17]. The chronological age of the children ranged from 31 months to 18 years and the cognitive age ranged from 24 months to 4 years. Most of the children also had cognitive impairments. Because of the complexity of the conditions, the cognitive age cannot be defined specifically. Children A, B, N, S and T participated in individual sessions with ZORA, and also three groups of each four children participated in the study (group 1 includes participants $C, D, E$ and $G$, group 2 includes participants $\mathrm{H}-\mathrm{K}$ and group 3 consists of participants $\mathrm{O}-\mathrm{R}$ ) (Table 3 ). Children participated in group or individual sessions on the basis of scheduled existing group and individual sessions.

Table 3 Characteristics of the participating children

\begin{tabular}{lllll}
\hline Child & $\begin{array}{l}\text { Chronological age } \\
\text { (months) }\end{array}$ & Sex & Ability to walk & GMFCS Level * \\
\hline A & 139 & Female & Yes & II \\
B & 150 & Male & Yes & II \\
C & 186 & Male & Yes & II \\
D & 164 & Male & Yes & II \\
E & 211 & Male & Yes & II \\
G & 222 & Female & Yes & I \\
H & 207 & Female & Yes & II \\
I & 176 & Female & Yes & I \\
J & 185 & Female & Yes & II \\
K & 198 & Female & Yes & II \\
N & 39 & Male & Yes & I \\
O & 45 & Male & Yes & II \\
P & 48 & Male & Yes & IV \\
Q & 43 & Male & Yes \\
R & 36 & Male & No (Wheelchair) \\
S & 41 & Female & No (Able to crawl) & IV \\
T & 31 & Male & Yes & II \\
\hline$*$ & & &
\end{tabular}

* GMFCS, Gross Motor Function Classification System

Seven professionals participated in the ZORA sessions and in the qualitative interviews afterwards: two physiotherapists, two speech language therapists, one occupational therapist, one therapeutic group leader and one physical education teacher. The diversity of professionals shows that there is interest in working with and application of ZORA from different therapy and educational disciplines. The age of the professionals ranged 
between 26 and 63 years. The number of years of working experience with children with physical disabilities ranged from 4 to 33 years.

\section{Quantitative outcomes}

All goals selected by the professionals could be related to three main domains, that is movement skills, cognitive skills or communication skills. Figure 2 shows the IPPA scores. The mean score of IPPA before the sessions was 11.8, with a minimum of 6 and a maximum of 15 (SD: 3.0), and the mean score after the sessions was 8.8, with a minimum of 3 and a maximum of 15.3 (SD: 3.5). This significant difference ( $P=0.002)$ between the IPPA before and after scores indicates the contribution of ZORA towards achievement of the goals.

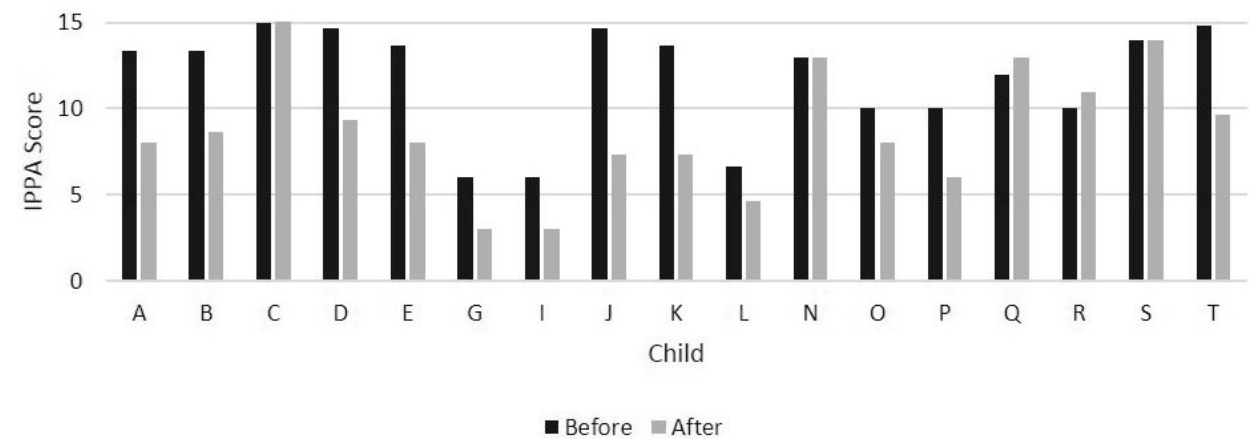

Figure 2 Individually Prioritized Problem Assessment (IPPA) scores before and after the ZORA sessions

The results of the playfulness scale are shown in Table 4. Across all sessions, the maximum playfulness score was 10 and the minimum score was 4 . Generally, the playfulness score is almost stable during the six sessions, and overall quite high, which means that the children showed playful behaviour during the sessions and liked playing with ZORA according to the professionals.

Table 4 Results on the 10-point playfulness scale

\begin{tabular}{llllc}
\hline & Mean & SD & Minimum & Maximum \\
\hline Session 1 $(n=15)$ & 7.6 & 0.61 & 6 & 8 \\
Session 2 $(n=16)$ & 6.8 & 1.52 & 4 & 10 \\
Session 3 $(n=17)$ & 7 & 0.97 & 5 & 8 \\
Session 4 $(n=15)$ & 7 & 1.27 & 4 & 9 \\
Session 5 $(n=16)$ & 7.3 & 1.20 & 5 & 10 \\
Session 6 $(n=16)$ & 7 & 1.50 & 5 & 9.5 \\
\hline
\end{tabular}

With respect to children's ( $N=17)$ impression about the sessions, for children $N-T(n=7)$, it was impossible to indicate the smiley representing their feelings because they were 
too young to understand. Professionals asked the children whether they liked the session and interpreted the communication of the children. According to the professionals, children N-T all liked playing with ZORA. From the total of 60 sessions in which indication of smileys could be performed (children A-K), 58 sessions were liked, one value was missing because of absence of the child and one score was doubtful; the child indicated the dislike as well as the like smiley. Both for individual and for group sessions, there were children who did not achieve their individual goals, which makes it impossible to conclude anything about the preference for group or individual sessions with ZORA.

\section{Qualitative outcomes}

Usability and feasibility aspects

Professionals indicated that they like working with ZORA. The time they had to spend to work with ZORA was comparable with the preparation of regular therapeutic or educational session. Extra time was only related to participation in this research (training session, setting goals and evaluation). Professionals were not able to talk about the usability of the robot control and software because the researchers took care of this. The usability of the robot together with the child was reasonable and everything functioned as expected. Two barriers were indicated: scanning the cards with the cognitive card games was difficult and pressing different sensors is confusing (e.g. robot asks for pressing foot, but actually only toes react). Professionals considered the robot safe to use and they were convinced that they would be able to control the robot themselves in the future.

Usual classrooms or therapy rooms were most of the times of perfect size for a ZORA session, except the physiotherapy sessions; for these sessions, a larger gym (for training of gross motor skills) was preferred. The professionals believed that the presence of cameras and researchers during the ZORA sessions did not influence the sessions.

\section{Effects of ZORA}

Professionals do see possibilities for the application of ZORA in their treatments and education. According to them, ZORA has great potential to improve motivation, concentration, taking initiative and attention span. Three main domains were indicated in which ZORA may be beneficial: (re)learning of movement skills, cognitive skills and communication/social interaction skills. These domains were identical to the domains found in the quantitative part of this study. On the basis of the professionals' assessment, all children liked the ZORA sessions and had a playful experience. Progress in the achievement of goals has been observed, but a period of 3-6 weeks was, for some children (especially those with lower cognitive levels), too short to be able to reach the goals. ZORA elicited curiosity and emotional responses in almost all children. Over time, 
children began to feel safe and comfortable with the robot, but sometimes, the enthusiasm to play and exercise with the robot diminished. Both in individual and in group sessions, ZORA may be able to contribute towards achievement of goals. Some professionals $(n=2)$ mentioned that in group sessions, ZORA may elicit more interaction and may fit best. ZORA should be used, combined and varied with other toys, materials, instruments or interventions to stay attractive over time.

\section{Discussion and conclusion}

The aim of this study was to explore the potential of a ZORA-based intervention for children with severe physical disabilities in rehabilitation and special education. The quantitative results of this study showed a positive contribution of ZORA towards achieving therapeutic and educational goals as measured with the IPPA. All of the established goals were in the domains stimulation of movement skills, communication skills and cognitive skills. On the basis of the goals established in the IPPA baseline form, we can conclude that in the field of rehabilitation and special education, play is being used to achieve therapeutic and educational goals (play-like activities), and not play for play's sake. Endeavouring for play for play's sake, on the basis of the ideas of the LUDI network, is an interesting concept [18]. LUDI comes from the Latin word ludi, which refers to play or games. The aim of this European leading network on the topic of play it is to increase attention to and awareness of the importance of play for play's sake, especially for children with disabilities. On the basis of the current arrangement of rehabilitation and special education in the Netherlands and the reporting duties in a goal-oriented way, it seems inconvenient to work with play for play's sake in this area. On a closer look at the playfulness score based on the professionals view, there is no clear increase or decrease of playfulness. This may indicate that sessions with ZORA were playful and did not become boring or less playful over time during the six sessions. The children indicated that they liked the sessions with ZORA almost all the time.

In the interviews, professionals also indicated that the three domains movement skills, communication skills and cognitive skills were the most promising for the application of ZORA interventions. They suggested that, overall, ZORA can contribute towards eliciting motivation, concentration, taking initiative and improving the attention span of the children. The qualitative results also showed positive results on the application of ZORA, and suggestions for further development and improvement of ZORA-based interventions were provided. Professionals prefer to alternate between ZORA and other materials because they expect that interest in ZORA will diminish over time. Usability of scanning the cards or using the sensors was sometimes hard or confusing, which should be improved in the future.

The number of participants in this study was sufficient to gain an idea of usability and feasibility aspects and to gather worthwhile insights on the application of ZORA. 
Compared with an earlier study with the IROMEC robot [6], the sessions with ZORA were also highly dependent on the use of the robot by the professional and the professionals' creativity. This led to a high diversity in the robot sessions. Because this study was carried out in two organizations comparable with other rehabilitation and special education in the Netherlands, comparable results may have been found in other organizations in the Netherlands.

For future research, it is recommended to further focus on studying the application of ZORA in more detail. The present study was explorative and aimed to gather a first impression of the potential of ZORA, but for successful implementation of robots and ZORA in particular in daily practice, it is essential to gain more insight into for example: how should professionals apply ZORA, for which specific goals, for which children in particular, which different roles can ZORA play and also which conditions are necessary to be able to work with ZORA (independently)? Other relevant questions for further research are as follows: will ZORA be interesting over time or will children get used to it and will interest diminish?

\section{Conclusion}

It can be concluded that ZORA-based interventions have potential in rehabilitation and special education for children with severe physical disabilities (developmental age: 2-8 years). The most promising domains are the stimulation of movement and motor skills, communication skills and cognitive skills. More research is needed to gain insight into how ZORA can be best applied in rehabilitation and special education.

\section{Acknowledgements}

This work would not have been possible without the children, their parents and the professionals participating in this study. This work has been carried out in the context of the project 'Social robots in care' (project number PRO-4-10) funded by the RAAK-PRO programme of Stichting Innovatie Alliantie.

\section{Conflicts of interest}

There are no conflicts of interest. 


\section{References}

1. Besio S. Analysis of critical factors involved in using interactive robots for education and therapy of children with disabilities. Italy: Editrice UNI Service; 2008.

2. Spaargaren E. Het meten van spelparticipatie met de Test of Playfulness en Test Of Environmental Supportiveness. Wetenschappelijk Tijdschrift Ergotherapie [Measurement of play participation using the Test of Playfulness and Test of Environmental Supportiveness. Scientific Journal for Occupational Therapy] 2011; 4:13-21.

3. Kronreif G, Prazak B, Mina S, Kornfeld M, Meindl M, Furst M. Playrob-robot-assisted playing for children with severe physical disabilities. International Conference on Rehabilitation Robotics. ICORR 2005. 9th IEEE; 28 June - 1 July 2005; Chicago, Illinois, USA. pp. 193-196.

4. Schulmeister J, Wiberg C, Adams K, Harbottle N, Cook A. Robot assisted play for children with disabilities. 29th annual RESNA conference proceedings; Atlanta; 2006.

5. Van den Heuvel RJ, Lexis MA, Gelderblom GJ, Jansens RM, De Witte LP. Robots and ICT to support play in children with severe physical disabilities: a systematic review. Disabil Rehabil Assist Technol 2016; 11:103-116.

6. Van den Heuvel RJ, Lexis MA, De Witte LP. Can the IROMEC robot support play in children with severe physical disabilities? A pilot study. Int J Rehabilit Res 2016;40:53-59.

7. Fernaeus $Y$, Håkansson $M$, Jacobsson $M$, Ljungblad S. How do you play with a robotic toy animal?: a longterm study of pleo. Proceedings of the 9th international conference on interaction design and children. ACM; 2010. pp. 39-48.

8. Görer B, Salah AA, Akin HL. An autonomous robotic exercise tutor for elderly people. Auton Robots 2016; 41:1-22.

9. Ismail LI, Shamsudin S, Yussof H, Hanapiah FA, Zahari NI. Robot-based intervention program for autistic children with humanoid robot NAO: initial response in stereotyped behavior. Procedia Eng 2012; 41:1441-1447.

10. Malik NA, Yussof H, Hanapiah FA, Rahman RAA, Basri HH. (2015). Human-robot interaction for children with cerebral palsy: reflection and suggestion for interactive scenario design. Procedia Comput Sci 76:388-393.

11. Wessels R, Persson J, Lorentsen $\varnothing$, Andrich R, Ferrario M, Oortwijn W, et al. IPPA: Individually prioritised problem assessment. Technol Disabil 2002; 14:141-145.

12. Van den Heuvel RJ, Lexis MA, Jansens RM, Marti P, De Witte LP. (2017). Robots supporting play for children with physical disabilities: exploring the potential of IROMEC. Technol Disabil 29:109-120.

13. Freyd M. The graphic rating scale. J Educ Psychol 1923; 14:83.

14. Bernd T, Gelderblom GJ, Vanstipelen S, De Witte L. Short term effect evaluation of IROMEC involved therapy for children with intellectual disabilities. International Conference on Social Robotics. Berlin, Heidelberg: Springer 2010; 259-264.

15. Frøkjær E, Hertzum M, Hornbæk K. Measuring usability: are effectiveness, efficiency, and satisfaction really correlated? Proceedings of the SIGCHI conference on Human Factors in Computing Systems. ACM. 2000; pp. 345-352.

16. Hsieh H-F, Shannon SE. Three approaches to qualitative content analysis. Qual Health Res 2005; 15:1277-1288

17. Palisano R, Rosenbaum P, Bartlett D, Livingston M.. GMFCS - R \& E gross motor function classification system expanded and revised. CanChild Centre for Childhood Disability. Hamilton, ON: McMasters University; 2007

18. Besio S, Bulgarelli D, Stancheva-Popkostadinova V. Play development in children with disabilities. Berlin: De Gruyter Open; 2017. 


\section{Chapter 6}

\section{ZORA robot based interventions to achieve therapeutic and educational goals in children with severe physical disabilities}

This chapter was submitted as:

Van den Heuvel RJF, Lexis MAS, Witte, LP. (submitted) ZORA robot based interventions to achieve therapeutic and educational goals in children with severe physical disabilities. International Journal of Social Robotics 


\section{Abstract}

This study aimed 1) to examine the contribution of robot ZORA in achieving therapeutic and educational goals in rehabilitation and special education for children with severe physical disabilities, and 2) to discover the roles professionals attribute to robot ZORA when it is used in robot-based play interventions in rehabilitation and special education for children with severe physical disabilities. A multi-centre mixed methods study was conducted among children with severe physical disabilities in two centres for rehabilitation and one school for special education. The participating children played with robot ZORA six times, during a period of six weeks (in individual or group sessions). Quantitative data were gathered about the contribution of ZORA in reaching individual goals for all of the participating children, using the Individually Prioritized Problem Assessment (IPPA). Playfulness was measured with a visual analogue scale (0-10) and children could indicate whether they liked the sessions using a scale consisting of smileys. Videostimulated recall interviews were used to collect qualitative data about the different roles of ZORA. In total, 33 children and 12 professionals participated in the study. The results of the IPPA showed a significant contribution of ZORA to the achievement of (children's) individual goals. The data that was gathered using the IPPA during the ZORA-based interventions showed that the largest contributions of robot ZORA lie in the domains of movement skills and communication skills. Playfulness of the sessions was 7.5 on average and $93 \%$ of the sessions were evaluated as 'enjoyable' by the children. Overall then, ZORA could positively contribute to the achievement of individual goals for children with severe physical disabilities. According to the participating professionals the most promising roles in which robot ZORA can be used are as motivator, rewarder or instructor.

Keywords: robot, effects, goals, roles, children, physical disabilities 


\section{Introduction}

Robots are becoming more and more advanced, their presence in society is increasing, and they have great potential to improve our daily lives at home, at work and at play. However, there are still some challenges, such as integrating robots into the human world, fine-tuning and customising robots for particular purposes and increasing their reasoning abilities [1]. There is increased attention for the possible role of robots in health and care and generally there is an expectation that robots will play a role in future healthcare. ZORA is an example of a popular robot, commercially available in the Netherlands since March 2014. The popularity of applying ZORA in health care is increasing, and currently the robot is available on the market in several countries, including the Netherlands. ZORA has often been used in elderly care. A study in the Netherlands in 15 elderly homes found that clients enjoyed using ZORA and that the robot had positive influences on the behaviour of the residents. For example, ZORA elicited spontaneous participation and, in addition, a resident who normally did not speak, started to do so. Positive influences were also experienced by many of the professionals who worked with ZORA: Two thirds of them had more fun at work, but clear goals for applications of ZORA and the role the robot can have were not described. Furthermore, the care professionals working with ZORA also indicated several barriers of using robot ZORA, such as limited battery life, long start-up time and the technical complexity of programming the robot to perform certain activities [2]. A Finnish study about the use of ZORA in elderly care yielded comparable results. In this study there were positive, negative and neutral reactions on the use of the robot. Overall, care professionals indicated that ZORA has potential for rehabilitative work and activities [3].

For children with severe physical disabilities, robots may offer a solution in the provision of new possibilities for play, which may also be used in therapeutic and educational settings. Studies show promising results when it comes to letting children with severe physical disabilities work with robots and technology. The IROMEC robot a mobile robot which is programmed to play simple games with children such as a turntaking game or the follow-me game, is one example of such an application [4]. Another example is the PLAYROB robot, which enables children with severe physical disabilities to play with standard toys (LEGO) [5]. In addition to robot systems, other technologies are being used to facilitate play. A computer game-based rehabilitation platform for children with cerebral palsy, which is currently being evaluated [6], and a virtual reality system to support upper limb rehabilitation in children with motor impairment [7] are two examples of such technologies.

A pilot study with robot ZORA was carried out in 2016 to explore the potential of ZORA for children with severe physical disabilities and to test different scenarios and applications for different goals. The results of this pilot study showed that ZORA could make a positive contribution to achieving these children's therapeutic and educational goals, and professionals indicated that ZORA has great potential for (use in) rehabilita- 
tion and special education, especially in the domains of movement, communication and cognitive skills. This pilot study triggered us to further study the possibilities of ZORA by developing detailed applications and specifying the possible roles of ZORA [8].

According to the literature, robots can fulfil different roles in the context of humanrobot interaction. These roles are categorised and defined in different ways. For example, in a study by Giuliani and Knoll (2011), robots were applied in, amongst others, an instructive role in which the robot gave instructions to the user (adults 17-59 years) to teach them something or get them to do something. Robots could also be given a supportive role, in which they perform tasks (e.g. handing things over to the user) and only instruct the user when needed [9]. Mubin et al. (2013) suggested different roles that might be attributed to robots in the context of the learning process of children, depending on the content, the instructor, the type of student and the nature of the learning activity. Robots can also have a passive role. This is the case of they are used as a learning tool or teaching aid,for example, when students build, create and program robots themselves to improve their technical skills. Furthermore, robots can have the role of co-learner, peer or companion and care receiver. The role of a robot can also be that of a mentor. In summary, Mubin et al. defined the aforementioned roles of robot into three categories: tools, peers or tutors [10]. Dautenhahn (2003) described six different roles of robots in human society: the autonomous robot operating without significant contact with humans, the robotic tool used by human operators, the robot operating in a human-inhabited environment, the robot as a persuasive machine, the robot as a social mediator and the robot as a model social actor [11]. These last three roles were identified based on a research in the Aurora project focusing on children with autism. In 2005, Dautenhahn et al. already described the potential role of a robot companion in their study. The participants of this study were asked what role a future robot companion in the home should have. The majority of the participants indicated they preferred the robot to be an assistant, a machine or a servant. Fewer people preferred the robot to be a friend or a mate [12]. Overall then, it is clear that robots can be used in a variety of roles. Each of these roles might have different effects on people's behaviour. This also applies to the behaviour of children with severe physical disabilities. For application of ZORA these different roles may be relevant as well, which is relevant to study in more detail. The aim of our study was twofold and translated into two research questions:

- To what extent can individual goals within the domains of movement, communication and cognitive skills be achieved using robot ZORA?

- In which different roles can robot ZORA be applied in therapeutic or educational sessions for children with severe physical disabilities, during a period of six weeks? 


\section{Methods}

\section{Study design}

A multi-centre mixed methods study combining quantitative and qualitative methods was executed among children with severe physical disabilities in two centres for rehabilitation and one school for special education between May 2017 and October 2017.

\section{Robot ZORA}

ZORA is a humanoid robot, which was originally produced by Softbank Robotics as a robot called NAO (https://www.ald.softbankrobotics.com). The Belgium company Zora Robotics (https://www.zorarobotics.be) worked with Softbank Robotics to develop accessible and unique software for the robot to make it useable for the field of care. This combination of robot NAO with the new software was called 'ZORA'. ZORA is a 58 $\mathrm{cm}$ high humanoid robot with seven senses for natural interaction: moving, feeling, hearing and speaking, seeing, connecting and thinking. ZORA is one of the first humanoid robots that is commercially available and sold as a care robot. ZORA has three sensors on the head, two sensors on the feet, and two sensors on the hands. Furthermore, ZORA can recognise speech (preprogrammed answers) and is equipped with a camera, which enables it to scan $Q R$ codes or to make pictures and videos. The robot can for example dance and interact with the user via preprogrammed scenarios. Via the ZORA software, users can easily select standard scenarios (for example, dancing, movement exercises, card games). Via the composer software, users can create new scenarios based on the basic functionalities of the robot. Sensors can be programmed to react to the user's touch. Some scenarios can be executed with the tablet control using the Wizard of Oz technique because, with the current software, it is not possible to create all the desired behaviours of ZORA as autonomous scenarios. Figure 1 shows a picture of ZORA while dancing. Examples of ZORA scenarios used in our study are described in section 2.3 . 


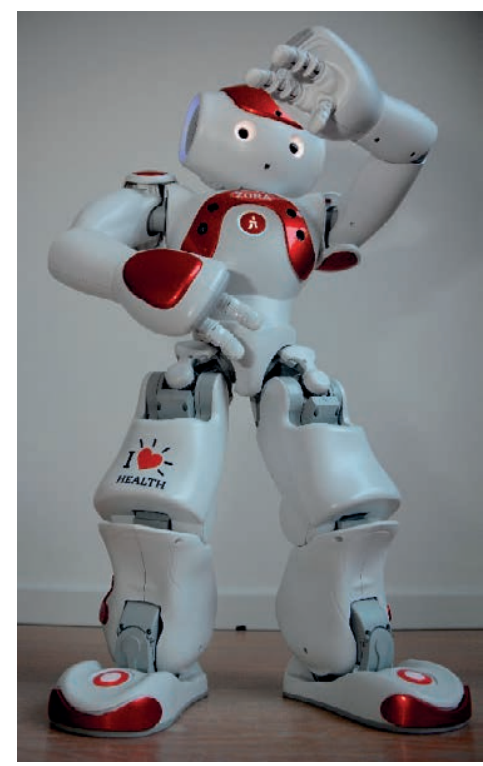

Figure 1 Robot ZORA dancing

\section{Study population}

The study was performed in three facilities for children with severe physical disabilities in the Netherlands: two paediatric rehabilitation centres (which also offer special education facilities) and a school for special education (which also offers rehabilitation). The main researcher of the current study invited the professionals (therapists and special educators) to participate in this study. These professionals were selected by the head of their organisation, trying to select a mix of teachers and therapists from different disciplines. The invited therapists and special educators selected and invited children (via their parents) to participate in this study. The selection of children was done by convenience sampling, because the professionals selected children from their own therapy list or class, keeping in mind the in- and exclusion criteria of this study [13]. Inclusion criteria for children to participate in this study were: children with a severe physical disability (gross motor function classification system ranging from I to V), a developmental age between approximately 2 and 8 years, a chronological age between 2 and 18 years, and a stable cardiopulmonary status. Exclusion criteria were: epilepsy, deafness, blindness and severe aggressive behaviour. To ensure that all 3 studied domains (communication skills, cognitive skills and movement skills) were sufficiently represented in the goals of the participating children, the decision was made to include at least 30 children in the study. 


\section{Intervention and study procedure}

Before starting this study, a training session with the main researcher and the professionals took place in which the professionals could discover and try out ZORA and the possibilities it offers. During this session, the professionals decided which goals they were going to work on for each of the three domains (movement skills, cognitive skills and communication skills) with each of the participating children and how they would like to apply ZORA. For each child the goals were determined and the specific scenario with ZORA was designed. After this session, the scenarios designed by the professionals were realised with ZORA by the researcher and IT specialists. All newly created approaches/options were checked with the professionals individually before the intervention sessions with the children took place. The intervention sessions were also preceded by an introduction session in the first week of the study, to allow all children to get used to robot ZORA. Over the next five weeks intervention sessions with ZORA took place. Each child took part in a total of six sessions. Examples of scenarios related to the individual goals of the children are displayed in table 1 . Most of the scenarios were tailormade for the child(ren) and setting, or used in Wizard of Oz-technique (not functioning autonomously, but remotely controlled by an IT expert). Professionals prepared the sessions in advance and decided during the sessions which scenarios they were going to use at which moment (based on their preparation and the response of the child). The duration of a ZORA session was approximately 30 minutes. The robot was controlled by the researcher using the tablet interface, upon requests for scenarios from the professional. Examples of these goals were 'Child imitates after six weeks the arm movements of ZORA', 'Child speaks to ZORA within six weeks' and 'Child recognized within six weeks the sounds of the farm animals'.

When children were selected based on the in- and exclusion criteria by the participating professionals, their parents received informed consent forms and they had seven days to decide whether they agreed with participation of their child in the study and videotaping of the sessions. Children were included after signed informed consent. An accredited medical ethics committee approved this study (Medisch Ethische Toetsingscommissie Zuyderland NL 31192.096.17). 
Chapter 6

Table 1 Examples of goals set and ZORA scenarios used in the study

\begin{tabular}{|c|c|c|}
\hline Domains & Example goals & Short description the scenario \\
\hline \multirow[t]{2}{*}{ Movement skills } & \multicolumn{2}{|c|}{$\begin{array}{l}\text { Child is able to imitate the movements of Movement exercises, robot explains and } \\
\begin{array}{l}\text { ZORA. } \\
\text { carries out exercises (e.g. sitting, standing, } \\
\text { lying on your back). }\end{array}\end{array}$} \\
\hline & $\begin{array}{l}\text { Child spontaneously dances with ZORA } \\
\text { after } 6 \text { weeks. }\end{array}$ & $\begin{array}{l}\text { Robot dances to famous songs which have } \\
\text { been selected in advance together with the } \\
\text { professional. }\end{array}$ \\
\hline \multirow[t]{2}{*}{ Cognitive skills } & $\begin{array}{l}\text { Child is able to choose the animal card } \\
\text { that ZORA asks for. }\end{array}$ & $\begin{array}{l}\text { ZORA asks to show cards with pictures of } \\
\text { different animals and gives a reward by } \\
\text { clapping or cheering when answer is } \\
\text { correct. }\end{array}$ \\
\hline & $\begin{array}{l}\text { Child is able to link the sounds of } \\
\text { different animals to the right pictures. }\end{array}$ & $\begin{array}{l}\text { ZORA makes the sounds of different } \\
\text { animals and gives a verbal reward when } \\
\text { the answer of the child is correct. }\end{array}$ \\
\hline \multirow[t]{2}{*}{ Communication skills } & $\begin{array}{l}\text { Child is able to answer questions using } \\
\text { his/her speech generating device. }\end{array}$ & $\begin{array}{l}\text { ZORA asks different questions and child } \\
\text { searches for the answers on their speech } \\
\text { generating device. ZORA gives a reward by } \\
\text { e.g. clapping. }\end{array}$ \\
\hline & $\begin{array}{l}\text { Child is able to say goodbye in different } \\
\text { ways. }\end{array}$ & $\begin{array}{l}\text { ZORA sits and responds to different } \\
\text { touches (hands, feet and head). ZORA } \\
\text { shakes hands if its hand is touched,, ZORA } \\
\text { gives a high five if its foot is touched and } \\
\text { ZORA waves if its head is touched. }\end{array}$ \\
\hline
\end{tabular}

\section{Measurements and data collection}

A mix of quantitative and qualitative methods was used to examine the contribution of ZORA robot-based play intervention to the achievement of goals and to gain insight into the roles for which ZORA is best suited.

\section{Quantitative outcome measures}

In order to gain (further) insight into whether the ZORA robot can contribute to the achievement of goals in the fields of movement skills, communication skills and cognitive skills, it was necessary to assess the extent to which such goals (more precisely, goals that were set by the therapist/special educator for each individual child before the intervention sessions) were reached in robot-based play interventions with ZORA. The measurement tool used for this assessment was the IPPA. During a baseline interview each professional was asked to determine goals for each of the children and to rate the importance and level of difficulty associated with each goal on a baseline form before the intervention sessions (scale 1-5). After the sixth session, a follow up interview was conducted in which the professionals were asked to complete the follow-up form (scale 1-5) to evaluate the level of difficulty associated with each goal after the intervention sessions.

To gain insight into how children experienced the sessions, playfulness and the children's experience of the sessions were measured. The level of playfulness children 
experience as interpreted by the respective professionals was measured using a visual analogue playfulness scale (0-10). After every session, professionals were asked: "In your view, how high was the level of playfulness of the child during the play session?". Children's experience of the play sessions was taken into account as well. After every session, the children were asked to indicate their feelings (scaled as like, neutral, or dislike) by pointing out one of three different symbols (smileys). Furthermore, during each session notes were made by the respective professional on circumstances or issues which might have influenced the (outcomes of the) session (such as information on the general health/wellbeing of the child or unusual incidents), as prior research indicated that such factors can affect results. In addition, two cameras were used to record the sessions, so that the sessions could be reviewed afterwards.

\section{Qualitative outcome measures}

Video-stimulated recall interviews with the participation professionals were used to gain insight into the different roles the robot fulfils in the sessions. Additionally, during the same interview semi-structured interview questions were asked with the participating professionals. Approximately one week after the last session the qualitative interviews took place. They lasted 30 to 45 minutes. Before the interviews were held, the main researcher viewed the video footage of each session to select relevant fragments to be used during the interviews. Video fragments were selected based on the different scenarios the professionals used during the ZORA sessions. Four fragments of four different scenarios were selected for each child or group of children. Fragments were only taken from the videos of sessions 2, 3, 4 and 5, since session one was an introductory session and session six was the goodbye session. To make sure that the selected video fragments contained a broad spectrum of different roles ZORA can be used in, they were assessed independently by two researchers using the list of aspects of roles of robots as presented in table 2 , which was based on the literature described in the introduction. Once the independent assessments were done, the researchers compared their assessments of the video fragments and they verified if they assigned comparable roles to the fragments. Initial consensus was $80 \%$. The fragments the researchers did not agree on were discussed until consensus was reached about the roles of ZORA in these fragments. Based on this discussion two roles were added to the overview, namely the robot teaches the child specific knowledge, and the child elicits a response from the robot (table 2). 
Table 2 Aspects of roles of robots

\begin{tabular}{ll}
\hline Source & Aspects \\
\hline From the literature & Robot gives instructions to the child \\
& Robot supports the child \\
& Robot elicits verbal interaction \\
& Robot attracts and maintains attention \\
& Robot involves the child in the activity \\
& Robot supports social behaviour between the children (or between child and adult) \\
& Robot teaches the child a (social) behaviour \\
& Robot has a passive role \\
& Robot shows spontaneous active participation (applause, reward, support) \\
& Robot helps the child \\
& Robot elicits imitation \\
& Robot teaches the child social skills \\
& Robot teaches the child specific knowledge (e.g. recognizing animal sounds) \\
Additional roles based on & The child elicits a response from the robot \\
coding of video fragments &
\end{tabular}

The selected video fragments were used during the video-stimulated recall interviews to stimulate professionals' thinking about ZORA's different roles. The video fragments a professional was shown, were always taken from the video footage of the intervention sessions the respective professional participating in themselves. Although the main topic that was discussed during the interviews was the roles the professionals attributed to ZORA, the interviews also offered room for discussing conditions that are necessary to work with ZORA independently in the future, which target group(s) would likely benefit from working with ZORA, what goals could be achieved with ZORA, the influence of ZORA on the attention of participants, and how using ZORA compared to the regular situation in the participating facilities. The topic of the influence of the robot on the attention of the child was incorporated in the interview guide, since professionals indicated in the pilot study that ZORA can contribute to the improvement of attention span, motivation, concentration and taking initiative [4].

\section{Data analysis}

Descriptive statistics were used to analyse the quantitative data. IPPA scores were calculated according to Wessels et al. by using rated importance as weighting factor and multiplying this rated importance with the level of difficulty of a goal before and after the intervention [14]. The difference between the IPPA before and IPPA after scores represents the degree to which the difficulty has diminished, the significance of the difference was calculated with a Wilcoxon signed rank test in SPSS [15]. Furthermore, average IPPA scores were calculated per child and for each of the different domains per child. Subsequently, for these scores per child the average difference between before and after per domain was calculated, to have an overall score of each domain.

Qualitative data (interviews) were transcribed verbatim and subsequently divided into fragments and labelled. Two researchers independently coded two interviews based on the principles of directed content analysis guided by the topics of the inter- 
view guide [16] and then compared their coding (approximately 75\% consensus), to ensure coding was objective enough They reached consensus about their coding by discussing the differences (approximately 25\%) and one of the two researchers proceeded coding the other 10 interviews.

\section{Results}

\section{Description of the participants}

In total, 33 children (11 girls and 22 boys) participated in our study. All children had a physical disability ranging from very mild to very severe (I-V) on the Gross Motor Function Classification Scale [17]. The chronological age of the children ranged from 3 to 21 years, and their developmental age varied between 2 and 8 years old. The cognitive age of the children could not be defined very specifically, because a child might have a different developmental age in each of the different domains (e.g. emotional, cognitive) of development. The children were selected based on the in- and exclusion criteria and, after selection, were divided into group and individual sessions, based on their goals and the professionals' estimation of their suitability for group or individual sessions. Children $B$ to $P$ all participated in group sessions at institution 1 , with group sizes varying from 2 to 7 children. At institution 2, children $Q, R, S$ and $Z$ participated in individual sessions, and children $T$ to $Y$ participated in a group session. And at institution 3,3 children participated in individual sessions ( $A A, A B$ and $A C$ ), while children $A E$ to $A J$ participated in a group session. An overview of the characteristics of the participating children (and the type of session they participated in) can be found in table 3.

In addition to the children, 12 professionals took part in this study. They prepared and lead the (individual and group) sessions, and took part in the video-stimulated recall interviews. The professionals represented different expertises and occupations: 3 were physiotherapists, 3 were speech language therapists, 2 were occupational therapists, 1 was a physical education teacher, 2 were special education teachers and 1 was a group leader of a daycare group with pedagogical support. The age of the professionals ranged from 25 to 63 years old and they had between 2,5 and 35 years of working experience with children with physical disabilities. 
Table 3 Description of the participating children

\begin{tabular}{|c|c|c|c|c|c|}
\hline Child (code)* & Age (years) & Sex (male/female) & $\begin{array}{l}\text { Ability to walk } \\
\text { (mobility aid) }\end{array}$ & GMFCS & Group/individual \\
\hline B & 17 & Female & Yes (with crutches) & III & Group \\
\hline C & 14 & Male & Yes & $\|$ & Group \\
\hline $\mathrm{D}$ & 21 & Male & No (electric wheelchair) & IV & Group \\
\hline$E$ & 19 & Male & No (electric wheelchair) & IV & Group \\
\hline $\mathrm{F}$ & 11 & Female & Yes & ॥ & Group \\
\hline G & 10 & Male & Yes & III & Group \\
\hline $\mathrm{H}$ & 8 & Male & Yes & ॥ & Group \\
\hline I & 6 & Female & Yes & II & Group \\
\hline J & 11 & Female & Yes & I & Group \\
\hline K & 12 & Male & Yes & $\|$ & Group \\
\hline L & 12 & Male & Yes & $\|$ & Group \\
\hline M & 12 & Male & Yes & $\|$ & Group \\
\hline $\mathrm{N}$ & 12 & Male & No (electric wheelchair) & IV & Group \\
\hline $\mathrm{O}$ & 13 & Male & No (wheelchair) & V & Group \\
\hline$P$ & 9 & Female & Yes & $\|$ & Group \\
\hline Q & 16 & Female & Yes & $\|$ & Individual \\
\hline $\mathrm{R}$ & 5 & Male & No (wheelchair) & IV & Individual \\
\hline S & 7 & Male & Yes & I & Individual \\
\hline $\mathrm{T}$ & 4 & Male & No (electric wheelchair) & IV & Group \\
\hline V & 3 & Male & Yes & II & Group \\
\hline W & 3 & Male & No (wheelchair) & IV & Group \\
\hline$x$ & 3 & Male & Yes (walker) & III & Group \\
\hline Y & 4 & Female & Yes (walker) & III & Group \\
\hline Z & 7 & Female & Yes & ॥ & Individual \\
\hline AA & 3 & Female & No (wheelchair) & IV & Individual \\
\hline$A B$ & 5 & Male & Yes & ॥ & Individual \\
\hline$A C$ & 8 & Male & Yes & 1 & Individual \\
\hline$A E$ & 7 & Male & No (electrical wheelchair) & IV & Group \\
\hline$A F$ & 8 & Male & Yes (walker) & III & Group \\
\hline$A G$ & 7 & Male & Yes & $\|$ & Group \\
\hline $\mathrm{AH}$ & 7 & Female & Yes & I & Group \\
\hline Al & 7 & Female & Yes & III & Group \\
\hline AJ & 7 & Male & No (wheelchair) & IV & Group \\
\hline
\end{tabular}

* Children $A, U$ and $A D$ are missing since these children were selected by the professionals, but did not meet the in- and exclusion criteria. 


\section{Quantitative outcomes}

Individually prioritized problem assessment (IPPA)

The IPPA scores show to what extent robot ZORA was able to contribute to the achievement of the individual goals of the children (measured for each child) Professionals set between 2 and 11 goals per child to be reached during the six sessions. In figure 2 the individual IPPA scores of each child are displayed in a graph, showing a decrease in IPPA scores between the start and the end of the ZORA intervention in 26 of the 33 children. This means that there was a decrease in the level of difficulty these children experienced in performing in a way that enabled them to reach their goals. The mean IPPA score before the intervention sessions was 13.5 (SD 4.3), with a minimum of 6.3 and a maximum of 28 , and the mean IPPA score after the intervention sessions was 10.3 (SD 4.2), with a minimum of 3.2 and a maximum of 18. A significant difference was found between IPPA before and after the intervention sessions ( $p=0.001 ; z=-3.43$ ), which indicates a positive contribution of the ZORA-based intervention sessions to the achievement of goals.

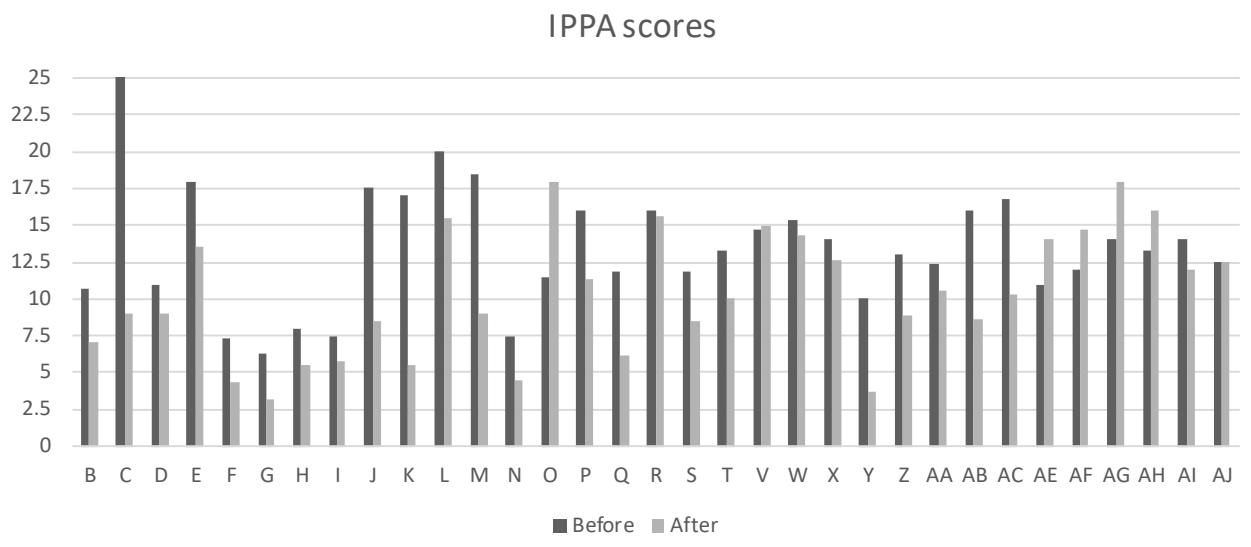

Figure 2 IPPA scores before and after the ZORA based intervention sessions for each child

The goals that were established by the professionals were categorised into the domains 'movement skills', 'communication skills' and 'cognitive skills'. However, some goals could not be categorised into these three domains. These goals all turned out to be related to attention, motivation and concentration. Therefore, an additional domain could be identified and was named: attention. In table 4 the average of the mean differences (corrected for child), standard deviations and ranges of the scores within the four different domains are displayed. These mean differences show a decrease in the difficulty of reaching a certain goal, which indicates a positive contribution to the achievement of goals. The highest mean differences were those for the domains of movement skills and communication skills. 
Table 4 IPPA scores categorised for the four domains

\begin{tabular}{lllll}
\hline Domain & Mean difference & SD & Minimum & Maximum \\
\hline Movement skills & 4.50 & 5.58 & -6 & 20 \\
Communication skills & 3.47 & 5.56 & -5 & 15 \\
Cognitive skills & 1.56 & 4.72 & -8 & 9 \\
Attention & 2.79 & 2.06 & -0.33 & 6.33 \\
\hline
\end{tabular}

In addition, it is possible that either group sessions or individual sessions are more 'successful' at achieving decreases in IPPA scores. When comparing the results of children participating in the group sessions to the results of children participating in the individual sessions (using figure 2), no relevant difference can be observed between the two conditions. Both increases and decreases can be seen in the scores of the children in group sessions as well as in the scores of the children in individual sessions.

Playfulness and children's feelings about the sessions.

Table 5 shows the scores that were given concerning playfulness using the visual analogue playfulness scale (0-10) for the six sessions. The maximum playfulness score that was awarded across all sessions was 9 and the minimum score was 0 . The average playfulness score across all sessions was 7.5. According to the professionals, children mostly liked playing with ZORA during the sessions. Based on the fact that children frequently indicated the 'like' smiley after a session, it can be concluded that 93\% of children felt positive about the ZORA-based intervention sessions ( $n=159)$.

Table 5 Descriptives of the playfulness scores

\begin{tabular}{llllll}
\hline Session & N & Minimum & Maximum & Mean & SD \\
\hline 1 & 28 & 3 & 9 & 7.34 & 1.38 \\
2 & 30 & 0 & 9 & 7.02 & 2.03 \\
3 & 24 & 6 & 8.5 & 7.71 & 0.72 \\
4 & 25 & 3 & 9 & 7.50 & 1.43 \\
5 & 31 & 6 & 9 & 7.89 & 0.94 \\
6 & 28 & 5 & 10 & 7.66 & 1.25 \\
\hline
\end{tabular}

\section{Unplanned circumstances/issues during sessions}

The notes that were made by the professionals in each session about the general wellbeing/health of the children and about unforeseen or unplanned issues/circumstances that might influence the session, were clustered into three themes: participation of the child, functionalities of ZORA, and environmental factors. Some examples of notes on occurrences belonging to the first theme are "participation is very good and increases when ZORA mentioned the name of the child", "after some sessions focus on ZORA increases", "participation increases with ZORA", "child seems to be annoyed and participation decreases with time". Notes on the functionalities of ZORA included "ZORA 
distracts the child from the actual task in a negative way", "child needs new scenarios/features to stay focused", child gives varying responses to ZORA, sometimes laughing and very happy; sometimes sad", "session cancelled because ZORA wasn't functioning (properly)".And concerning environmental factors, the professionals mentioned things such as "child was distracted by people close by", "temperature was very high, which influenced the wellbeing of the child in a negative way", "ZORA is speaking too fast".

\section{Qualitative outcomes}

The video-stimulated recall interviews lead to relevant results on a number of topics (the role of the robot, conditions to work with ZORA independently, target groups that might benefit from working with ZORA, goals ZORA can help achieve, ZORA's influence on attention, and how ZORA interventions compare to regular therapy/education). In the following paragraphs the main findings on each of these topics are described.

\section{The role of the robot in the fragments}

During the recall interviews various roles that can be ascribed to ZORA came up. The professionals mentioned that ZORA could be used as an instructor, a motivator, a (co)therapist, a rewarder, a buddy, an interlocutor/intermediate, as a tool during movement exercises, as support, as an example, and in a comforting role.

The role for which ZORA was most suitable, which was also the role that was identified as being most effective by all professionals, was the role of motivator. Most of the professionals also mentioned the role of rewarder in relation to ZORA. Some other professionals also mentioned the role of instructor (imitation) as most suitable role. Although it technically does not say anything about the role of the robot, it is worth mentioning that most of the participating professionals experienced their own role as difficult at times. They often responded too fast, even though they felt that they should wait for the response of ZORA, which was sometimes delayed. In an effort to deal with this issue, professionals experimented with finding the right balance between supporting the child and waiting for ZORA's response.

\section{Conditions necessary to work with ZORA independently}

A number of points were made concerning what is required to successfully work with ZORA independently in the future. With regard to the space and location in which the intervention sessions take place, professionals indicated that the existing therapy rooms or classrooms were suitable for the sessions with ZORA, and that no special rooms were needed. In addition, one of the professionals mentioned that there was a difference between using ZORA on the table and using ZORA on the floor. Using ZORA on the floor felt much more threatening for the youngest children who participated, because these children felt less save without their chair. 
Some professionals indicated that at least two therapists or teachers should be present in a session, to allow working with ZORA independently (without IT assistance), so that one person can control ZORA, while the other works with the child. Others are convinced that they could work with ZORA independently in the future after some training (e.g. a ZORA training course) in using and programming the robot. Furthermore, professionals indicated that more time should be facilitated for training and programming ZORA.

Some professionals suggested that an expert should be available to program the options they suggest into ZORA, as these professionals feel it is not their role to take care of this (more) technical side of working with ZORA. Furthermore, professionals indicated that it is sometimes impossible to respond immediately to the child using ZORA, because there is a delay between giving a command (through, for example, speech) to ZORA and the actual performance by ZORA. One of the occupational therapists participating in our study suggested that ZORA should be able to grab things with its hands, which would make the robot more suitable for occupational therapy related goals. A point that was highlighted by the speech language therapists concerned the intonation of ZORA, which, they indicated, is often unclear or confusing, and should be improved.

\section{Relevant target groups for working with ZORA}

Regarding the question whether the use of ZORA is more or less useful with children with a minimum level of specific kind of skills (whether they be movement skills, cognitive skills, communication skills, or attention/motivation skills), the professionals gave some valuable insights. In their view, ZORA can best be used among children who are able to understand simple instructions from ZORA (cognitive skills). The level of motor skills (e.g. wheelchair or no wheelchair user), however, does not really matter, because important aspects, like the instructions given to the child, can be adapted to the abilities and limitations of the child. Professionals also indicated that children who need to be motivated to move can possibly benefit the most from using ZORA. In addition, it became apparent from the interviews that ZORA can be used for children with autistic characteristics, because of the structure a robot can offer and the option to repeat scenarios exactly the same, again and again with ZORA. Some professionals mentioned that they saw the most possibilities for young children between four and eight years old or two and twelve years old, also depending on their developmental age.

Relevant goals for application of ZORA

Professionals suggested that ZORA is most suitable for helping to achieve goals related to gross motor skills and eliciting communication. For example, ZORA can offer support in the instruction and guidance of imitation of e.g. arm movements, lying on the belly, sitting. And when it comes to communication, ZORA can, amongst others, teach social manners (handshake, saying goodbye etc.) and help children to tell stories. 


\section{Influence of ZORA on attention}

The professionals indicated that most of the children were attracted to ZORA during the six-week session period and that they were able to have and keep their attention on ZORA during the 30 minutes sessions. Some professionals indicated that the attention children had for ZORA was better than the attention the children had for the professionals when they gave instructions or rewards. Some professionals mentioned that the concentration of the children was outstanding, While others mentioned that the level of attention children paid to ZORA differed depending on the way in which ZORA was used. For example, the dances (songs with movement) ZORA performed, were more attractive to most children and got more attention than verbal instructions.

\section{Comparison with regular therapy or education}

When professionals compared ZORA-based intervention sessions with regular therapeutic or educational sessions, they highlighted both positive and beneficial aspects and influences of ZORA as well as negative points and recommendations for improvement of ZORA. One of the positive points that were mentioned was the fact that professionals could let ZORA take over tasks, giving them the opportunity to observe the child, instead of giving instructions. This increased opportunity for observation allowed the professionals, amongst others, to measure the performance of the child on a weekly basis. Professionals also highly appreciated that the sessions were very similar, which was the case because ZORA gives exactly the same instruction every time. Furthermore, professionals mentioned that ZORA was attractive, nice and fascinating for the children as compared to the usual everyday routines of the therapists or teachers. As a result of this attractiveness and fascination, children were, for example, more willing to listen to ZORA than they were willing to listen to their mentors/supervisors in regular sessions, and the level of concentration of the children in sessions with ZORA as compared to their concentration in sessions without ZORA also stood out. As became apparent from the recall interviews, ZORA's interactive dances were experienced by the children as very attractive. Professionals noted that they simplywere not able to perform such dances in a comparable way. Additionally, the professionals said that the size of ZORA was a positive aspect, as it was easier for children to see ZORA as a friend or mate, rather than seeing their teacher or therapist as such, because ZORA is closer in size to that of the child than a teacher's or therapist's size is. Furthermore, ZORA offers the possibility to exclude certain stimuli, for example, only giving a verbal instruction without an accompanying facial expression, which is much more difficult to do for a professional. An aspect of ZORA which professionals indicated as being both positive as well as negative, was the strict structure in the pre-programmed scenarios, which cannot be adapted during a session. This characteristic can be seen as positive because some children prefer and like repetitions and predictability (e.g. with autistic characteristics), and can be seen as negative, since it would be useful if the professionals could adapt scenarios during a session (f.e. when something did not work out as expected or when 
something was too difficult for the child). In addition, professionals gave negative feedback about the fact that the use of the robot in sessions with very severely disabled children is limited, as there are no options for these children to control ZORA (for instance via switches or table commands). Lastly, one child was very afraid of ZORA and this influenced her muscle tension in a negative way.

\section{Discussion and conclusion}

The aim of this study was to examine to what extend individual goals within the domains of movement, communication and cognitive skills can be achieved using robot ZORA and to examine the different roles in which ZORA can be applied in therapeutic and educational sessions for children with severe physical disabilities. The main results of this study indicate that ZORA-based intervention sessions contribute to the achievement of goals of children with severe physical disabilities, especially in the domains of movement skills and communication skills. ZORA may also contribute in the domains of cognitive skills and attention. Out of the different roles in which ZORA can be used, professionals indicate that a role as motivator is most promising. Other roles in which ZORA could make valuable contributions to children's success in achieving their goals are the role of rewarder and instructor. Furthermore, children mostly liked playing with ZORA and the professionals appreciated working with ZORA.

When the results of the present study are compared with studies that used ZORA in the care for elderly people, ZORA also seemed to have an important contribution in the motivational domain, because ZORA stimulated spontaneous participation [2]. This matches with the results of our study with ZORA contributing to attention and the role of ZORA as being a motivator. Apart from ZORA, in rehabilitation and special education more and more innovative technologies are being used and tested. For example the PITS system from the study of Wille et al. (2009) appeared to have high motivated children also over time [7]. This might indicate a positive contribution of innovative technologies to motivation of the children, compared to commonly used interventions.

With respect to the different roles ZORA can fulfil, the insights the professionals in this study described in the recall interviews partly overlap with roles that were described in the literature (which were introduced in the introduction of this paper). The three roles of which the professionals indicated ZORA would be most suited to perform (motivator, rewarder, instructor), were also described by Guiliani and Knoll (2011), and Mubin et al. (2013) [10]. Other roles mentioned in the literature did not come up in the current study as roles ZORA would be suitable to fulfil. This discrepancy might be explained by the fact that ZORA is a so-called social robot and (in its current state) not an assistive robot delivering physical support. In addition, some roles described in the literature (e.g. the passive robot role which allows children to learn things from robots by for example building or programming them) may not fit the specific target popula- 
tion of this study, and were therefore not identified by the professionals.. Furthermore, the roles of assistant, machine, servant and care receiver were not mentioned. These roles are probably more suitable for assistive robots.

When comparing the roles ZORA can be used for to the roles or professional competencies of therapists (occupational therapists, speech language therapists and physiotherapists) and special educators, it becomes clear that the competencies 'giving instructions' and 'motivating' that ZORA performs amongst others, are part of the competence profiles of these professionals[18]. And, although the role 'rewarder' is not specifically described as a competence of the professionals, it is, of course, part of the natural behaviour of professionals working with children. Given the competences of the professionals working with the severely disabled children in this study, it is likely that ZORA might serve as a support or additional tool to fulfil their professional competencies. This idea is further supported by the fact that, when they elaborated on how they would like to use ZORA, professionals seemed to choose roles that are closely related to their own roles, responsibilities and competencies. The range and working experience of the professionals participating may have contributed to a broad range of roles, based on the different backgrounds and experiences of the professionals.

Professionals have many tools, toys and materials at their disposal to match with children's therapeutic and educational goals and match their play preferences. This study aimed to examine if robots and ZORA in particular can add to the repertoire of play and treatment therapeutic or educational materials. This study showed that ZORA can be an attractive, stimulating tool to support play and that ZORA-based interventions can contribute to the achievement of goals in rehabilitation and special education. Robots may offer more variety in play and interventions for the children and professionals and offer them new possibilities regarding control options, communication and interaction which are continuously improving due to ongoing technological advancements. In this explorative phase with ZORA in this context the testing with 33 children provided meaningful insights into contribution of ZORA to reach individual goals in different domains and into different roles of ZORA. Besides on the functionalities of the robots, the success of the robot mainly depends on the way the robot is used in practice. Therefore, the total package of the intervention and the role of the professional should be carefully considered. To limit the chance of creating significant differences in the skill with which ZORA was controlled (which could occur if, for example, technical experts were in charge of ZORA in some sessions and not in charge in other sessions) and thereby possibly skewing the results of this study, the researcher controlled ZORA in all sessions. To be able to realize sustainability in the future it should be arranged that the professionals receive a longer and proper training and instruction to be able to work with ZORA independently and ideally program ZORA themselves. Recommendations for future use also include improvements of technical performance of the robots.

In total, three organisations, 12 professionals and 33 children participated in this study, which makes it a relatively large study in this field of research. And as with any 
study, both large and small, some limitations have to be acknowledged. When interpreting the results of this study, it is important to keep in mind that regular therapy and educational activities continued during the period of the ZORA study. These activities might have influenced the results. For example, in general physical activity lessons they may also have been working on improvement of gross motor skills. During the group sessions, peers also may have influenced the children, particularly during the group sessions. In addition, the use of convenience sampling (via the professionals) means that, despite the inclusion criteria, preferences of the professionals could have influenced the results. They might have selected children for which they thought ZORA could be most beneficial or children of which they expected that they would really like ZORA. As also mentioned in the results section in the registration forms of the sessions some additional aspects were filled in which, according to the professionals, might have influenced the ZORA sessions as well. For example, the study was conducted in summer and the temperature was very high during some of the weeks (also inside the buildings), which might have influenced the alertness or the physical condition of the children.

For future studies, it is recommended to supply robot ZORA to rehabilitation centres and/or schools for special education for a longer time (e.g. 6 months instead of 6 weeks), allowing both children and professionals to work and get properly acquainted with the robot and all of its technical functionalities.. Combined with proper instructions and training sessions in advance, and ICT support during future studies if necessary, it should possible to allow professionals to work with ZORA independently. Research may support practical use and sustainable implementation of robots, by gathering and providing data during a longer research period for example data about the actual frequency of use, the goals they work on with the children, the problems they encounter, and solutions for these problems.. It would be worthwhile to involve managers or policy makers of institutions that work with ZORA in this process, since they play an important role in creating conditions for sustainable implementation of innovations.

This study showed that robot ZORA can be an effective tool to be used in rehabilitation and special education. ZORA in particular, and robots in general, may offer the next generation of play for children with severe physical disabilities. 


\section{References}

1. Rus D. The robots are coming. Foreign Aff 2015; $94: 2$

2. Kort H, Huisman C. Care Robot ZORA in Dutch Nursing Homes; An Evaluation Study. Studies in health technology and informatics 2017; 242:527-534

3. Melkas H, Hennala L, Pekkarinen S, Kyrki V. Human impact assessment of robot implementation in Finnish elderly care. In: International Conference on Serviceology, 2016. pp 202-206

4. van den Heuvel RJ, Lexis MA, de Witte LP. Can the IROMEC robot support play in children with severe physical disabilities? A pilot study. International Journal of Rehabilitation Research 2017; 40 (1):53-59

5. Kronreif G, Prazak B, Mina S, Kornfeld M, Meindl M, Furst M. Playrob-robot-assisted playing for children with severe physical disabilities. International conference on Rehabilitation Robotics, 2005; pp 193-196

6. Kanitkar A, Szturm T, Parmar S, Gandhi DBC, Rempel GR, Restall G, Sharma M, Narayan A, Pandian J, Naik N, Savadatti RR, Kamate MA. The Effectiveness of a Computer Game-Based Rehabilitation Platform for Children With Cerebral Palsy: Protocol for a Randomized Clinical Trial. JMIR Research Protocols 2017; 6 (5):e93

7. Wille D, Eng K, Holper L, Chevrier E, Hauser Y, Kiper D, Pyk P, Schlegel S, Meyer-Heim A. Virtual realitybased paediatric interactive therapy system (PITS) for improvement of arm and hand function in children with motor impairment-a pilot study. Developmental Neurorehabilitation 2009; 12 (1):44-52

8. van den Heuvel RJ, Lexis MA, de Witte LP. Robot ZORA in rehabilitation and special education for children with severe physical disabilities: a pilot study. International Journal of Rehabilitation Research 2017; 40(4): 353-359

9. Giuliani $M$, Knoll A. Evaluating supportive and instructive robot roles in human-robot interaction. In: International Conference on Social Robotics, 2011; Springer, pp 193-203

10. Mubin O, Stevens CJ, Shahid S, Al Mahmud A, Dong J-J A. review of the applicability of robots in education. Journal of Technology in Education and Learning 2013; 1:209-0015

11. Dautenhahn K. Roles and functions of robots in human society: implications from research in autism therapy. Robotica 2003; 21 (4):443-452

12. Dautenhahn K, Woods S, Kaouri C, Walters ML, Koay KL, Werry I. What is a robot companion-friend, assistant or butler? International Conference on Intelligent Robots and Systems, 2005; pp 1192-1197

13. Etikan I, Musa SA, Alkassim RS. Comparison of convenience sampling and purposive sampling. American Journal of Theoretical and Applied Statistics 2016; 5 (1):1-4

14. Wessels R, Persson J, Lorentsen $\varnothing$, Andrich R, Ferrario M, Oortwijn W, VanBeekum T, Brodin H, de Witte L. IPPA: Individually prioritised problem assessment. Technology and Disability 2002; 14 (3):141-145

15. SPSS. IBM SPSS statistics 22. Algorithms Chicago: IBM SPSS Inc; 2013.

16. Hsieh H-F, Shannon SE. Three approaches to qualitative content analysis. Qualitative health research 2005; 15 (9):1277-1288

17. Palisano R, Rosenbaum P, Bartlett D, Livingston M, Walter S, Russell D. GMFCS-E \& R: Gross Motor Function Classification System expanded and revised. Can Child Centre for Childhood Disability Research 2007; $1-4$

18. Verhoef J, Zalmstra A Beroepscompetenties ergotherapie: een toekomstgerichte beschrijving van het gewenste eindniveau van de opleiding tot ergotherapeut. Boom Lemma Uitgevers, Den Haag; 2013. 

Chapter 7

General discussion 

The main objective of this dissertation was to explore and examine the contribution robots can give when it comes to supporting play and achieving therapeutic and educational goals in children with severe physical disabilities. First, a systematic literature review was performed to create an overview of the aims, control options and commercial availability of ICT and robots to support play in children with severe physical disabilities. Second, together with professionals and parents an overview was created of goals for children with physical disabilities and the potential of robots (specifically IROMEC) to support these goals. After this mainly qualitative exploration, a pilot study with robot IROMEC was conducted in rehabilitation and special education practice, and the experiences with and contribution of the robot were evaluated using both quantitative and qualitative outcome measures. Based on the results of this pilot study, which indicated serious technical limitations, the decision was made to continue the research with robot ZORA, a commercially available robot. To explore the potential of ZORA, a pilot study was performed and subsequently a larger study with ZORA was conducted to collect more detailed information about the contribution of ZORA to the achievement of therapeutic and educational goals and to discover which roles professionals attribute to ZORA.

\section{Main findings}

Based on the results of the studies, it can be concluded that robots showed promising and meaningful contributions to support play and to achieving goals in both rehabilitation and special education for children with severe physical disabilities. This offers new chances and possibilities for the children to play and perform meaningful activities as well as for the professionals and the parents of the children. For all people involved playing and working with robots resulted in a lot of fun and nice experiences. Notwithstanding the functionalities the robots already offered, many inspiring and meaningful suggestions for improvements and innovation, as well as comments, were made. This section offers a summary of the main findings of the conducted studies.

\section{ICT and robots to support play for children with severe physical disabilities}

Because of the importance of play for the development of a child and the difficulties children with physical disabilities experience with play, the literature was studied systematically to discover technologies which might offer solutions for this target group [1]. Analysis of 61 scientific publications led to a total of 27 different technologies being distinguished. Three main groups of technologies could be identified: robots, virtual reality systems and computer systems (without virtual reality). The majority of the technologies was developed to achieve a specific goal or solve a specific problem. Some systems were developed to tackle more than one goal or problem, and others were 
developed for play for play's sake. Most of the technologies developed and used for play for play's sake are robots. A variety of control options (such as joysticks, switches and a sensing glove), is used to give the user the opportunity to operate the technologies. Although most of the technologies only offer one control option, offering more control options may increase the accessibility of the system [2]. In addition, it is noteworthy that the commercial availability of the different technologies is low, making it hard or even impossible for professionals, parents or children to use these products in settings which are not related to research.

More promising robots and technologies which are worthwhile to explore for children with severe physical disabilities, became commercially available while this study was being conducted. Within the LUDI network a database has been created to gain insight into the availability of toys and technologies to support play for children with disabilities and the research conducted with these toys and technologies (http://ludi.utad.pt/). This database also gives more insight into new developments and technologies. ZORA is one of the robots that were not commercially available at the start of our study. It received a lot of media attention when it was launched on the Dutch market in 2014, and was included in this study as its functionalities and attractive appearance seemed to make it worthwhile to study in more detail.

\section{Therapeutic and educational goals for children with severe physical disabilities and application of robots}

Relevant goals for children with severe physical disabilities related to the domains of the ICF-CY were selected, and the most promising domains for application of robots (especially the IROMEC robot) were identified in close collaboration with the professionals. The domains of movement functions, learning and applying knowledge, communication/interpersonal interactions and relationships, and engagement in play were the most promising for (testing) the application of robots according to the professionals' opinion [3]. These are all domains in the ICF-CY, commonly used in the context of rehabilitation and special education when working with this specific target group [4]. In addition to identifying the domains this study looks at, the improvements that were required in order for the robots to be used in practice were highlighted. This included not only improvements relating to the robots themselves, but also adjustments and requirements relating to the professionals working with the robots and to the environment in which the robots would be used in general. This information may serve as input for designers in the field of robotics to help them develop the best robots possible (in terms of meaningfulness and functionalities) for this specific target group.

\section{Convincing results of robots applied in rehabilitation and special education}

To explore the potential of robots in supporting play and therapeutic or educational goals, two different robotic platforms (IROMEC and ZORA) were tested in rehabilitation 
and special education settings. Professionals were very enthusiastic about the functional possibilities of both platforms, and the children who participated also responded very positively. Meeting the robots almost always resulted in smiles on their faces and spontaneous interaction with the robot in question. ZORA, in particular, elicited great enthusiasm from the children as well as the professionals. During the different studies several assessment tools were used to examine relevant outcomes. The Individually Prioritized Problem Assessment (IPPA) instrument was for example used to see if the individual goals for the children could be reached during the robot based interventions. For both robotic platforms, a significant contribution of the robotic interventions to the achievement of individual goals could be identified. These are very relevant and promising outcomes for actual application of these robot interventions in these settings. These results provide professionals with meaningful innovative tools and ideas for application in their daily work with this target population. Besides meaningful application of the robots, professionals indicated that technical stability and possibilities to adapt or extend the platforms are of equal importance $[5,6]$. For this reason the first part of our study was focused on IROMEC, but due to technical limitations the study was proceeded with robot ZORA, which is commercially available and distributed by a company located in the Netherlands which is able to deliver support and maintenance if necessary.

In the pilot study conducted with ZORA, three main domains for meaningful application were identified: improvement of movement skills, improvement of communication skills and improvement of cognitive skills. Furthermore, a fourth domain related to all three of these domains, in which the professionals were very convinced the robot could have added value, was identified and defined as attention/motivation/concentration.

When evaluating the contribution of the robot to the different domains, the largest improvement was found within the domains of movement skills and communication skills. Furthermore, different roles could be identified which the professionals gave ZORA during the intervention. According to the professionals, the most promising roles of the robot were the role of motivator, instructor and rewarder. The roles of robots that were identified by this study, were found in the analysis of the use of the ZORA robot specifically. However, these findings can, offer more insight into the possibilities and roles of social robots for children with severe physical disabilities in a broader perspective. Based on the results of our studies, both IROMEC and ZORA have some challenging technical issues. In addition, they offer limited control possibilities, which as described in the literature study [1], makes them less accessible than if they would offer a variety of control options (joystick, switches, etc.). This is especially the case given the target group this study focusses on. Professionals were very enthusiastic about robot ZORA, and did not mention limitations, such as limited control options, for the children related to the use of ZORA. 


\section{IROMEC and ZORA placed in broader perspective}

The findings of our study are in line with other studies in the field of robots and technology in care. As mentioned in the chapters before other studies using robots IROMEC and ZORA showed promising results in children with different kinds of disabilities [7-9]. Other studies on robots for children with severe physical disabilities also show positive and promising results. The assistive robotic prototype CPwalker, for example, which was created to support children with cerebral palsy in their rehabilitation gait training [10] as well as several socially assistive robots encouraging the children in motor training and increasing their interest in therapy [11]. Encarnação and Cook (2017) described several examples of socially assistive robots (SARs) for children with complex disabilities and present recommendations for the design of robots for children with autism spectrum disorder (ASD) as well as for children with cerebral palsy. For example adaptability of the robot platform was highlighted as an important factor to maintain interaction and to provide the best therapeutic experience for the child (12). Adaptability also came up as important in our studies, the ability to individually customize the robot is important when using technology/robots for professionals to be able to work on individual goals. Furthermore, Encarnação and Cook also described the rapid improvements in sensors, actuators and processing capabilities, which are promising developments increasing the potential of SARs for children with ASD and other complex disabilities [12]. Preliminary results from tests in which children with ASD interact with robot NAO indicate that interacting with a humanoid robot facilitates engagement and goals achievement in educational activities [13]. This matches with our results that show the robots have added value when it comes to the achievement of goals and especially when it comes to the increase of motivation/attention/concentration.

Aside from studies concerning the use of robots in the care and rehabilitation of children with disabilities, findings of other studies in the field of robots and technology used in care are also in line with the findings of our study. For example, in their studies about service robots for older adults, Bedaf et al. (2017) concluded that these robots are likely to become a key aspect of the elderly care domain, and that the elderly are open to the idea of a robot [14]. The professionals as well as the children that participated in our study were also open to the idea of working and playing with the robot and liked working with it very much. The rapid current technological developments suggest that there will likely be a more prominent role for robots in the field of rehabilitation and special education in the future. With regard to innovations in elderly care, robotics seal PARO showed to be effective in interventions in intramural psychogeriatric care when aiming at a therapeutic effect (e.g. at the onset of a targeted behaviour) [15]. Robot PARO was also tested with people with severe intellectual disabilities. Although this did not show any effect on the alertness and/or mood of the participants, it was noted that positive interactions with the PARO robot could be of therapeutic value in themselves [16]. Robot ZORA is also being used in elderly care, because a study con- 
ducted in elderly care in Finland showed there was potential for success if it was used in elderly rehabilitation [17]. ZORA also showed promising results in elderly care in the Netherlands: it had a positive influence on clients and staff and the participating organizations saw the potential of ZORA [18].

Overall, both previous studies and the study described in this dissertation clearly demonstrate the large potential of using robots in different areas of health care and for different target groups.

\section{Methodological considerations}

Besides the limitations of the studies that were described in chapters 2 to 6 , there were three general methodological considerations. The first one was the complexity of the target group of our study, being severely physically disabled and often also having cognitive impairments. The second one was the difficulty of measuring outcomes and the difficulty professionals experienced during the goal setting process. The third methodological consideration was related to the user-centred design used for the development of IROMEC.

\section{Target group and context}

Initially the target group of our study consisted of children with severe physical disabilities. Because of the context of special education and rehabilitation in the Netherlands, it was decided not to exclude children with cognitive impairments. Therefore, many of the children who participated in this study had cognitive or behavioural problems in addition to their physical disabilities. In other words, participants were often children with multiple disabilities. Children who only have a physical disability are increasingly attending mainstream education in the Netherlands, because of the introduction of the Act on inclusive education in 2014, which states that children attend regular education if possible, and that schools have a duty of care and give the child a suitable education place [19]. Including children with multiple disabilities as well makes the results of our study more generalizable for the rehabilitation and special education context in the Netherlands and abroad.

Children were included in the studies according to the predefined in- and exclusion criteria, which resulted in a population of children of different (actual) ages and developmental ages between approximately 2 and 8 years old. The developmental age is based on the experience and background information provided by the professionals, but may differ within the different domains of development. For example, a child can cognitively be 3 years old, while being 6 years old in a social-emotional sense. This can make it difficult to correctly interpret the results of the conducted studies: when the interventions show a limited effect or no effect, is it due to the physical or due to the 
cognitive and/or developmental problems of the child? Moreover, other factors such as the intervention or the role of the professional during the intervention may have influenced the results. According to the literature it is likely that the professional (e.g. paediatric rehabilitation therapist) plays an important role in client outcomes [20]. However, despite these considerations, our study overall shows a positive contribution of the robotic interventions for this target group, which means that robots actually contribute to rehabilitation and special education for children with physical disabilities, as well as those with multiple disabilities (physical and cognitive).

\section{Measurement of outcomes and goal setting}

The mixed methods used in our study in which qualitative and quantitative tools were combined give insight into the contribution of robots for children with severe physical disabilities from different perspectives. Especially the qualitative data give detailed insights into the professionals' view on the introduction of robots in this field and on the possibilities of these robots. However, using the IPPA instrument to measure the contribution robots make to reaching goals, appeared to be a challenge for the professionals. Most of the professionals indicated that setting goals before the start of the studies was difficult. There are two reasons that might explain this response. Firstly, the complexity of the target group (that was discussed in the previous paragraph) makes it difficult to set goals for a relatively short period of 3 or 6 weeks. Perhaps, due to the children's cognitive level it would also be impossible to reach the goal using different materials than a robot. Complexity of the child's goals or problem and impairments in development of the children could have played a role in not reaching the predefined goal. Secondly, the unfamiliarity of the professionals in working with the robot platforms and interventions may have contributed to the difficulty of setting realistic goals for the period and of estimating beforehand what will work for a child or how a child would respond.

Regarding the content of the goals established (Chapter 3 ) it is remarkable that the professionals indicated 'play' as one of the main domains for the children and also with large potential for the application of robots (IROMEC). While, in chapters 4, 5 and 6 professionals did not set play as a goal for the children using the IPPA instrument. It seemed in the context of rehabilitation and special education that play is a means to achieve other goals (play-like activities), and that play for play's sake hardly occurs. The distinction between play for play's sake and play-like activities is discussed in more detail in the section about theoretical considerations.

Overall a positive contribution of the robots to reaching individual goals in therapy and special education could be identified. However, looking into the contribution of the robots in more detail there sometimes seems to be a discrepancy between the results acquired through the IPPA instrument and the information acquired in the interviews about the enthusiasm about and estimation of the contribution of the robot. It may be 
that the selected measurement instruments which were used in our study were not suitable or sensitive enough to 'catch' or 'measure' the actual added value or contribution of ZORA. ZORA elicited responses which we did not measure, for example enthusiasm, motivation, smiling of the children and others, which were very relevant outcomes according to the professionals. In other studies, such as the study by Luyten et al. (2018), examples are available of (verbal and non-verbal) responses of humans when they come into contact with interactive technology. Verbal, physical and emotional/mental responses were identified based on transcription of visible and audible recordings. Human-human and human-technology interactions were coded [21]. In the case of our study, this way of coding could have helped to register and code responses to the robot in a more open way, could have led to more detailed results, and may have more accurately represented the real responses and added value of the robot. Next to this, involving the professionals in the selection of measurement instruments may be useful in future studies.

\section{Design and User-Centred Design (UCD)}

To answer the research questions of this research, explorative designs with mixed methods were used. These designs were relevant to be able to answer the research questions and to reach the aim of the study. Before the robots could be compared to therapy as usual, more insight was needed into the application possibilities and the potential of the robots. To study the effect of the robots and compare for example ZORA with therapy as usual, another study design might be relevant in the future. Because of the heterogeneity and complexity of the target group a longitudinal design with alternating experimental treatment and care as usual conditions ( $A B A B$ design) might be relevant to compare therapy or education with the robot $(A)$ and without the robot (B) on an individual level. Other studies with robots and a complex target group (e.g. elderly) used this design before, and their outcomes suggest that such a design may help to achieve research data and enable us to draw conclusions about the effectiveness and efficacy of the application of a robot compared to other interventions [22].

Furthermore, there is one important difference between the two robotic platforms that the current study focusses on, which might have played an important role in our results. The IROMEC platform is a robot platform developed following the principles of User-Centred Design (UCD), for the target groups children with mild mental retardation, severe motor impairment and children with autism [23]. The current study focusses specifically and in more detail on studying this second sub-group of children with severe motor impairments, because of the promising results found within the European IROMEC project (www.iromec.org). The ZORA platform, on the other hand, was originally not specifically developed for care purposes. The platform, originally created by SoftBank Robotics and known as NAO (https://www.ald.softbankrobotics.com/en), had initially been developed as companion robot. Other companies decided to develop 
tailored software for this robot for use in care, rehabilitation and animation. The development of ZORA could therefore be called a more 'technology-centred approach'. During the development of the software and the improvement of ZORA users were involved. As well as user-centred design developments as technology-centred design developments seemed to have potential according to the results of our study.

Intensive involvement of professionals, children and their parents is a crucial factor in research concerning this target group. Professionals were involved in all the phases of our study, children in chapters 4, 5 and 6 and parents in chapter 3. Unfortunately, parents could only be involved in the first part of our study (chapter 3), because of privacy issues and the fact that (some) schools and rehabilitation centres did not want to make high practical demands of parents for the purpose of our studies. Involvement of parents in this phase might have offered more meaningful results to use alongside the results gained from the input and views of professionals and children. Involving parents in a broader way is therefore recommended for future studies.

\section{Theoretical considerations}

In this section, theoretical considerations regarding play for play's sake, the ICF-CY model and regarding the roles of robots will be discussed.

\section{Play for play's sake}

As described in the methodological considerations, play came up as one of the goals in chapter 3, but was not chosen in the subsequent studies as one of the individual goals for the children. It seems that in practice, professionals commonly use play-like activities according to the definition of LUDI [24], and are not used to applying play for play's sake. This might be influenced by the context they are working in (rehabilitation and special education), and the reporting systems they are obliged to work with. Within the REPD or KinderRAP described in the introduction, there is no prominent place for play for play's sake, and the professionals are used to working in a very goal-oriented way based on the framework of ICF-CY, in which play has a relatively small role [24]. This makes it more difficult to achieve LUDI's recommendation to encourage play for play's sake in this context. In addition, professionals mentioned that they are afraid they cannot justify play for play's sake meaning play just for fun to parents, colleagues and others. The concept of play for play's sake can also be related to the research of Heah et al. (2007) about successful participation of children with physical disabilities. Children with physical disabilities experience successful participation when they have fun, when they feel successful, when they can do things themselves, and when they are with others [25]. This knowledge can be used in the future to make professionals aware of successful participation and how play can be used. Additionally, the fact that the robots were 
pre-programmed could have influenced the decision for play-like activities instead of play for play's sake. Because the robots are programmed and it was determined in advance what would be done during the sessions, there were limited possibilities for professionals and children to show creativity and spontaneity, which likely limited free play and play for play's sake.

Play is a difficult concept to evaluate. Play has different dimensions, and can be defined in a lot of different ways, which makes it hard to assess. There is no golden standard for the assessment of play. LUDI distinguished play assessment tools, and playbased assessment tools. Play assessment tools focus on the child and the child's interaction with its environment, while play-based assessment tools focus more on the evaluation of particular developmental skills (linked with the play-like activities as described in the introduction) [26]. For the assessment of playfulness, which was the main interest in this study, there we no appropriate assessment tools available. For this reason the decision was made to use a visual analogue scale (0-10) and evaluate playfulness from the professionals' perspective.

\section{ICF-CY domains}

The ICF-CY framework was used in this study, because it is a commonly used framework in rehabilitation and special education. Goals were categorized according to the domains of the ICF-CY [4], which makes the results more general and transferable to other contexts or other children with disabilities. Setting goals within the domains of the ICF$\mathrm{CY}$ which were selected beforehand, was not as easy as expected. Professionals indicated that it was hard to set specific goals on an individual level. Professionals seemed to overestimate their goal setting skills, while they are used to formulating goals SMART (specific, measurable, attainable, realistic and time-bound). In practice, perhaps because of the use of unfamiliar technology (robots), the goal setting was not easy and the professionals indicated afterwards that the goals they formulated may not have been the most suitable ones. Two modifications in the study protocol may therefore lead to improved goal setting. Firstly, professionals should be better trained in goal setting, for example using the social cognitive theory, goal setting theory and the health action process approach as described by Scobbe et al. in 2009 [27]. Based on these theories, the insights of the professionals into goal setting and the importance of formulation of SMART goals may improve their goal setting skills. Secondly, more and longer introduction to and training with the robots and get familiar using the robots for a longer period may help the professionals to set better goals matching the child's specific characteristics and (developmental) age as well as with the possibilities of the robot. One introduction session is probably not enough to allow professionals, who are completely unfamiliar with the technical and functional options of robotic platforms, to discover the potential and opportunities they offer. The difficulty of professionals in goal setting, could 
have influenced our results. For example, a longer period working with the robot and setting goals for a longer period, could have led to other outcomes.

\section{Roles of robots}

The robots ZORA and IROMEC, which were used in this study, can both be defined as socially assistive robots (SAR). At the International Conference of Rehabilitation Robotics in 2005 the definition of SAR was established as the intersection of assistive robotics (AR) and socially interactive robotics (SIR) [28]. SAR shares with assistive robotics the aim to provide assistance to the user, but this assistance is through social interaction. Because of the focus on social interaction, SAR has a similar focus as SIR, but in SIR the aim is to develop close and effective interactions for the sake of interaction itself. With SAR, the aim is to create close and effective interaction with the user for the purpose of giving assistance, and achieving measurable progress (in e.g. rehabilitation and learning). Based on the results in chapter 6 it can be concluded that for robot ZORA the most suitable roles for application were the role of motivator, instructor and rewarder. In the literature, additional roles for robots were described, for example the role of butler [29]. When having a closer look at the definition of SAR, the roles which we found match with this definition and also focus on interaction with the purpose of assisting the user and achieving progress.

\section{Recommendations}

As already briefly indicated earlier, it is recommended to conduct future research with robots for children with severe physical disabilities using an experimental design, for example an $A B A B$ design, to be able to compare sessions with and without robots and study the difference. Such studies would be able to show the effectiveness of robots compared to care or education as usual. Furthermore, in order to observe the interaction and unique responses to the robotic platforms, other outcome measurements, for example those based on video analysis, should be used.

It is crucial to continue the development of robots for children with severe physical disabilities in close collaboration with professionals, children and their parents, based on the principles of UCD. UCD makes technologies safer, more usable and more patientcentred [30]. Investigation in user-centred design of robots during all stages of the development of the robots will lead to an increase of successful interventions with robots. In addition, professionals will show an increase in enthusiasm and cooperation when they can be involved in the design and development of robots and when they can use the robotic interventions they are really looking for.

For practice, it is recommended to invest in instruction and training, as well as implementation of knowledge in education regarding robots and new technologies. Pro- 
fessionals should be prepared for the upcoming role of technology and robots in their jobs, and incorporating these topics into training and education will probably influence their attitude towards working with innovative technology. The train-the-trainer principle would be a meaningful tool in this endeavour, as key users in the organization could be trained first, to then go on to train their colleagues. A user manual, comparable to the one that was developed for the PARO seal robot, combined with an online training course would be useful [31]. Furthermore, professionals should be trained in goal setting processes which may help to set realistic and SMART goals in the future. Setting realistic and SMART goals may also lead to better insights into the contribution robots can bring to reaching these goals. Aside from training professionals in goal setting, it would also be meaningful to train them in the application of robots and in evaluating the contribution of robots to achieving the goals that have been set. Next to the recommendations for optimizing rehabilitation and education practice, it can be recommended for the developers of robots to invest in the development of a stable platform and in the improvement of the functionalities of the platform, before implementation on a larger scale is considered.

Even though evidence for application of robots in rehabilitation and special education is still limited, the potential and contribution possibilities are evident and should be emphasized by policymakers and health insurers, to open up possibilities to study the application of technology in the sector or rehabilitation and special education. Rehabilitation and special education organizations should, for example, have the freedom to spend a certain amount of 'innovation' budget based on their own preferences and experiences, to be able to come up with new innovations and to aim for implementation and sustainable use.

\section{General conclusion}

Based on the results of this research, it can be concluded that socially assistive robots offer a convincing, promising and meaningful new possibility for children with severe physical disabilities. More research is still needed to discover the effectiveness of robots and ascertain application opportunities in more detail. However, it is evident that professionals and children are enthusiastic about robot applications and that robots can offer the next generation of play in rehabilitation and special education, whether be play for play's sake of play-like activities. 


\section{References}

1. van den Heuvel RJ, Lexis MA, Gelderblom GJ, Jansens RM, de Witte LP. Robots and ICT to support play in children with severe physical disabilities: a systematic review. Disability and Rehabilitation: Assistive Technology. 2016;11(2):103-16.

2. Jones M, Trapp T, Jones N, Brooks D, Howard AM, editors. Engaging children with severe physical disabilities via teleoperated control of a robot piano player. Proceedings of the 12th International ACM SIGACCESS Conference on Computers and Accessibility; 2010.

3. van den Heuvel RJ, Lexis MA, Janssens RM, Marti P, de Witte LP. Robots supporting play for children with physical disabilities: exploring the potential of IROMEC. Technology and Disability. 2017;29(3):109-20.

4. World Health Organization. International Classification of Functioning, Disability, and Health: Children \& Youth Version: ICF-CY: World Health Organization; 2007.

5. van den Heuvel RJ, Lexis MA, de Witte LP. Can the IROMEC robot support play in children with severe physical disabilities? A pilot study. International Journal of Rehabilitation Research. 2017;40(1):53-9.

6. van den Heuvel RJ, Lexis MA, de Witte LP. Robot ZORA in rehabilitation and special education for children with severe physical disabilities: a pilot study. International journal of rehabilitation research. 2017;40(4):353.

7. Malik NA, Yussof H, Hanapiah FA, Rahman RAA, Basri HH. Human-Robot Interaction for Children with Cerebral Palsy: Reflection and Suggestion for Interactive Scenario Design. Procedia Computer Science. 2015;76:388-93

8. Besio S, Carnesecchi M, Converti RM. Prompt-fading strategies in robot mediated play sessions. Proceedings of Assistive Technology: From Research to Practice, AAATE. 2013:143-p8.

9. Iacono I, Lehmann H, Marti P, Robins B, Dautenhahn K, editors. Robots as social mediators for children with Autism-A preliminary analysis comparing two different robotic platforms. International conference on Development and Learning (ICDL), IEEE; 2011.

10. Bayón C, Ramirez O, Velasco M, Serrano J, Lara SL, Martinez-Caballero I, et al. Pilot study of a novel robotic platform for gait rehabilitation in children with cerebral palsy. 6th IEEE International Conference on Biomedical Robotics and Biomechatronics (BioRob), IEEE; 2016.

11. Malik NA, Hanapiah FA, Rahman RAA, Yussof H. Emergence of socially assistive robotics in rehabilitation for children with cerebral palsy: A review. International Journal of Advanced Robotic Systems. 2016; 13(3):135.

12. Encarnação P, Cook A. Robotic Assistive Technologies: Principles and Practice: CRC Press; 2017.

13. Desideri L, Negrini M, Cutrone M, Rouame A, Malavasi M, Hoogerwerf E, et al. Exploring the Use of a Humanoid Robot to Engage Children with Autism Spectrum Disorder (ASD). Stud Health Technol Inform. 2017;242:501.

14. Bedaf SM. The future is now: the potential of service robots in elderly care: Maastricht University; 2017.

15. Bemelmans RFJ. A study of the possibilities and effect of assistive robots in the intramural elderly healthcare: Maastricht University; 2015.

16. Wagemaker E, Dekkers TJ, Agelink van Rentergem JA, Volkers KM, Huizenga HM. Advances in Mental Health Care: Five $N=1$ Studies on the Effects of the Robot Seal Paro in Adults With Severe Intellectual Disabilities. Journal of Mental Health Research in Intellectual Disabilities. 2017;10(4):309-20.

17. Melkas H, Hennala L, Pekkarinen S, Kyrki V, editors. Human impact assessment of robot implementation in Finnish elderly care. International Conference on Serviceology; 2016.

18. Kort H, Huisman C. Care Robot ZORA in Dutch Nursing Homes; An Evaluation Study. Stud Health Technol Inform. 2017;242:527-34.

19. Rijksoverheid. Organisatie van het speciaal onderwijs; 2017 [Available from: https://www.rijksoverheid.nl/onderwerpen/passend-onderwijs/speciaal-onderwijs.

20. King $\mathrm{G}$. The role of the therapist in therapeutic change: How knowledge from mental health can inform pediatric rehabilitation. Physical \& occupational therapy in pediatrics. 2017;37(2):121-38. 
21. Luyten T, Braun S, Jamin G, van Hooren S, de Witte L. How nursing home residents with dementia respond to the interactive art installation 'VENSTER': a pilot study. Disability and Rehabilitation: Assistive Technology. 2018;13(1):87-94.

22. Bemelmans R, Gelderblom GJ, Jonker P, de Witte L. Effectiveness of robot paro in intramural psychogeriatric care: A Multicenter Quasi-Experimental Study. Journal of the American Medical Directors Association. 2015;16(11):946-50.

23. Robins B, Dautenhahn K, Ferrari E, Kronreif G, Prazak-Aram B, Marti P, et al. Scenarios of robot-assisted play for children with cognitive and physical disabilities. Interaction Studies. 2012;13(2):189-234.

24. Bulgarelli D, Bianquin N. Conceptual review of play. Play development in children with disabilities De Gruyter, Warsaw. 2016.

25. Heah T, Case T, McGuire B, Law M. Successful participation: The lived experience among children with disabilities. Canadian Journal of Occupational Therapy. 2007;74(1):38-47.

26. Besio S, Bulgarelli D, Stancheva-Popkostadinova V. Evaluation of Children's Play. Tools and Methods. Berlin: De Gruyter Open; in press.

27. Scobbie L, Wyke S, Dixon D. Identifying and applying psychological theory to setting and achieving rehabilitation goals. Clinical Rehabilitation. 2009;23(4):321-33.

28. Feil-Seifer D, Mataric MJ, editors. Defining socially assistive robotics. 9th International Conference on Rehabilitation Robotics ICORR: IEEE; 2005.

29. Dautenhahn K, Woods S, Kaouri C, Walters ML, Koay KL, Werry I, editors. What is a robot companionfriend, assistant or butler? International Conference on Intelligent Robots and Systems, 2005 IEEE/RSJ; 2005.

30. Tippey KG, Weinger MB. User-Centered Design Means Better Patient Care. Biomedical Instrumentation \& Technology. 2017;51(3):220-2.

31. Bemelmans R, Gelderblom GJ. Werkboek PARO. Heerlen: Zuyd Hogeschool; 2011. 

Chapter 8

valorisation 

The work described in this dissertation was part of a larger project called 'Social Robots in Care' (funded by SIA RAAK-PRO). The aim of the overall project was to generate knowledge and expertise about the application of social robots in daily care practice. This chapter describes the actions that have already been taken to disseminate the knowledge that was acquired through the current research and looks at possibilities and emerging opportunities for valorisation.

\section{Innovation in care and education}

Social robots in care are of increasing interest to society. The use of robots can give a new impulse to the fields of healthcare and education. More and more robots are being developed to be used by different target populations, such as elderly people and people and children with disabilities. In the 'Social Robots in Care'-project, three different robots, in different stages of development, were tested within three target groups: children with autism, elderly people with dementia and children with physical disabilities (the target group and part of the project described in this dissertation). In this project, professionals, i.e. therapists and special educators, were involved intensively in order to provide thorough insight into the goals that exist for the target group, and into the potential of the application of the robots IROMEC and ZORA to support play and predetermined goals in rehabilitation and special education. The application of robots in this field is still rather uncommon and innovative. Numerous different materials, tools and toys are nowadays being used to stimulate and activate children with physical disabilities and to make their rehabilitation, learning and playing as successful and attractive as possible.

\section{Relevance for different stakeholders}

Although many (prototype) robots specifically meant for children with physical disabilities have been developed over the past decades, these robots are often still in a developmental stage, being used in a research context and often not commercially available. Not much is known about applying these technologies in daily care practice. The knowledge presented in this dissertation is not only relevant for application of robots IROMEC and ZORA, but may also be useful for other developments in the field of innovative care technology for children with physical disabilities, such as virtual reality, computer games and adapted toys. Because of the possibilities robots offer, that are (partly) described in this dissertation, there is enormous market potential. Different stakeholders in education, research and also in daily care and education practice may benefit from these studies. The potential value of robots (specifically IROMEC and ZORA) and 
the related knowledge is described in the upcoming sections for the different stakeholders.

\section{Children with (severe) physical disabilities and their network}

The research described in this dissertation clearly shows that children like playing with robots, and also demonstrates the potential that robots can have in therapy and special education, especially for children with severe physical disabilities. The output of this study may be helpful to parents in coming up with new creative ideas to stimulate their children and to offer them new play possibilities. Although parents were not intensively involved, the fact their child participated in one of our studies may make parents aware of the potential of technology for the physical as well as emotional well-being of their child. This awareness may influence parents in the opportunities and possibilities they want to realise or use in their home situation. Although these studies focussed on children with physical disabilities who receive treatment or education in rehabilitation centres and special education schools, the results could be translated to the home context as well. Based on the results, parents might want to start using other commercially available technologies with functionalities that are comparable to the IROMEC and/or the ZORA robot e.g. toy robots or computer games.

In the three studies described in chapters 4, 5 and 6 of this dissertation, in total 61 children were involved. These children participated in the robotic play sessions and were also involved in the evaluation by indicating smileys representing their mood after each session. The study results showed that for example ZORA can contribute to movement skills and communication skills of the children. These domains may be also interesting for other target groups, for example children with autism. For children with autism especially the communication skills are interesting and worthwhile to further investigate, because it is known that children with autism often have a special interest in robots and the predictability and repetitions of a robot are preferred by children with autism.

\section{Professionals in rehabilitation and special education}

To make sure that care professionals could use the robotic interventions and that the children could benefit from them, all the interventions with the robots described in chapter 4, 5 and 6 were co-created and thoroughly planned together with all the participating rehabilitation therapists, teachers and/or group leaders, within the possibilities and limitations of the existing platforms. The involved professionals also applied the interventions in practice. In doing so, they not only contributed to the research, but also gained valuable experience in applying robot-based interventions in their therapy or education practices. By intensively involving the professionals they received training and clues to make working with robots easier in the future and to gain guided experience, which may contribute to actual implementation of robots and other care technology in 
the future. Participation of the professionals in this project created numerous meaningful starting points which can be used by the professionals immediately. For example, by participating the professionals gained knowledge and experience of working with robots or new technologies, and this knowledge and experience might be passed on to their peers and colleagues in a natural way and make them aware of the importance of innovation, technology and participating in research. Furthermore, for some of the professionals it was an eye-opener to gain insights into the practice of measuring the achievements of the children. Overall, the professionals adopted an open attitude towards technology and robots which can contribute to application and implementation of technology in the future. These new insights could influence future interventions and measurements conducted by these professionals.

\section{Researchers}

The studies described in this dissertation significantly contributed to the knowledge about the application of robots in rehabilitation and special education. This research gives us insights into essential steps in the development and evaluation process of new technologies, in terms of usability and feasibility, which are prerequisites for performing studies on the effects of these robots in the future. Robots are being developed and commercially available more and more, and create a lot of enthusiasm and new possibilities, also in the field of care and education. Because of this enthusiasm it is important to search for an evidence based foundation for the application of robots. The studies described in this dissertation initiated the first steps into evidence-based research and application of robots IROMEC and ZORA, to check if professionals and children are enthusiastic and if there is evidence that it would be good to continue with the development of robot-based interventions. More research is needed to further investigate the effect of specific interventions with socially assistive robots for children with severe physical disabilities. Useful interventions which were developed from a usercentred perspective proved to be practically applicable and meaningful for daily practice. Involving the end-users intensively led to more commitment to the actual use and acceptance of robots in rehabilitation and special education in specific, and in the field of healthcare in general. Further research is necessary to study the effects of socially assistive robots and specific interventions (e.g. ZORA) for children with severe physical disabilities. Some suggestions for further research are given in the general discussion of this dissertation.

\section{Industry and developers of technology}

The results of the studies described in this dissertation, which indicate the great potential of robots, are of interest to industry and developers of technology, as they are keen to further develop existing technologies for play and create new ones. Insights on, for example, usability and feasibility information about the products may help technology 
developers to improve current products or may be used as input for the development of new technologies. In turn, the (newly developed) robots and other care technologies can make a big difference in the lives of children with severe physical disabilities.

Companies that develop and create social robots should continuously update their products and improve them with new insights, ideas and suggestions directly from the care context. The involvement of robot industry in research as well as in the implementation of robots would be recommended. This involvement may contribute to improvement of robotic interventions. Furthermore, to be able to implement interventions with social robots in a broad field, maintenance and service are extremely important. Which during the studies described in this dissertation was mainly done with students. In addition, to make sure robotic and other technological care interventions are successful, it is important to make sure that the professionals and/or family members who are going to work with them are trained properly, which could be a responsibility of the suppliers of the products.

The author of this dissertation will discuss future steps about the improvement and re-design of robotic interventions with the companies providing robot ZORA. Insights and experiences form this dissertation may contribute to the success of ZORA and may help to improve this social robot for the context of rehabilitation and special education.

\section{Education}

The expertise gained during the studies described in this dissertation has contributed and will continue to contribute to different types of education, for example, the development and evolution of several areas of education; healthcare, social work, pedagogics, technical studies, design education and ICT, but also inter-professional education. The expertise from our studies contributes to the continuous innovation of education and to an optimal connection with the needs that exist in care practice. First of all, several bachelor students had the possibility to participate in the studies (in the form of an internship or graduation project or as job student), and, as such, got the opportunity to gain expertise in the field of social robots in the context of rehabilitation and special education. Furthermore, the insights gained from this research were used to develop modules for different levels of education (such as vocational education and bachelor education) for the departments of healthcare and engineering. For example, it is important for engineering students to learn about and understand the context of healthcare and to see what technology might offer to this domain. In addition to the knowledge integrated in the different modules of curricula, numerous workshops, lectures and demonstrations were conducted for national and international audiences, students and healthcare professionals, to achieve broad dissemination of knowledge. The results of this research do not only contribute to regular education, but have also been used to develop training sessions for the professionals involved in the studies. These training sessions were developed to get the professionals acquainted with the 
robot and to learn how to work with it using a role play. Because knowledge about care technology, and especially robotics, is crucial for current (and future) healthcare professionals, there is a large potential for educational institutions to invest in courses on this topic for students as well as for education of professionals who are life-long learners. Different educational programmes on different levels in the area of healthcare, education and technology, may benefit from the knowledge and expertise gained in this field.

\section{Exposure Activities}

Next to education, the most obvious valorisation activity performed during the project which is still ongoing is to present the results to national and international research and professional communities. Studies presented in this dissertation have been published in or submitted to international peer-reviewed journals. Furthermore, the dissemination of results took place via posters, presentations, and workshops at international and national conferences on various topics related to technology in care (assistive technology, robots in care). The project members of the 'Social Robots in Care'-project wrote a Dutch booklet containing the outcomes of the project as well as their (and other participants') experiences during the project. The booklet was written for those who participated in the project, but also for educational and dissemination purposes. The project gained a lot of interest from researchers all over the world, and from health professionals in the Netherlands and abroad working on similar topics. Because of the fast progress in technological developments, attention for the implementation of new technologies and for the knowledge and expertise that is accumulated about them in practice and education is crucial. 

Summary 

Play is of crucial importance for the development of a child. As a result of their disabilities, children who have them can experience problems when engaging in play. Especially children with severe physical disabilities may experience difficulties in for example manipulating toys or accessing playgrounds and they often need assistance while playing. Play activities may be partially or entirely impossible for children them. New developments in the field of technology and ICT create new opportunities. These new developments can improve the play possibilities for children with severe physical disabilities. Now that developments in the field of robotics in healthcare and education are being specifically catered to people with disabilities in general, and children with disabilities in specific, is it important (and relevant) to study the usability, feasibility and potential of (the use of) robots for children with severe physical disabilities. This dissertation presents a number of studies concerning social robots for children with severe physical disabilities.

\section{Chapter 1}

In this chapter the concepts and studies that are used in this dissertation are introduced. Information is provided about the difference between play-like activities and play for play's sake. Furthermore, the importance of play for the development of all children and for the (target group) children with severe physical disabilities is explained. In addition, the possibilities of technology for children with disabilities, and the environment in which (and regulations under which) rehabilitation and special education are practised are described. The robots IROMEC and ZORA are described in more detail. At the end of this chapter the objectives of the study and outline of the dissertation are presented.

\section{Chapter 2}

Chapter 2 provides an extensive systematic literature review of recent developments and studies in the field of ICT and robots, specifically when it comes to supporting play in children with severe physical disabilities. A literature search was conducted in the databases CINAHL, PubMed, ERIC and IEEE. The search query was composed according to the PICO structure and a secondary search was executed using reference lists, Google Scholar, and conference proceedings of key conferences in the field. Titles and abstracts were assessed independently by three reviewers. 61 publications were included in the review, which together report on 27 different technologies; eight robots, fifteen virtual reality systems (six using force/touch feedback, nine being screen-based) and four computer systems. Five of these 27 technologies (mostly robots), described the aim of play for play's sake, the other technologies were developed as a means to work on a specific 
goal or problem using play-like activities. A wide range of control options was identified, however, most of the technologies seem to have only one control option. Furthermore, the commercial availability of the technologies was (generally) low, which makes it impossible for parents, therapists or special educators to buy and work with these products.

\section{Chapter 3}

This chapter details the examination into the possibilities of using the IROMEC robot in rehabilitation and special education for children with severe physical disabilities. The examination was done using a mixed methods approach, combining the results of interviews with individuals, two rounds of focus group interviews, a questionnaire and a final session/final sessions to reach consensus. Experts in the field of rehabilitation and special education for children with physical disabilities were involved in the examination. An inventory was made of the goals in therapy and special education for children with severe physical disabilities and an assessment was made of whether these goals can be achieved with the possibilities the IROMEC robot offers. Professionals saw potential in the existing IROMEC play scenarios, especially in the domains of movement functions, learning and applying knowledge, communication/interpersonal interaction and relationships and play. In addition, many suggestions were given for the improvement of the robot as well as for new applications of the robot. The most important suggestions can be divided into three categories: suggestions concerning aspects related to the robot, suggestions concerning the context of the intervention and suggestions concerning the role of the professional. The study described in this chapter provides more insight into application possibilities of robots, especially IROMEC, in rehabilitation and special education for children with severe physical disabilities.

\section{Chapter 4}

This chapter discusses the two-month pilot study that was done to explore the application of the IROMEC robot to support children with severe physical disabilities with (their) play. The participants in the pilot study were 11 children with a physical disability and a developmental age between 2 and 8 years old, and they each had six sessions with the robot. A combination of qualitative and quantitative outcome measures was used to collect data on aspects of feasibility, usability, barriers for the child as well as the therapist and to get an indication of the effect of the robotic intervention on playfulness and on the achievement of therapeutic and educational goals. Individually Prioritized Problem Assessment (IPPA) scores indicated a positive contribution of the IROMEC robot to the achievement the children's goals. In addition, professionals men- 
tioned several meaningful application possibilities during qualitative interviews. Unfortunately, the lack of adaptability, expandability and technical stability of the platform make it impossible to use the robot in daily practice of rehabilitation and special education.

\section{Chapter 5}

Chapter 5 focuses on the ZORA-robot, and explains the two-centre explorative pilot study that was carried out to explore the potential of a ZORA-robot-based intervention in rehabilitation and special education for children with severe physical disabilities. During a 2.5-month period, 17 children with severe physical disabilities and a developmental age between 2 and 8 years old were involved. The children participated in six group sessions or individual sessions with the ZORA robot. Seven professionals, who are intensively involved in the rehabilitation or education of these children also participated in this study. Qualitative and quantitative data were collected on aspects of feasibility, usability, barriers and facilitators for the child as well as the therapist, and to get an indication of the effect of the robotic intervention on playfulness and the achievement of goals. The results of the study show a positive contribution of ZORA to the achievement of both of these kinds of goals. Furthermore, professionals indicated that the children showed playful behaviour (mean 6.8-7.6, on a scale of 0-10) during the sessions. Where possible, children were also given the opportunity to indicate their feelings about the robot and their interaction with it after each session. This was done by allowing the children to refer to a particular smiley that indicated the extent to which they liked the experience. Out of the 60 sessions that were 'assessed' by children, 58 sessions were liked, one score was doubtful, and the score for one session was missing. The participating professionals indicated three main domains for application of the ZORA robot they saw as being most promising: movement skills, communication skills and cognitive skills. In addition, ZORA could contribute to the overall goals of eliciting motivation, increasing concentration, encouraging children to taking initiative and improving their attention span. Based on both the quantitative and qualitative outcomes of this study, it can be concluded that ZORA has potential in therapy and special education for children with severe physical disabilities. However, more research is needed to gain insight into how ZORA can best be applied in rehabilitation and special education environments.

\section{Chapter 6}

This chapter focuses the set-up and results of a second study concerning robot ZORA. This study is an examination into the contribution of ZORA to the achievement of thera- 
peutic and educational goals. The examination also aims at discovering which roles professionals attribute to ZORA. The study uses a mixed methods approach and was conducted among children with severe physical disabilities, in multiple rehabilitation and special education environments. Over a period of six weeks, children played with ZORA six times in either individual or group sessions. Chapter 6 describes our study to examine the contribution of ZORA to the achievement of therapeutic and educational goals, and to discover the roles professionals attribute to ZORA. A multi-centre mixed methods study was conducted among children with severe physical disabilities in rehabilitation and special education. Professionals (therapists and teachers) attended a training session to explore and try out ZORA and its possibilities. During these training sessions they decided for which goals they would like to apply ZORA and a specific scenario was designed in cooperation with the researcher and IT expert. Professionals were leading the therapeutic or educational sessions with ZORA. Based on the results described in chapter 5, the professionals were told that the goals they selected needed to fit within the domains of movement skills, communication skills and cognitive skills. Before starting the study all the scenarios were tested and checked together with the researcher and adapted if necessary. During a period of six weeks, children played in individual or group sessions with ZORA six times. A mix of quantitative and qualitative outcomes was used to examine the contribution of the ZORA robot-based play intervention on the achievement of goals and to gain insight into the roles ZORA can have. The Individually Prioritized Problem Assessment (IPPA) was used to assess the extent to which to what extend the individual goals set before the intervention were reached according to the professional. Furthermore, playfulness and the children's experience of the sessions were assessed using a visual analogue playfulness scale (0-10) and smileys (like, neutral or dislike). Next to the quantitative outcomes, qualitative outcomes were measured. Video-stimulated recall interviews were used to gain insight into the different roles that were ascribed to the robot during the sessions. Additionally, semistructured interviews were conducted with the participating professionals. During these interviews, the main topic was the role(s) professionals attribute to ZORA. Additionally, these interviews were used to discuss which conditions are necessary to work with ZORA independently in the future, what target group(s) are relevant when it comes to working with ZORA, what goals are relevant in this context, how ZORA influences (children's) attention, and how the use of ZORA compares to the regular situation. The information acquired during these interviews was analysed using descriptive statistics. First, the qualitative data were transcribed, two interviews were labelled and coded by two researchers independently and after reaching consensus, the other ten interviews were coded by the main researcher. In total 33 children (11 girls, 22 boys) with a physical disability participated in this study. The degree of physical disability these children have ranged from mild to very severe. The chronological age of the children was 2 to 21 years old, and their developmental age was between 2 and 8 years old. In addition, 12 professionals took part in this study by preparing and leading the sessions and taking 
part in the video stimulated recall interviews. Regarding the contribution of ZORA, a significant difference could be found between IPPA scores before and IPPA scores after the sessions. Looking at specific domains, the largest mean differences, so the biggest contributions, could be found for the domains of movement skills and communication skills. No relevant difference could be observed between the contribution of ZORA interventions in group sessions or in individual sessions. The average score of playfulness of all sessions taken together was 7.5. Overall, the children also indicated they experienced the sessions as positive, by choosing the 'like' smiley in 93\% of the sessions. The most suitable roles according to the professionals are the roles of motivator, rewarder and instructor.

\section{Chapter 7}

The general discussion provides a reflection on the main findings of the conducted studies and addresses some methodological considerations concerning the target group and context of the studies, the measurement of outcomes and setting of goals as well as the design of the studies. Moreover, theoretical considerations concerning play for play's sake, the use of the ICF-CY model and the roles of robots are discussed. The chapter concludes by identifying implications of the studies for practice, research and policy. Based on the results of the different studies described in this dissertation, it can be concluded that robots contribute in a promising meaningful way to the support of play and the achievement of goals in both rehabilitation and special education for children with severe physical disabilities. The new insights achieved through the conducted studies offer new chances and possibilities for children with severe physical disabilities as well as the professionals who (help) care for them. 

Nederlandse samenvatting 

Spelen is van cruciaal belang voor de ontwikkeling van een kind. Kinderen met een beperking kunnen problemen ervaren bij het deelnemen aan spel. Kinderen met een ernstige fysieke beperking kunnen problemen ervaren bij bijvoorbeeld het vasthouden en bedienen van speelgoed en/of bij de toegankelijkheid van speeltuinen of speelpleinen. Daarnaast hebben ze vaak ondersteuning nodig bij het spelen. Spelactiviteiten kunnen gedeeltelijk of geheel onmogelijk zijn voor kinderen met een ernstige fysieke beperking. Nieuwe ontwikkelingen op het gebied van technologie en ICT creëren nieuwe mogelijkheden voor deze doelgroep. Deze technologieën kunnen hun spelmogelijkheden vergroten. Als reactie op de voortdurende ontwikkelingen op het gebied van robotica in de gezondheidszorg en in het onderwijs, is het relevant om de gebruiksvriendelijkheid, haalbaarheid en potentie van robots voor kinderen met een ernstige fysieke beperking te onderzoeken. Dit proefschrift presenteert de resultaten van een aantal studies op het gebied van de inzet van sociale robots voor kinderen met een ernstige fysieke beperking.

\section{Hoofdstuk 1}

Dit hoofdstuk is een algemene introductie van de concepten en studies die aan bod komen in dit proefschrift. Daarnaast wordt er achtergrondinformatie gegeven over spel en het belang van spel voor de ontwikkeling van alle kinderen, over de doelgroep van kinderen met een ernstige fysieke beperking, de mogelijkheden van technologie en over de context van revalidatie en speciaal onderwijs. Binnen deze context worden de robots IROMEC en ZORA uitgelicht. Het hoofdstuk eindigt met de doelen en een overzicht van de inhoud van dit proefschrift.

\section{Hoofdstuk 2}

Een uitvoerig systematisch literatuuronderzoek werd uitgevoerd om inzicht te krijgen in recente ontwikkelingen en studies op het gebied van ICT en robotica ter ondersteuning van spel voor kinderen met een ernstige fysieke beperking. In de databases CINAHL, PubMed, ERIC en IEEE is een zoekstrategie uitgevoerd. De zoekstrategie was opgebouwd volgens de PICO structuur en aanvullende literatuur is gezocht op basis van referentielijsten, Google Scholar, en publicaties van belangrijke congressen in dit vakgebied. Titels en abstracts van de gevonden artikelen zijn beoordeeld door drie reviewers onafhankelijk van elkaar. Uiteindelijk zijn 61 publicaties opgenomen in het literatuuronderzoek die in totaal rapporteerden over 27 verschillende technologieën: acht robots, vijftien virtual reality systemen (zes gebruik makend van feedback in de vorm van het geven van druk/weerstand, negen werkend met enkel een beeldscherm) en vier computersystemen. Vijf van de in totaal 27 systemen, allen robots, beschreven het doel 
'spelen om te spelen' (spel als doel), de andere technologieën zijn ontwikkeld om te werken aan een specifiek doel of probleem gebruikmakend van spel als middel. Een verscheidenheid aan bedieningsmogelijkheden is aan bod gekomen, maar de meeste gevonden technologieën lijken maar één bedieningsmogelijkheid te hebben. Daarnaast bleek de commerciële beschikbaarheid van de technologieën laag, wat het onmogelijk maakt voor ouders, therapeuten of onderwijzers in het speciaal onderwijs om deze producten te kopen en ermee te werken.

\section{Hoofdstuk 3}

In hoofdstuk 3 zijn de mogelijkheden van de toepassing van robot IROMEC in de revalidatie en het speciaal onderwijs voor kinderen met een ernstige fysieke beperking onderzocht. Een methode, waarbij gebruik wordt gemaakt van verschillende onderzoekstechnieken, is toegepast, namelijk het uitvoeren van individuele interviews, twee rondes aan focusgroepen, een vragenlijst en een afsluitende sessie om met alle deelnemers overeenstemming te bereiken. Experts op het gebied van revalidatie en speciaal onderwijs voor kinderen met een fysieke beperking zijn hierin betrokken. Als eerste zijn doelen waaraan in de praktijk van therapie en speciaal onderwijs voor kinderen met een ernstige fysieke beperking wordt gewerkt verzameld en is gekeken waar een mogelijke match mogelijk was met de functionaliteiten van robot IROMEC. Professionals zagen potentie in de bestaande IROMEC spelscenario's, met name in de domeinen bewegingsfuncties, leren en toepassen van kennis, communicatie/tussenmenselijke interacties en relaties en spel. Daarnaast zijn er een hoop suggesties gedaan voor verbetering van de robot en voor nieuwe toepassingen. De belangrijkste suggesties kunnen worden ingedeeld in drie categorieën: suggesties gerelateerd aan de robot, suggesties gerelateerd aan de context van de interventies en suggesties gerelateerd aan de rol van de professional bij het gebruik van de robot. De studie beschreven in dit hoofdstuk draagt bij aan het vergroten van het inzicht in de toepassingsmogelijkheden van robots, specifiek IROMEC, in het domein van revalidatie en speciaal onderwijs voor kinderen met een ernstige fysieke beperking.

\section{Hoofdstuk 4}

Om de toepassing van IROMEC ter ondersteuning van spel voor kinderen met een ernstige fysieke beperking te verkennen is een pilotstudie uitgevoerd gedurende twee maanden. Elf kinderen met een fysieke beperking en een ontwikkelingsleeftijd tussen de 2 en 8 jaar oud hebben deelgenomen aan zes sessies met de robot. Een combinatie van kwalitatieve en kwantitatieve uitkomstmaten is gebruikt om data te verzamelen over aspecten van gebruiksvriendelijkheid, haalbaarheid, barrières voor zowel het kind 
als de therapeut en een indicatie van het effect van de robot op 'playfulness' (vrij vertaald: spelplezier) en op het behalen van doelen voor de kinderen. IPPA scores (Individually Prioritized Problem Assessment) hebben een positieve bijdrage laten zien van de IROMEC interventiesessies aan het behalen van de doelen van de kinderen. Professionals gaven in de interviews ook aan dat ze waardevolle toepassingsmogelijkheden hebben gezien. Helaas maken de beperkte aanpasbaarheid, uitbreidbaarheid en technische stabiliteit van het robotplatform het onmogelijk om de IROMEC robot toe te passen in de dagelijkse praktijk van revalidatie en speciaal onderwijs.

\section{Hoofdstuk 5}

In twee verschillende centra is een pilotstudie uitgevoerd om de potentie van een ZORA-robot interventie in de revalidatie en het speciaal onderwijs voor kinderen met een ernstige fysieke beperking te verkennen. De kinderen hebben deelgenomen aan zes groepssessies of individuele sessies met robot ZORA. Kwalitatieve en kwantitatieve data zijn verzameld over aspecten van gebruiksvriendelijkheid, haalbaarheid, barrières en facilitators voor zowel het kind als de therapeut en een indicatie van het effect op 'playfulness' en het behalen van doelen. Zeventien kinderen en zeven professionals hebben deelgenomen aan deze studie. De resultaten laten een positieve bijdrage zien van ZORA aan het behalen van therapeutische en onderwijsdoelen. Daarnaast hebben de professionals op basis van een schaal variërend van score 0-10 aangegeven dat de kinderen een hoge mate van 'playfulness' hebben laten zien tijdens de sessies (gemiddelde scoren tussen 6.8 en 7.6). Indien het mogelijk was voor het kind hebben de kinderen na de sessies ook hun ervaring met/gevoel over de sessie aan kunnen geven. Van de 60 sessies die beoordeeld zijn door de kinderen door het aanwijzen van smileys, is 58 keer 'leuk' aangegeven, één waarde miste uiteindelijk en één score die gegeven was bleek niet duidelijk. Drie hoofddomeinen voor toepassing van ZORA zijn door de professionals als meest veelbelovend aangegeven, namelijk: bewegingsvaardigheden, communicatie vaardigheden en cognitieve vaardigheden. Daarnaast kan ZORA bijdragen aan het overkoepelende doel van het uitlokken van motivatie, concentratie, initiatiefname en het verbeteren van de aandachtsspanne van de kinderen. Gebaseerd op zowel de kwantitatieve als de kwalitatieve uitkomsten van deze studie kan worden geconcludeerd dat ZORA potentie heeft in therapie en speciaal onderwijs voor kinderen met een ernstige fysieke beperking. Meer onderzoek is nodig om te kijken op welke manier ZORA het beste kan worden toegepast in revalidatie en speciaal onderwijs. 


\section{Hoofdstuk 6}

Een tweede studie met robot ZORA is gestart om de bijdrage van ZORA aan het bereiken van therapeutische of onderwijsdoelen te onderzoeken en om te ontdekken welke rollen de professionals toewijzen aan ZORA. Een studie waarin een combinatie van kwantitatieve en kwalitatieve onderzoeksmethoden werd toegepast heeft in verschillende centra voor revalidatie en speciaal onderwijs plaatsgevonden met kinderen met een ernstige fysieke beperking. Gedurende een periode van zes weken hebben kinderen in groeps- of individuele sessies zes keer met ZORA gespeeld. Professionals (therapeuten en leerkrachten) hebben voorafgaand aan het onderzoek een trainingssessie bijgewoond om ZORA te ontdekken en de mogelijkheden te verkennen. Gedurende deze sessie hebben de professionals voor elk van de deelnemende kinderen vastgesteld voor welke doelen ze ZORA willen gaan inzetten en een specifiek scenario hiervoor werd opgesteld in samenwerking met de onderzoeker en een ICT expert. Voor de start van de studie zijn alle scenario's die in de robot geprogrammeerd zijn samen getest en gecontroleerd en aangepast wanneer nodig. De doelen die geformuleerd werden door de professionals moesten passen binnen de domeinen van bewegingsvaardigheden, communicatievaardigheden en cognitieve vaardigheden, gebaseerd op de resultaten uit hoofdstuk 5. Een mix van kwalitatieve en kwantitatieve uitkomstmaten is gebruikt om de bijdrage van een spelinterventie met ZORA te onderzoeken bij het bereiken van doelen en om inzicht te krijgen in de rollen die ZORA kan hebben. De IPPA is gebruikt om te beoordelen in welke mate de individuele doelen opgesteld voor de interventie bereikt zijn volgens de professional. Daarnaast zijn playfulness en de ervaring van de kinderen gedurende de sessies in kaart gebracht met behulp van een spelplezier schaal, een zogenaamde Visual Analogue Scale (met scores variërend tussen 0-10) en smileys (leuk, neutraal, niet leuk). Naast de kwantitatieve uitkomsten zijn kwalitatieve uitkomsten gemeten. Aan de hand van zogenaamd 'think aloud' interviews waarbij de onderzoeker samen met de deelnemende professionals video's van de sessies terug heeft gekeken en geanalyseerd werd inzicht verkregen in de verschillende rollen van de robot gedurende de sessie. Aanvullend zijn semi-gestructureerde interviews afgenomen met de deelnemende professionals, met als hoofdonderwerp de rol of rollen die professionals toewijzen aan ZORA. Daarnaast zijn er nog aanvullende onderwerpen bevraagd: randvoorwaarden om zelfstandig met ZORA te kunnen werken in de toekomst, relevante doelgroep(en) waarbij ZORA toegepast zou kunnen worden, relevante doelen, de invloed van ZORA op aandacht en tenslotte de vergelijking met hun reguliere werkwijze. De kwantitatieve data zijn met beschrijvende statistiek beschreven. Kwalitatieve data zijn getranscribeerd, gelabeld, gecodeerd door twee onderzoekers onafhankelijk van elkaar (twee interviews hebben zij samen gedaan) en na het bereiken van consensus zijn de rest van de interviews door de hoofdonderzoeker gecodeerd. In totaal deden 33 kinderen mee aan deze studie (11 meisjes en 22 jongens) met een fysieke beperking variërend van mild tot ernstig. De kalenderleeftijd van de kinderen was tussen de 2 en 
21 jaar oud, en de ontwikkelingsleeftijd tussen de 2 en 8 jaar oud. Twaalf professionals hebben meegedaan aan deze studie door het voorbereiden en leiden van de sessies, en daarnaast ook het deelnemen aan de interviews. Gebaseerd op de resultaten van de IPPA werd er een significant verschil gevonden tussen de scores op de IPPA voor en de scores op de IPPA na de sessies. Kijkend naar specifieke domeinen, het grootste gemiddelde verschil, dus de grootste bijdrage, werd gevonden bij de domeinen bewegingsvaardigheden en communicatievaardigheden. Er kon geen klinisch relevant verschil worden gevonden tussen groepssessies en individuele sessies. De gemiddelde playfulness score van alle sessies in totaal was 7,5. Over het algemeen werden de sessies positief geëvalueerd door de kinderen, in 93\% van de gevallen werd de 'leuk' smiley aangewezen na een sessie. De meest geschikte rollen voor ZORA volgens de professionals zijn de rol van motivator, beloner en instructeur.

\section{Hoofdstuk 7}

De algemene discussie geeft een reflectie op de belangrijkste bevindingen van dit proefschrift en beschrijft enkele methodologische overwegingen op het gebied van de doelgroep en de context van dit onderzoek, de uitkomstmaten en daarbij het formuleren van doelen en als laatste over het design van de studie. Daarnaast worden in de discussie ook theoretische overwegingen beschreven op het gebied van 'spelen om te spelen', het gebruik van het ICF-CY model en de rollen van robots. Het hoofdstuk eindigt met implicaties voor de praktijk, voor onderzoek en voor beleid. Gebaseerd op de resultaten van de hierboven beschreven hoofdstukken kan worden geconcludeerd dat robots veelbelovende en waardevolle bijdragen kunnen leveren aan spel en het behalen van doelen in zowel revalidatie als speciaal onderwijs voor kinderen met een ernstige fysieke beperking. De nieuwe inzichten uit dit proefschrift bieden nieuwe kansen en mogelijkheden voor zowel de kinderen als de professionals. 

Dankwoord 

Zonder alle mensen om mij heen, was ik nooit zover gekomen. Daarom wil ik iedereen die heeft bijgedragen aan mijn onderzoek en dit proefschrift heel graag bedanken. Hopelijk zonder iemand te vergeten wil ik een aantal mensen in het bijzonder bedanken.

Ten eerste, Gert Jan. Zonder jou had ik deze kans niet gekregen. In 2012 schreef je het projectvoorstel voor 'sociale robots in de zorg' waardoor ik in 2013 de kans kreeg om dit promotietraject te starten. Ik had het geluk om onder jouw begeleiding met promoveren te mogen starten. Helaas kwam daar na 1,5 jaar heel plotseling een einde aan en ben je ons ontvallen. Het gemis is nog steeds niet te beschrijven en even wist ik ook niet hoe verder te gaan. Bij jou stond de deur altijd open, je kwam telkens met goede ideeën en een groot deel van het projectplan zat in je hoofd, ook al stond dat niet op papier. Ik hoop dat we het project zo hebben uitgevoerd zoals dat in je hoofd zat... wekelijks of eigenlijk dagelijks heb ik het je willen vragen. Na jouw plotselinge overlijden werd mij nóg meer duidelijk wat jij betekende voor ons onderzoek en ons team. Wat had jij een geweldige kennis van zaken en ervaring, maar nog veel belangrijker, je was een hele prettige en betrokken begeleider. Zonder jou had ik hier nooit gestaan, bedankt voor alles!

Dan Luc, toen ik inmiddels bijna 6 jaar geleden bij je op gesprek kwam voor een functie als trainee was er meteen een 'klik'. Na een periode van 8 maanden diverse hand en spandiensten gedaan te hebben voor verschillende projecten was het tijd voor een nieuwe stap. Voordat ik het zelf eigenlijk wist zei je tijdens de promotie van collega Uta tegen mij: Renée, over een jaar of 4-5 sta jij ook hier, het project Sociale robots is goedgekeurd en jij mag hierop promoveren. Bij mezelf sloeg de twijfel toe, kan ik dat allemaal wel? Jij gaf me het vertrouwen. En nu... inderdaad ongeveer 5 jaar later is het zo ver. Bedankt Luc, voor al je tips en adviezen, voor je vertrouwen en het feit dat je (ondanks je overvolle agenda) altijd voor je promovendi klaar staat, zowel dichtbij op Zuyd in de eerste jaren, als daarna op afstand vanuit Sheffield!

Monique, jij nam de begeleiding van Gert Jan over, en ik had me geen betere vervanging kunnen bedenken! Wat is het fijn om met jou samen te werken. Elke keer weer waardevolle feedback op mijn stukken, waardoor ik ook echt het gevoel kreeg dat ik groeide en dat de stukken beter werden. Je hebt in mijn ogen de perfecte eigenschappen van een copromotor: perfectionistisch, positief, toegankelijk, snel met het geven van feedback, betrouwbaar, ga zo maar door.... Daarnaast hebben we het ook vaak heel gezellig gehad, o.a. de Bagels \& Beans lunches om een van onze artikelen te vieren (samen met Claire en Rianne). Laten we die erin houden, ook na de promotie! Ik vind het fijn dat we intensief mogen blijven samenwerken in het CRDL project.

De leden van de beoordelingscommissie (Prof. Dr. Frans Feron, Prof. Dr. Susan van Hooren, Prof. Dr. Jeanine Verbunt en Prof. Dr. Caroline van Heugten), bedankt voor het lezen en beoordelen van mijn manuscript. Prof. Dr. Serenella Besio, grazie mille, for the assessment of this manuscript. 
Ramon, niet direct bij dit promotietraject betrokken, maar wel vanaf januari 2017 onze lector. Bedankt voor al je support, voor je vertrouwen en voor de ruimte die je me hebt gegeven om dit promotietraject te kunnen afronden.

Bedankt lieve Claire, mijn partner in crime. Bij jou kan ik altijd terecht voor een vraag over het onderzoek, of gewoon om even te klagen als het even niet zo lekker gaat. Wat ben ik blij dat jij mijn collega bent! Collega's werden al snel colleginnekes, en inmiddels echte vriendinnekes (:). Je bent het zonnetje op ZAP! Bedankt dat je er altijd voor me bent.

Ook bedank ik alle collega's, ik kan me geen betere collega's wensen. De robotica dames: Loek, Sandra, Claire en Rianne bedankt voor jullie support, afleiding, samenwerking en gezelligheid. Het is heel fijn om met jullie samen te sparren over het onderzoek, maar ook om samen de menukaarten van restaurants te bekijken of om over sushi weg te dromen. Rianne, bedankt voor je ondersteuning en je 'meedenken', je beseft je soms niet hoe waardevol dat is. En natuurlijk ook bedankt voor al onze gezellig LUDI tripjes! De rest van het OT team: Ramon, Monique, Edith, Uta, Jeanne, Ruth, Paulette en Manon, bedankt voor jullie interesse in mijn onderzoek, vanaf nu weer meer tijd om hopelijk ook met jullie samen te werken in projecten. Sarah, Nadine, Laura, Marieke, Charles, Renée en Esther, we zijn dan nu wel verdeeld werkzaam over verschillende lectoraten, maar het voelt gelukkig nog gewoon als een team. Ook oud collega's René, Ger, Roger en April dankjewel voor jullie interesse en support.

En natuurlijk collega's Bea, Marja en Lisette, wat zouden we toch zonder jullie moeten. Als je aan jullie iets overlaat, dan weet je dat het goed komt!

Sinds kort heb ik nog meer leuke collega's erbij gekregen, binnen het lectoraat Voeding, Leefstijl en Bewegen. Susy, bedankt voor je vertrouwen en de kans die je me gegeven hebt. Iris, Andreas, Li-Juan en Melanie, jullie zijn een top team om mee te werken. Bedankt voor jullie begrip als het proefschrift even voorrang kreeg, hopelijk gaan we nog veel mooie nieuwe projecten samen doen. Ook de overige collega's van de promovendikamer, bedankt voor jullie interesse, support en gezelligheid.

Gedurende het project hebben heel wat studenten meegewerkt, zowel als afstudeerder, als stagiaire of als werkstudent. Bas, Danique, Sifra, Nina, Lara, Marcel, Remco, Rüben, Rianne, Andy, Mathieu, Daniël en Ellis dankjewel! Zonder jullie met name technische ondersteuning had ik vast en zeker meer slapeloze nachten gehad. Met jullie erbij wist ik dat het goed kwam!

Patrizia Marti from the University in Siena, thank you for your support, your encouragements and the nice dinners in Eindhoven together. I hope we can collaborate together in the future. Other international partners from the LUDI network, thanks a lot! I feel privileged to be part of this wonderful network, and I hope that we can continue the very important work, also after LUDI. 
Ouders die betrokken zijn geweest in verschillende fases van het project, in het bijzonder Kim, Nicole en Karen, bedankt voor het meedenken, voor jullie enthousiasme, voor de waardevolle discussie en voor jullie input. Jullie kinderen mogen trots zijn op zulke fanatieke, betrokken en lieve ouders.

Dan, de partners, de scholen en revalidatie instellingen die deelgenomen hebben aan het project, zonder jullie hadden we dit onderzoek niet kunnen uitvoeren. Alle therapeuten en leerkrachten van Adelante locatie Valkenburg, in het bijzonder Yvonne en Silvie, bedankt voor jullie flexibiliteit, planning skills en begrip voor de strubbelingen die het doen van onderzoek soms met zich mee brengt. Heliomare in Wijk aan Zee, bedankt voor het meedenken in het begin van de studie. Tyltylschool de Maasgouw, bedankt voor jullie enthousiasme om met ons onderzoek mee te willen doen, bij jullie is alles mogelijk, elke keer kwam ik met zoveel plezier jullie kant op. Ton, Cyril, Hans, Debbie en Linda, jullie zijn toppers! Geweldig om te zien met hoeveel passie jullie werken op jullie school. En als laatste Adelante locatie Ulingshof, pas later aangesloten bij dit onderzoek, maar zeker niet minder enthousiast. Anke en Judith, maar ook alle therapeuten en groepsleidsters, bedankt!

Degenen die ik het meest moet en wil bedanken zijn toch echt de ouders en kinderen die hebben deelgenomen aan dit onderzoek. Bedankt, dat jullie er open voor stonden om jullie kinderen te laten deelnemen aan dit toch wel soms spannende en innovatieve onderzoek. Dankzij jullie hebben we meer inzicht gekregen in de mogelijkheden van robots voor deze doelgroep. De kinderen zijn zo puur, ik heb er elke keer met ontzettend veel plezier mee gewerkt en hoop in de toekomst nog vaak met deze doelgroep te mogen werken.

Al mijn lieve vrienden en vriendinnen die hebben gezorgd voor afleiding en gezelligheid tussen het promoveren door. Ellen en Rachel, ons 25 jarig vriendschapsjubileum zou nu ongeveer moeten zijn, ik ben blij dat jullie mijn vriendinnen zijn en wat is het dan ook heerlijk om niet over werk te hoeven praten en met jullie lekker mezelf te kunnen zijn. Waar gaat ons vriendinnen jubileum tripje naartoe? Daan en Laura, onze gezellige etentjes en wandelingen zorgden ook voor afleiding en even het hoofd leegmaken. Laura, wij begrijpen elkaar, en het is fijn om af en toe even te klagen en elkaar daarna weer te motiveren. Wie had gedacht dat we tegelijk aan de afronding bezig waren! Dat zelfde geldt voor Lucien en Iris, bedankt voor jullie support. Dionne en Shannen, de terrasjes en etentjes samen met de andere dames waren altijd even gezellig en elke keer weer veel te snel voorbij. Shannen, super bedankt voor het ontwerp van deze mooie kaft. Ook dankjewel aan mijn studie vriendinnen waarvan ik heel blij ben dat we nog steeds zo'n leuk contact hebben, en die elke keer weer even geïnteresseerd vroegen hoe het met het boekje gaat: Judith, Kennie, Esther, Ruth en Maike. Inge, vriendin en Zuyd collega, de kopjes koffie met jou tussen het werken door en af en toe eens binnen lopen als ik weer in de buurt was, wij raken nooit uitgekletst! Lieve Lian, ook al woon je niet 
echt naast de deur, de keren dat we elkaar zien zijn altijd weer als vanouds. En natuurlijk mijn fanfare vrienden met wie ik elke vrijdagavond weer met plezier samen muziek maak, waarmee naast muziek maken bijkletsen in het café minstens zo belangrijk is: Sylvia, Stefan, Jolanda, Judith en Shannen, dankjulliewel!

Bedankt paranimfen Claire en Rim, dat jullie op deze bijzondere dag achter mij staan! Ik weet het, het is een beetje poppenkast, maar het is zo voorbij en dan gaan we het samen vieren $:$;

Dankjewel ook aan mijn schoonfamilie. Ik ben nu eindelijk ook 'afgestudeerd'. Jos en Marij, jullie hebben altijd alle vertrouwen in ons, en staan altijd voor ons klaar. Evelien, we zaten in hetzelfde schuitje, allebei aan het promoveren, alleen op een hele andere plek, toch begrepen we elkaar en ben ik blij dat ook jij bijna klaar bent met de afronding.

Opa, wat was je altijd trots op ons allemaal! Meteen na je operatie aan je gebroken heup eind maart zei je nog: 4 juli moet ik weer op de been zijn voor de promotie van Renée. Helaas heeft het niet zo mogen zijn, maar ik weet zeker dat je er toch bij bent vandaag, samen met de andere oma's en opa.

En dan nu toch echt over naar het Limburgs...

Rim en Claudia, es eemes goot kint aafsjakele en effe neet mit werk bezig kint zin dan zeet geer dat waal. Doa kinne Stefan en ich soms nog waal get van laere. Ich ving 't heerlijk om te zeen wie gelökkig dat geer same zeet, en dat al meer dan 10 jaor. Bedank veur alles!

Pap en mam, wat ich ouch deeg in mien laeve, geer steunt mich euveral in! In mien ouge hub geer de ideale balans gevonge tusse os allebei te stimulere en tegeliek ouch vrie te laote om zelf oet te zeuke wat veer wille. 't Biezondere van dit ongerzeuk is dat 't precies ein combinatie is van uch twee. Pap wirkzaam in de revalidatietechniek en mam in 't ongerwies, daorom woar 't vaak leuk om veural de praktische ervaringen mit uch te deile. Veer kinne altied op uch raekene, dankjewel!

En es allerlitste, leeve Stefan, dich leuts mich straole, en hoals 't allerbiste in mich noa boave. Same op vakansie (van 38 grade tot -30), same wandele, same bank hange, alles is leuker mit dich. Veer vulle elkaar aan en mit dich kin ich lache, huule, geniete en veural lekker michzelf zin. Bedank dasse der altied veur mich bis en dasse mich zo gelukkig maaks. Love you! 
About the author 

Renée van den Heuvel was born on December 18, 1988 in Beek, the Netherlands. In 2007 she completed secondary school at Graaf Huyn College, Geleen and started her bachelor Health Sciences at Maastricht University. In 2010, she completed her bachelor with a major in Health Promotion and a minor in Movement Sciences. In 2010, she started with her master in Physical Activity and Health (Sports and Physical Activity Interventions). Renée finished her master thesis

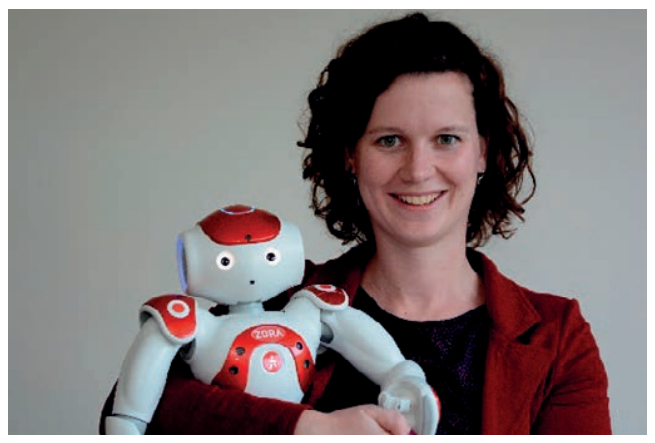
about health promotion at secondary schools in 2011.

Renée started working as a junior researcher via the traineeship Jump Start at Zuyd University of Applied Sciences, research Centre for Technology in Care in 2012. After eight months of working in various projects, she got the opportunity to start as a PhD student for the project 'Social robots in Care'. Her project focused on the potential of social robots for children with severe physical disabilities. During her PhD, Renée was involved in educational activities at the faculty of Health and the faculty of Bèta Sciences and Technology. From September 2015 Renée is involved in the international LUDI network about play for children with disabilities. In October 2017 Renée started working as a researcher for two days a week at the research group for Nutrition, Lifestyle and Exercise, also at Zuyd University. Renée will proceed working on different research projects at Zuyd University of Applied Sciences, combined with educational activities. 

List of publications 



\section{International publications}

van den Heuvel RJF, Lexis MAS, Gelderblom GJ, Jansens RML \& de Witte LP. (2016) Robots and ICT to support play in children with severe physical disabilities: a systematic review. Disability and Rehabilitation: Assistive Technology. 11(2): 103-116.

van den Heuvel RJF, Lexis MAS \& de Witte LP. (2017) Can the IROMEC robot support play in children with severe physical disabilities? A pilot study. International Journal of Rehabilitation Research. 40(1): 53-9.

van den Heuvel RJF, Lexis MAS, Jansens RML, Marti P \& de Witte LP. (2017) Robots supporting play for children with physical disabilities: exploring the potential of IROMEC. Technology and Disability. 29(3): 109-120.

van den Heuvel RJF, Lexis MAS \& de Witte LP. (2017) Robot ZORA in rehabilitation and special education for children with severe physical disabilities: a pilot study. International journal of rehabilitation research. 40(4): 353-359

\section{Book chapters}

Bedaf S, Huijnen C, van den Heuvel R \& de Witte LP. (2017). Robots Supporting Care for Elderly People. In P. Encarnação \& A Cook (Eds.), Robotic Assistive Technologies: Principles and Practice (pp. 309-332). Boca Raton, FL: CRC Press.

\section{Conference proceedings and abstracts}

van den Heuvel RJF, Lexis MAS \& de Witte LP (2015). ICT based technology to support play for children with severe physical disabilities. In: Sik-Lányi C, E-J H, Miesenberger K, Cudd P (Eds.), Studies in health technology and informatics; AAATE 2015; Budapest, Hungary: IOS Press; 573-7.

van den Heuvel RJF, Lexis MAS \& de Witte LP (2015). Possibilities of the IROMEC robot for children with severe physical disabilities. In: Heerink $M$, de Jong $M$ (Eds.), New Friends 2015 Conference on social robots in therapy and education; Almere: Windesheim Flevoland; 46-7.

van den Heuvel RJF, Lexis MAS, Jansens RML \& Witte LP (2016). Professionals view on IROMEC play sessions for children with severe physical disabilities. Universal Learning Design; Linz: Brno: Masaryk University. 
van den Heuvel RJF, Lexis MAS \& de Witte LP (2017). Introducing ZORA to Children with Severe Physical Disabilities. Studies in health technology and informatics. AAATE 2017; Sheffield, United Kingdom: IOS Press; 242:510-6. 
